\author{
Universidade de São Paulo \\ Instituto de Astronomia, Geofísica e Ciências Atmosféricas \\ Departamento de Ciências Atmosféricas
}

\author{
Angel Liduvino Vara Vela
}

\title{
Modelling the formation of atmospheric aerosol particles in the Metropolitan Area of São Paulo
}

"Modelagem da formação de aerossóis atmosféricos na Região Metropolitana de São Paulo"

São Paulo 



\section{Modelling the formation of atmospheric aerosol particles in the Metropolitan Area of São Paulo}

"Modelagem da formação de aerossóis atmosféricos na Região Metropolitana de São Paulo"

Thesis submitted in partial fulfillment of the requirements for the degree of Doctor of Sciences in the Institute of Astronomy, Geophysics and Atmospheric Sciences

Major field: Atmospheric Sciences

Advisor: Prof. Dr. Maria de Fatima Andrade

Final version. The original copy is available at the library

São Paulo 




\section{Acknowledgements}

Firstly, I would like to express my profound gratitude and appreciation to my advisor, Dr. Maria de Fatima Andrade, for her patient guidance, constant encouragement and support over the duration of my $\mathrm{PhD}$.

I am very grateful to the Brazilian National Council for Scientific and Technological Development (CNPq, Portuguese: Conselho Nacional de Desenvolvimento Científico e Tecnológico), the Brazilian Coordination of Improvement of Higher Education Personnel (CAPES, Portuguese: Coordenação de Aperfeiçoamento de Pessoal de Nível Superior), and the Institute of Astronomy, Geophysics and Atmospheric Sciences (IAG) at the University of São Paulo, for providing PhD funding support and care for this work. Special thanks to Professors Rita Yuri Ynoue, Edmilson Dias de Freitas, Adalgiza Fornaro, Márcia Akemi Yamasoe and Fabio Luiz Teixeira Gonçalves, and IAG staff members Elisabete Flores, Djalma Melo, Samuel Reis e Silva, Sebastião Antonio Silva, Lilian Monteiro da Silva, Enzo Todesco and Jean Peres. Thanks to the São Paulo State Environmental Agency (CETESB, Portuguese: Companhia Ambiental do Estado de São Paulo) and the São Paulo Research Foundation (FAPESP, Portuguese: Fundação de Amparo à Pesquisa do Estado de São Paulo; Grant no. 2011/58104-9) for providing ambient data for use in this thesis.

I also wish to thank Professor Prashant Kumar from the University of Surrey, UK, and Professor Yang Zhang from North Carolina State University (NCSU), USA, for their hospitality, support and enriched suggestions provided during my research internships, both through the University Global Parternship Network (UGPN) program. Thanks also to Anju Goel, Farhad Azarmi and Abdullah Al-Dabbous from the University of Surrey, and Pornpan Uttamang, Kai Wang, Kai Duan, Khairunnisa Yahya, Qi Li, James Madden and Patrick Campbell from NCSU. 
Last but not least, I would also like to give a big thank you to my family, friends and IAG colleagues with whom I have shared so many good moments. Special thanks to Ana Maria, Carol, Mario and Natalia, "The Remainings", José, Ana Carolina, Eric, Pamela, Fernando, Sergio (cl), Sergio (py), João, Mayara, Tássio, Aline, Carolina, Stephanie, Noelia, Rafaela, Veronika, Karina, Luis, Alejandro, Jocelyn, and "THE HOBBITs". 


\section{Resumo}

Atualmente, megacidades ao redor do mundo enfrentam problemas de qualidade do ar, especialmente aqueles relacionados ao controle de poluentes secundários como o ozônio troposférico $\left(\mathrm{O}_{3}\right)$, mas principalmente partículas finas $\left(\mathrm{PM}_{2.5} ; \leq 2.5 \mu \mathrm{m}\right.$ em diâmetro). As partículas finas têm impactos significativos na saúde humana bem como no clima, através das mudanças climáticas. O entendimento da evolução destas partículas na atmosfera requer a descrição de suas fontes de emissão e também dos processos físico-químicos envolvidos na sua formação, crescimento e remoção. Neste estudo, o modelo Weather Research and Forecasting with Chemistry (WRF-Chem), um sistema de modelagem atmosférica estado-da-arte, juntamente com dados coletados durante duas campanhas experimentais realizadas em 2012 e 2014 no âmbito do projeto Narrowing the Uncertainties on Aerosol and Climate Change in São Paulo State (NUANCE-SPS, projeto temático FAPESP), foram usados para analisar as principais propriedades do aerossol atmosférico na Região Metropolitana de São Paulo (RMSP), no sudeste do Brasil, onde mudanças na composição e no consumo dos combustíveis têm afetado a evolução da concentração de poluentes. A aplicação combinada de dados experimentais e simulações numéricas com o WRF-Chem permitiu a representação de algumas das propriedades mais importantes do aerossol atmosférico como concentração do número de partículas e ativação de nucleos de condensação de nuvens, assim como a avaliação da contribuição de fontes antropogênicas e de queimadas na concentração do $\mathrm{PM}_{2.5}$. Por exemplo, fontes veiculares têm potencial para formar novas partículas entre 20 e $30 \%$ em relação à massa total do $\mathrm{PM}_{2.5}$, enquanto fontes de queimadas contribuíram, na média, entre 8-24\% $\left(5-15 \mu \mathrm{g} \mathrm{m} \mathrm{m}^{-3}\right)$ da massa total deste poluente. Outrossim, fontes de queimadas contribuíram em até $20 \%$ das concentrações base do número de partículas e de nucleos de condensação de nuvens sobre a RMSP 
(2300 $\mathrm{cm}^{-3}$ e $1400 \mathrm{~cm}^{-3}$, respectivamente). Os resultados indicam o potencial impacto das queimadas na qualidade do ar na RMSP, e enfatizam a necessidade de aprimoramentos nos modelos de emissão de aerossol, visando reduzir incertezas nas previsões do modelo. 


\section{Abstract}

Nowadays, megacities all over the world are facing air quality issues, especially regarding the control of secondary pollutants such as tropospheric ozone $\left(\mathrm{O}_{3}\right)$ but mainly fine particles $\left(\mathrm{PM}_{2.5} ; \leq 2.5 \mu \mathrm{m}\right.$ in diameter), as they have important impacts on both human health and climate change. Understanding the evolution of these particles in the atmosphere requires the description of emission sources as well as the physicochemical processes involved in their formation, growth and removal. In this study, the Weather Research and Forecasting with Chemistry (WRF-Chem) community model, a state-of-the-art coupled meteorology-chemistry modelling system, along with experimental data collected during the Narrowing the Uncertainties on Aerosol and Climate Change in São Paulo State (NUANCE-SPS, FAPESP thematic project) campaigns performed in 2012 and 2014, were used in order to examine the main properties of atmospheric aerosol particles over the Metropolitan Area of São Paulo (MASP), in southeastern Brazil, where changes in fuel blend and consumption in recent years have affected the evolution of pollutant concentrations. The combined application of aerosol data and WRF-Chem simulations made it possible to represent some of the most important aerosol properties such as particle number concentration (PNC) and cloud condensation nuclei (CCN) activation, besides allowing us to evaluate the contributions of anthropogenic and biomass burning sources to the $\mathrm{PM}_{2.5}$ loadings in the MASP. For instance, on-road vehicles have a potential to form new particles between 20 and $30 \%$ in relation to the total PM 2.5 mass, whereas biomass burning, on average, accounted for 8-24\% (5-15 $\left.\mu \mathrm{g} \mathrm{m}^{-3}\right)$ of it. In addition, biomass burning accounted for up to $20 \%$ of the baseline PNC- and CCN-weighted relative differences over the MASP (2300 $\mathrm{cm}^{-3}$ and $1400 \mathrm{~cm}^{-3}$, respectively). The results indicate the potential importance of biomass burning sources for air quality in the MASP, and underscore the 
need for more accurate representations of aerosol emissions to reduce uncertainties in the model predictions. 


\section{List of Figures}

1.1 Chemical links between $\mathrm{O}_{3}$ and PM formation processes. The major PM precursors and products are shown in green and red boxes, respectively (adapted from McMurry et al. (2004)) . . . . . . . . . . . . .

2.1 Idealised size distributions of aerosols with their production and removal mechanisms. The solid, trimodal curve represent the original hypothesis of Whitby and co-workers (Whitby et al., 1972,?; Husar et al., 1972), whereas the two dashed lines represent the ultrafine particle mode (left) and the two peaks sometimes observed in the accumulation mode (right) (figure extracted from Finlayson-Pitts and Pitts (2000)) . . . . . . . . . . .

2.2 Representation of gas-particle partitioning using ( $\mathrm{a}-\mathrm{b})$ the "two-product model", and (c-d) the "volatility basis set". Partitioning at two mass loadings of organic aerosol ( 1 and $10 \mu \mathrm{g} \mathrm{m}^{-3}$ ) is shown for each model (figure extracted from Kroll and Seinfeld (2008)). . . . . . . . . . . . . . .

2.3 Annual mean top of the atmosphere radiative forcing due to aerosol-radiation interactions (RFari, in $\mathrm{W} \mathrm{m}^{-2}$ ) due to different anthropogenic aerosol types, for the 1750-2010 period. Hatched whisker boxes show median (line), $5^{\text {th }}$ to $95^{\text {th }}$ percentile ranges (box) and min/max values (whiskers) from AeroCom II models (Myhre et al., 2013). Solid coloured boxes show the AR5 best estimates and $90 \%$ uncertainty ranges. BC FF is for black carbon from fossil fuel and biofuel, POA FF is for primary organic aerosol from fossil fuel and biofuel, BB is for biomass burning aerosols, and SOA is for secondary organic aerosols. (figure extracted from Boucher et al. (2013)) . . . . . . . . 
2.4 Köhler curve (thick line) as the product of the Kelvin effect and the Raoult effect (dashed lines) (figure adapted from (Stier, 2011)) . . . . . . . . . 40

3.1 ARW $\eta$ coordinate (figure extracted from Skamarock et al. $(2008)$ ). . . . . 47

3.2 Arrangement of variables in a staggered Arakawa-C grid (Skamarock et al.

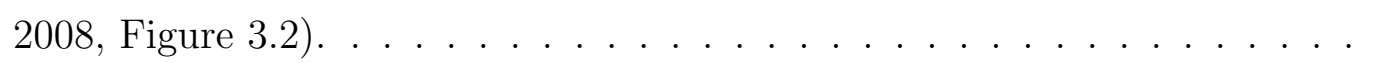

3.3 The triple (left) and double (right) nested domains for WRF-Chem modelling. The coarsest domains (d01) cover the south-eastern region of South America, whereas the finest domains (d03 and d02 for the case studies in 2012 and 2014, respectively) cover the MASP and surrounding urban areas.

3.4 WRF-Chem simulations flowchart. The WRF-Chem model consists of the Pre-processing, an initialization routine for real datasets, and of the Forecasting; i.e. the meteorological model with chemistry extension. For manipulating model outputs, some NCAR Command Language (NCL) routines have been developed for this study. . . . . . . . . . . . . 58

3.5 Spatial distribution of CO emission rates in the $25 \mathrm{~km}$ (left) and $3 \mathrm{~km}$ (right) modelling domains. Emissions in the coarse domain are based on the HTAPv2.2 estimates, whereas emissions in the fine domain are calculated following the approach of Andrade et al. (2015) . . . . . . . . . . 61 61

3.6 Spatial distribution of the total burned area in the $25 \mathrm{~km}$ modelling domain during the period from 22 August to 26 August 2014. The panels show the distribution of the total burned area for each FINN biome. . . . . . . 63

3.7 Spatial distributions of MEGAN2 canopy types (panels a, b, c and d), LAI (e) and isoprene emission factor (f) in the $5 \mathrm{~km}$ modelling domain. . . . . . 64

3.8 Zoom-in map for the $5 \mathrm{~km}$ modelling domain showing WRF topography height and the location of all measurement sites within the MASP. Red dots represent CETESB sites, whereas the blue and green dots represent, respectively, the locations of the NUANCE-SPS sampling campaigns and IAG-USP's meteorological station (AGFU). . . . . . . . . . . . . 68 
4.1 The observed and predicted (BASE) hourly variations of 2-m temperature, 2-m relative humidity, $10-\mathrm{m}$ wind speed and 10-m wind direction at two CETESB sites in the MASP during the period from 7 August to 6 September 2012 .

4.2 Hourly accumulated precipitation and relative humidity observed at the AGFU site during the period from 7 August to 6 September 2012. . . . . . 71

4.3 The observed and predicted (blue and orange dots for the BASE and BBE simulations, respectively) hourly variations of 2-m temperature, 2 -m relative humidity, 10-m wind speed and 10-m wind direction at two CETESB sites in the MASP during the period from 19 August to 3 September 2014. . . .

4.4 Accumulated daily rainfall measured at AGFU (black dots) compared with those estimated from the MERGE satellite data (blue dots) and BASE simulation $($ red dots $) \ldots \ldots \ldots \ldots \ldots \ldots \ldots$

4.5 The observed and predicted daily variations of $\mathrm{PM}_{10}$ concentrations at ten sites in the MASP for the $3 \mathrm{~km}$ modelling domain. . . . . . . . . . . . .

4.6 The observed and predicted daily variations of $\mathrm{PM}_{2.5}$ concentrations at three sites in the MASP for the $3 \mathrm{~km}$ modelling domain.

4.7 The observed and predicted hourly variations of $\mathrm{O}_{3}$ concentrations at six sites in the MASP for the $3 \mathrm{~km}$ modelling domain. . . . . . . . . . . . 78

4.8 Mean fractional bias (MFB) and mean fractional error (MFE) of different daily-average PM variables: $\mathrm{PM}_{10}, \mathrm{PM}_{2.5}$, $\mathrm{OC}$ and EC. Each point on the scatter plot, displayed with a marker (PM variable) and a color (site), represents the WRF-Chem performance considering the criteria proposed by Boylan and Russell (2006) (gray polygon in the figure) . . . . . . . . . .

4.9 Taylor diagram (Taylor, 2001) showing the individual correlation coefficients, mean biases, and normalized standard deviations for the $\mathrm{PM}_{10}$, $\mathrm{PM}_{2.5}$, OC and EC concentrations. 
4.10 The predicted average surface distribution of (a) $\mathrm{PM}_{2.5}$, (b) $\mathrm{PM}_{10}$ and (c) $\mathrm{PM}_{2.5}: \mathrm{PM}_{10}$ for the whole study period in the $3 \mathrm{~km}$ modelling domain. Red dots represent the locations of the measurement sites with information on PM, whereas cyan numbers represent the observed average PM concentrations in those sites: $23.4 \mu \mathrm{g} \mathrm{m}^{-3}$ in IPEN, $21.3 \mu \mathrm{g} \mathrm{m}^{-3}$ in IAGU and $22.2 \mu \mathrm{g}$ $\mathrm{m}^{-3}$ in CONG for $\mathrm{PM}_{2.5}, 49.5 \mu \mathrm{g} \mathrm{m}^{-3}$ in IAGU and $38.7 \mu \mathrm{g} \mathrm{m}^{-3}$ in CONG for $\mathrm{PM}_{10}$, and 0.43 in IAGU and 0.57 in CONG for $\mathrm{PM}_{2.5}: \mathrm{PM}_{10}$. . . . .

4.11 The observed and predicted (blue and red dots for BASE and NAE simulations, respectively) daily variations of OC and EC concentrations at the IAGU site during the period from 7 August to 6 September 2012. . . . . .

4.12 Hourly variations in $\mathrm{PM}_{10}$ concentrations during the period from 19 August to 3 September 2014, showing observed values (black dots) and predicted values (blue, orange and red dots, respectively, for the simulations BASE,

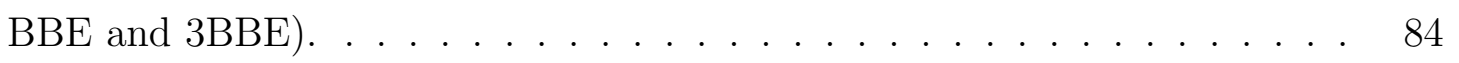

4.13 Hourly variations in $\mathrm{PM}_{2.5}$ concentrations during the period from 19 August to 3 September 2014, showing observed values (black dots) and predicted values (blue, orange and red dots, respectively, for the simulations BASE, $\mathrm{BBE}$ and $3 \mathrm{BBE}) \ldots \ldots \ldots \ldots \ldots$

4.14 Hourly variations in $\mathrm{O}_{3}$ concentrations during the period from 19 August to 3 September 2014, showing observed values (black dots) and predicted values (blue, orange and red dots, respectively, for the simulations BASE, $\mathrm{BBE}$ and $3 \mathrm{BBE}) \ldots \ldots \ldots \ldots \ldots \ldots \ldots$

4.15 Daily variations in EC concentrations at IAGU during the period from 19 August to 3 September 2014, showing the observed values (black dots) and predicted values (blue, orange and red dots, respectively, for the simulations BASE, BBE and 3BBE). . . . . . . . . . . . 86

4.16 PM soccer plots (NMB vs. NME) for the BASE simulation during the period from 19 August to 3 September 2014. . . . . . . . . . . . . 
4.17 The observed and predicted average aerosol mass size distribution for $\mathrm{SO}_{4}$, $\mathrm{NO}_{3}, \mathrm{NH}_{4}, \mathrm{Na}, \mathrm{Cl}$, and other $\mathrm{PM}_{10}$ constituents at IAGU. The observed aerosol distributions were collected in ten size classes using a rotated impactor (MOUDI) and joined adequately according to the three modes used by the MADE aerosol scheme: Aitken $(<0.1 \mu \mathrm{m})$, accumulation $(0.1-1 \mu \mathrm{m})$ and coarse $(>1 \mu \mathrm{m})$. The five inorganic ions carried in MADE are only calculated for the Aitken and accumulation modes. The WRF's $\mathrm{PM}_{10}$ aerosol variable does not include neither $\mathrm{OC}$ nor EC for this comparison. . . . . .

4.18 The observed and predicted average contributions for the main identified constituents of $\mathrm{PM}_{2.5}$ at IAGU

4.19 Observed and predicted particle mass concentration of average $\mathrm{PM}_{10}$ (top left) and EC (top right), together with the predicted average OC (bottom). The mass concentrations in each MOUDI bin were first grouped according to the three modes used in the MADE aerosol module, after which they were averaged for the MOUDI sampling period (eight days during the study

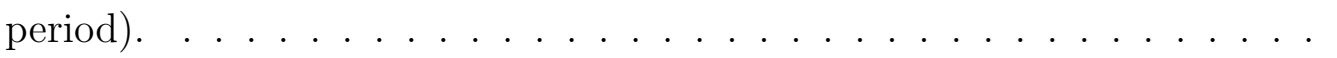

4.20 Time series (left) and box-whisker plots (right) of PNC, in the Aitken mode (nu0) and in the accumulation mode $(\mathrm{ac} 0)$, at the IAGU site showing observed values (in black) and predicted values (in blue, orange and red, respectively, for the simulations BASE, BBE and 3BBE). The box-whisker plots show the interquartile ranges for the periods from 22 August to 26 August 2014 (top) and from 19 August to 3 September 2014 (bottom). . .

4.21 Times series (left) and box-whisker plots (right) of CCN at the IAGU site showing observed values (in black) and predicted values (in blue, orange and red, respectively, for the simulations BASE, BBE and 3BBE). The boxwhisker plots show the interquartile ranges for the periods from 22 August to 26 August 2014 (top) and from 19 August to 3 September 2014 (bottom). 92

4.22 Times series (left) and box-whisker plots (right) of ARs at the IAGU site showing observed values (in black) and predicted values (in blue, orange and red, respectively, for the simulations BASE, BBE and 3BBE). The boxwhisker plots show the interquartile ranges for the periods from 22 August to 26 August 2014 (top) and from 19 August to 3 September 2014 (bottom). 93 
4.23 Spatial distributions of averaged AOD for (a) MODIS data, (b) BBE simulation, and (c) the difference between BBE and MODIS data. AOD data derived from the BBE simulation is compared with satellite-derived AOD (MODIS passing time approximately 15:00 UTC during wintertime) during the period from 19 August to 3 September 2014. . . . . . . . . . . . 94

4.24 Average observed (Obs) profiles of aerosol extinction obtained by lidar at IPEN (black lines), compared with the average profiles obtained from the simulations BASE, BBE and 3BBE (blue, orange and red lines, respectively). The panels on the left and right show the comparisons of averaged profiles between 12:00 and 13:00 UTC on 26 August (no rain conditions) and between 16:00 and 18:00 UTC on 1 September (rain conditions), respectively. Winds from fire regions were favourable during both observation

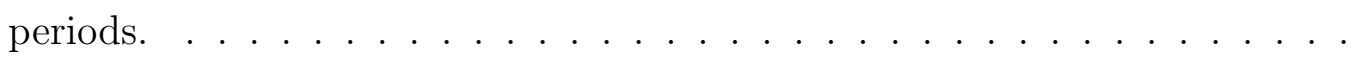

4.25 PM soccer plots (NMB vs. NME) for the simulations BASE (left), BBE (middle) and 3BBE (right) during the periods from 19 August to 3 September 2014 (upper) and from 22 August to 26 August 2014 (bottom). . . . . 97

4.26 Temporal mean spatial distributions of absolute and relative differences of the predicted daily maximum near-surface concentrations of EC (upper panels), OC (middle panels) and $\mathrm{PM}_{2.5}$ (bottom panels) during the fire emission contribution period, from 22 August to 26 August 2014. . . . . . . . . . .

4.27 Temporal mean spatial distributions of absolute and relative differences of the predicted daily maximum concentrations of ac0 (upper panels), $\mathrm{CCN}_{1.0 \%}$ (middle panels), both at surface, and column-integrated $\mathrm{AOD}_{600 \mathrm{~nm}}$ (bottom panels) during the fire emission contribution period, from 22 August to 26

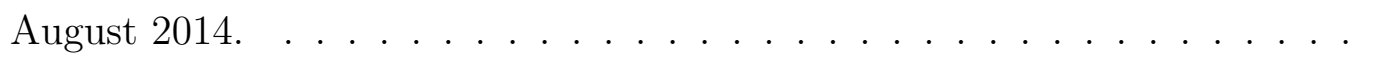

4.28 The impact of (a) emissions of primary gases on the fine particles formation, (b) emissions of dust-sea salt aerosols on the $\mathrm{PM}_{10}$ concentration, and (c) aerosol direct effect on the ground level $\mathrm{O}_{3}$ concentrations at 16:00 h (local time). . . . . . . . . . . . . . . . . . . . . 102 


\section{List of Tables}

2.1 Densities and refractive indices $(n-\mathrm{i} k)$ of the indicated species. Unless otherwise noted, the refractive indices are for a wavelength of $870 \mathrm{~nm}$ (table adapted from Barnard et al. (2010) . . . . . . . . . . . . . 33

3.1 WRF-Chem configurations. . . . . . . . . . . . . 55

3.2 Simulation design and evaluation periods. . . . . . . . . . . . 59

3.3 Continuation of Table $3.2 \ldots \ldots \ldots \ldots \ldots \ldots$. . . . . . . . . . . . . .

3.4 Description of the NUANCE-SPS aerosol sampling campaign performed at the IAGU site and other data sets included in the model evaluation. . . . . 66

3.5 Description of measurement sites. . . . . . . . . . . . . . 67

4.1 Performance statistics for WRF-Chem meteorological predictions for the period from 7 August to 6 September 2012 . . . . . . . . . . . 72

4.2 Performance statistics for WRF-Chem meteorological predictions for the period from 19 August to 3 September 2014. . . . . . . . . . . . . 74

4.3 Performance statistics for WRF-Chem chemical predictions for the period from 7 August to 6 September 2012. . . . . . . . . . . . . . 81

4.4 Performance statistics for WRF-Chem chemical predictions for the period from 19 August to 3 September 2014. . . . . . . . . . . . . . . 87

4.5 $\mathrm{PM}_{2.5}$ performance statistics for WRF-Chem predictions at all sites for the periods from 19 August to 3 September 2014 (ESP) and from 22 August to 26 August 2014 (FEC) . . . . . . . . . . . . . . . . 96 
4.6 WRF-Chem performance statistics for PNC (ac0), $\mathrm{CCN}_{1 \%}$ and $\mathrm{AR}_{1 \%}$ at the IAGU site for the periods from 19 August to 3 September 2014 (ESP) and from 22 August to 26 August 2014 (FEC) . . . . . . . . . . . . 100

A.1 List of performance measures used in the model evaluation. . . . . . . . 129

A.2 Continuation of Table A.1 . . . . . . . . . . . . . . . . 130 


\section{Contents}

1. Introduction . . . . . . . . . . . . . . . . . . 21

1.1 Justification . . . . . . . . . . . . . . . . . . . . . . . . 21

1.2 Aim and objectives . . . . . . . . . . . . . . . 24

2. Literature review . . . . . . . . . . . . . . . . . 25

2.1 Atmospheric aerosol processes . . . . . . . . . . . . . . 25

2.1.1 New particle formation . . . . . . . . . . . . . 27

2.1 .2 Aging processes . . . . . . . . . . . . . . . . 28 28

2.2 Global impacts of aerosols on meteorology and climate . . . . . . . . . 32

2.2.1 Aerosol direct effect . . . . . . . . . . . . . . . . 33

2.2.2 Aerosol indirect effects . . . . . . . . . . . . . . . 38

2.3 Aerosol studies conducted in the Metropolitan Area of São Paulo . . . . . 42

3. Method and Data . . . . . . . . . . . . . . . . 45

3.1 The Weather Research and Forecasting with Chemistry (WRF-Chem) community model . . . . . . . . . . . . . . . . . 45

3.1.1 The Advanced Research WRF (ARW) model . . . . . . . . . . 45

3.1.1.1 Governing equations ............... 45

3.1.1.2 Physics schemes _. . . . . . . . . . . . . . . . . 48

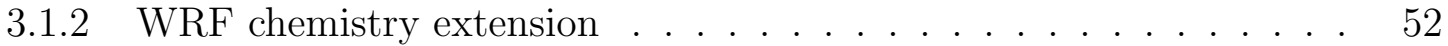

3.1.3 Aerosol effects in WRF-Chem . . . . . . . . . . . . . . 5 54

3.1.4 Boundary and initial conditions . . . . . . . . . . . 5 56

3.1 .5 Model setup . . . . . . . . . . . . . . . 56

3.2 Emissions .......................... 61 
3.2.1 Anthropogenic emissions . . . . . . . . . . . . . . 61 61

3.2 .2 Fire emissions . . . . . . . . . . . . . . . . . . 62

3.2 .3 Biogenic emissions . . . . . . . . . . . . . 63

3.2.4 Dust and sea salt emissions . . . . . . . . . . . . . . . 64

3.3 Measurements . . . . . . . . . . . . . . . . . . 65

3.3.1 The NUANCE-SPS project . . . . . . . . . . . 65

3.3 .2 Other data sets . . . . . . . . . . . . . . . 67

3.4 Statistical parameters . . . . . . . . . . . . . . . . . 68

4. Results . . . . . . . . . . . . . . . . . . . 69

4.1 Model evaluation . . . . . . . . . . . . . . . . . . 69 69

4.1.1 Meteorology ..................... 69 69

4.1.2 Chemical compounds concentrations . . . . . . . . . . 75

4.1.3 Size distribution and chemical composition . . . . . . . . . 87

4.1.4 CCN activation and optical properties . . . . . . . . . . 91

4.2 Impact of different emission sources on aerosol burdens . . . . . . . . . 95

4.2.1 Biomass burning emissions . . . . . . . . . . . . 95

4.2 .2 Anthropogenic emissions . . . . . . . . . . . . . . . . 101

4.2.3 Dust and sea salt emissions . . . . . . . . . . . . . 103

4.3 Aerosol impact on $\mathrm{O}_{3}$ photochemistry . . . . . . . . . . . . . . . . 103

5. Summary and Conclusions . . . . . . . . . . . . . . . . . 105

5.1 Final statement and suggestions for future works . . . . . . . . . . 106

Bibliography . . . . . . . . . . . . . . . . . . . . . 109

Appendix 127

A. Quantitative statistical measures . . . . . . . . . . . . . . . 129 
Chapter 1

\section{Introduction}

\subsection{Justification}

One of the main concerns in the Metropolitan Area of São Paulo (MASP), the largest metropolitan area in South America, with a population of more than 21 million people according to the Brazilian Institute of Geography and Statistics (IBGE 2018), is the frequent occurrence of violations of air quality standards for $\mathrm{O}_{3}$ and $\mathrm{PM}_{2.5}$, as recorded at different air quality stations from the São Paulo Environmental Agency (CETESB). Air pollutant emissions in the MASP are related to the burning of the vehicular fuels: ethanol, gasohol (gasoline with $25 \%$ of ethanol) and biodiesel (diesel with $8 \%$ of biodiesel). A recent report from CETESB (CETESB, 2018) highlighted that, in 2017, on-road vehicles contributed with $40 \%$ of the total $\mathrm{PM}_{10}$ (i.e. those $\leq 10 \mu \mathrm{m}$ in diameter) mass concentrations through direct emissions, whereas only $9 \%$ of $\mathrm{PM}_{2.5}$ is associated with the emission from industrial processes (Pereira et al., 2017). According to Martins et al. (2006), emissions from biogenic sources are considered to be substantially less important in the formation of particles over the MASP than those from anthropogenic sources.

Among all of the particulate matter (PM) components typically found in urban environments, organic carbon (OC) and elemental carbon (EC) have received considerable attention in recent years due to their complex and multiple radiative impacts on climate. A number of past studies have shown the significant participation of OC and EC in the concentration of fine particles in the MASP (Ynoue and Andrade, 2004; Miranda and Andrade, 2005; Albuquerque et al., 2012, Andrade et al., 2012; Brito et al., 2013), both of them making up the largest fraction of the $\mathrm{PM}_{2.5}$ mass with contributions of $40 \%$ and $21 \%$ for OC and EC, respectively. Organic aerosols not only offset the warming effects 
caused by indirect aerosol effects, but they can also further build up such warming effects by chemical aging processes, affecting the atmospheric radiation balance. Oxidative aging processes can alter aerosol properties and convert non-absorbing organic aerosols into compounds that are light-absorbing in the ultraviolet and even in the visible spectra, as demonstrated by Gelencser et al. (2003) in tropical clouds influenced by biomass burning. Boucher et al. (2013) reviewed studies on radiative forcing by aerosols and reported that contributions from black carbon offset those from organic aerosol via biomass burning emissions, resulting in an estimated mean forcing of $+0.0 \mathrm{~W} \mathrm{~m}^{-2}$ (with a range of -0.2 to $\left.+0.2 \mathrm{~W} \mathrm{~m}^{-2}\right)$. Most of the studies of such effects in Brazil, and in the rest of South America, have focused on the Amazon rainforest, as the smoke from biomass burning in the region can spread over significant portions of the continent, having a considerable effect on direct and indirect radiative forcing ( $\mathrm{PBMC}, 2013)$.

Smoke particles injected into the atmosphere from biomass burning can modify the atmospheric composition around and even far from the sources. In late winter and early spring, biomass burning emissions from inland regions can be efficiently transported to urban areas in southeastern South America, thus affecting air quality over those areas. Nevertheless, there have been only a few studies of such impacts, all of which have performed qualitative evaluations. In fact, there have been no studies that use the measurements of different aerosol properties in conjunction with air quality simulations to improve the understanding of the impacts that aerosol emissions have on air quality in those regions. In particular, atmospheric aerosol properties over the MASP have not been extensively modelled, mainly due to the lack of measurements for the validation of numerical results.

In addition, there remain many uncertainties about the role that carbonaceous particles, particularly those originating from biomass burning events, play in the composition and CCN activation of aerosols over the MASP. Oyama et al. (2016) showed that OC concentrations over the MASP are largely dominated by organic aerosols from on-road vehicle emissions, although the contributions from biogenic and biomass burning emissions are also important. The authors concluded that biomass burning accounts for 10-30\% of the OC, sugar cane burning accounting for $15 \%$ of the mass. Biomass burning emissions may also affect the CCN activation properties of air masses arriving at the MASP. Souto-Oliveira et al. (2016) reported that high night-time activation diameter values are associated with the passage of air masses over regions with active fires, which has a neg- 
ative impact on $\mathrm{CCN}$ activation, as high activation diameter can often be attributable to low particle hygroscopicity.

One of the most important aspects of this thesis is the quantitative analysis of the formation of $\mathrm{PM}_{2.5}$ and $\mathrm{O}_{3}$ in the MASP through numerical modelling. Although $\mathrm{NOx}$ and volatile organic compounds (VOCs) are precursors of both $\mathrm{O}_{3}$ and a fraction of atmospheric PM (nitrate $\left(\mathrm{NO}_{3}{ }^{-}\right)$and secondary organics) while they influence indirectly the formation of the rest of the secondary PM components such as sulphate $\left(\mathrm{SO}_{4}{ }^{=}\right)$, their control strategies, that are optimal for $\mathrm{O}_{3}$ controls, may even increase $\mathrm{PM}_{2.5}$ concentrations (McMurry et al., 2004). The complex web of common precursors and photochemical production pathways, through which PM species, $\mathrm{O}_{3}$ and other pollutants are related, is schematically illustrated in Fig. 1.1.

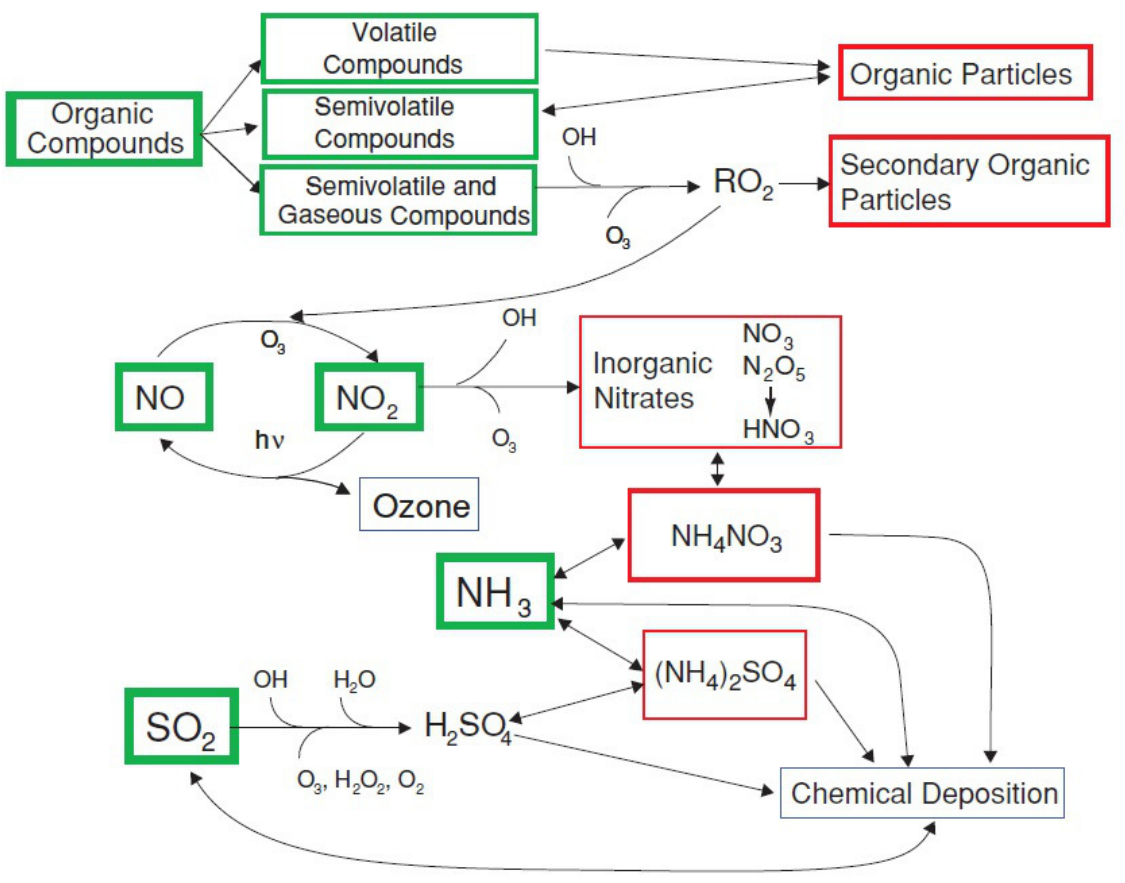

Figure 1.1: Chemical links between $\mathrm{O}_{3}$ and PM formation processes. The major PM precursors and products are shown in green and red boxes, respectively (adapted from McMurry et al. (2004)).

Therefore, an analysis with the use of a comprehensive air quality model along with an extensive set of measurements is important to understand the evolution and interaction of aerosol particles with meteorology and chemistry, as well as to evaluate the contribution of different emission sources to the concentration of these particles in a metropolitan area 
where the composition of fuel in vehicle fleet has changed significantly over the past years.

\subsection{Aim and objectives}

This work aimed to characterise the formation of atmospheric aerosol particles over the Metropolitan Area of São Paulo, in southeastern Brazil, with a special focus on quantifying the impact of different emission sources on aerosol burdens. The specific objectives of this research were:

- To evaluate the impact of biomass burning emissions on the main aerosol physical, chemical and optical properties.

- To evaluate the impact of vehicular emissions on the formation of fine particles.

- To evaluate the aerosol-radiation feedback on $\mathrm{O}_{3}$ photochemistry.

- To investigate the ability of aerosol particles to act as CCN.

- To determine the contribution of carbonaceous aerosols to the fine particles concentration.

In order for the simulations to properly represent the observed conditions, sophisticated aerosol-related modules in WRF-Chem have been previously identified and coupled to each other. 
Chapter 2

\section{Literature review}

This chapter presents a general review of the existing knowledge of atmospheric aerosols in terms of formation and aging processes. It also provides a description of aerosol impacts on meteorology and climate, including a discussion on modelling constraints, recent advances and future challenges. Lastly, a discussion on aerosol studies conducted in the Metropolitan Area of São Paulo is provided.

\subsection{Atmospheric aerosol processes}

Throughout their lifetime, atmospheric aerosols can be formed through homogeneous nucleation processes (i.e., the production of nanometer-sized clusters from gaseous vapours), and can continue to grow by condensation of condensable material onto existing particles, and by coagulation with pre-existing aerosol particle population to form larger particles (Kumar et al., 2011; Kulmala et al., 2012; Kumar et al., 2014; Vara-Vela et al., 2016). A summary of the different aerosol modes and their various production and removal mechanisms is shown in Fig. 2.1.

Ultrafine aerosol particles are found in the nucleation $\left(\mathrm{D}_{p}<20 \mathrm{~nm}\right)$ and Aitken modes $\left(20 \mathrm{~nm}<\mathrm{D}_{p}<100 \mathrm{~nm}\right)$. These newly nucleated particles can exist in massive numbers, but due to their small size, they make up only a tiny fraction of the total aerosol mass. Over time, these ultrafine particles grow and coagulate to form the accumulation mode, made up of particles with $90 \mathrm{~nm}<\mathrm{D}_{p}<1000 \mathrm{~nm}$. There are typically fewer accumulation mode particles than Aitken and nucleation particles. Collectively, all aerosols with $\mathrm{D}_{p}<$ $2.5 \mu \mathrm{m}$ are known as fine particles, while those with $\mathrm{D}_{p} \geq 2.5 \mu \mathrm{m}$ are known as coarse particles. The coarse mode contains much smaller number of aerosol particles but a large 
fraction of the total mass. Coarse particles are emitted as primary particles.

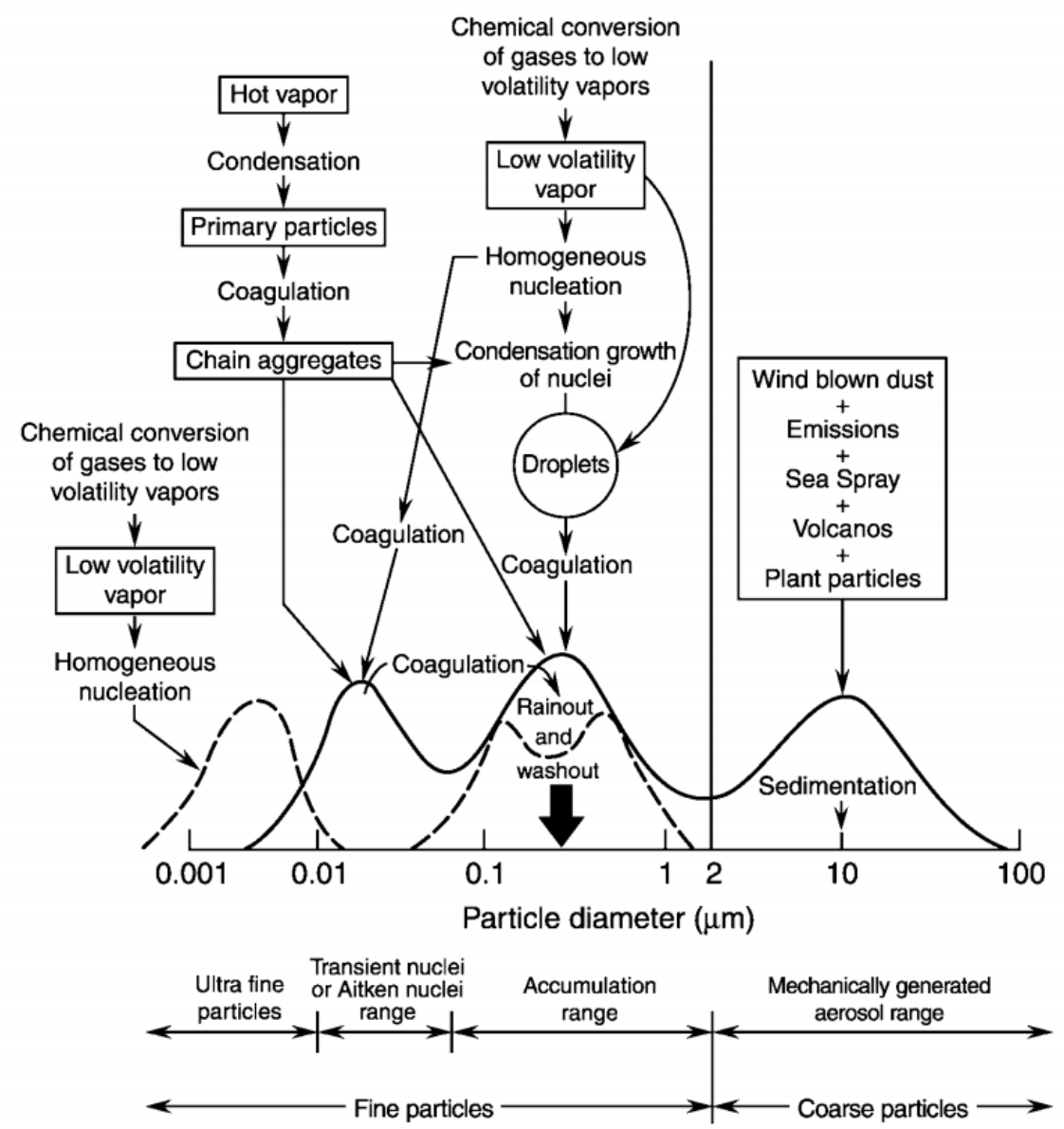

Figure 2.1: Idealised size distributions of aerosols with their production and removal mechanisms. The solid, trimodal curve represent the original hypothesis of Whitby and co-workers (Whitby et al., 1972 ? Husar et al., 1972), whereas the two dashed lines represent the ultrafine particle mode (left) and the two peaks sometimes observed in the accumulation mode (right) (figure extracted from Finlayson-Pitts and Pitts (2000)).

The size of aerosol particles also determines their lifetimes in the atmosphere. Coarse particles tend to have shorter lifetimes, typically a few days or less, because they gravitationally settle down on the surface in a process known as sedimentation or dry deposition. For most smaller aerosol particles, the main loss process is wet deposition. These are processes by which aerosol particles are removed through precipitation, either by forming droplets or ice particles within cloud, or by scavenging in falling droplets below cloud. Accumulation mode particles may exist in the troposphere for up to several weeks ArcherNicholls, 2014). 


\subsubsection{New particle formation}

New aerosol particles in the atmosphere are formed through homogeneous nucleation, i.e., condensation of low-vapour-pressure species. A variety of different nucleation mechanisms have been proposed to explain the formation of new particles; being the binary nucleation of $\mathrm{H}_{2} \mathrm{SO}_{4}$ and $\mathrm{H}_{2} \mathrm{O}$ and the ternary nucleation of $\mathrm{H}_{2} \mathrm{SO}_{4}, \mathrm{NH}_{3}$ and $\mathrm{H}_{2} \mathrm{O}$ the most commonly used in atmospheric models. However, their model implementations have tended to under and over-predict nucleation rates respectively, and do not apply for atmospheric aerosol formation in general. A binary nucleation theory that is in agreement with the classical binary nucleation theory (Wilemski, 1984), accounts for hydration effects (Jaecker-Voirol et al., 1987) and is best suited for quick estimation purposes, is the one proposed by Kulmala et al. (1998). According to this theory, the $\mathrm{H}_{2} \mathrm{SO}_{4}$ mole fraction in the critical nucleus can be calculated as:

$$
\chi_{a l}=1.2233-\frac{0.0154 R A}{R A+R H}+0.0102 \ln N_{a v}-0.0415 \ln N_{w v}+0.0016 T
$$

where $\mathrm{N}_{a v}$ and $\mathrm{N}_{w v}$ are sulfuric acid and water vapour concentrations (in $\mathrm{cm}^{-3}$ ), $T$ the temperature (in $K$ ), RA and $\mathrm{RH}$ denote relative acidity and relative humidity divided by $100 \%$. The sulfuric acid vapour concentration needed to produce the nucleation rate $\mathrm{J}=$ $1 \mathrm{~cm}^{-3} \mathrm{~s}^{-1}$, can be expressed, at given $T$ and $R H$, as:

$$
N_{a, c}=\exp \left(-14.5125+0.1335 T-10.5462 R H+1958.4 \frac{R H}{T}\right)
$$

Then, the sulfuric acid/water nucleation rate is calculated, based on the Eqs. (2.1) and (2.2), as follows:

$$
J=\exp (\chi)
$$

with

$$
\begin{array}{r}
\chi=25.1289 N_{\text {sulf }}-4890.8 \frac{N_{\text {sulf }}}{T}-1743.3 \frac{1}{T}-2.2479 \sigma N_{\text {sulf }} R H+ \\
7643.4 \frac{\chi_{a l}}{T}-1.9712 \frac{\chi_{a l} \sigma}{R H}
\end{array}
$$




$$
N_{\text {sulf }}=\ln \left(\frac{N_{a}}{N_{a, c}}\right) ; \quad \sigma=1+\frac{T-273.15}{273.15}
$$

As this parameterization requires only a few lines in a computer program, several 3-D atmospheric models (WRF-Chem model among them) have been using this parameterization to simulate new particle formation. However, its derivation contains mistakes in the kinetic treatment for hydrate formation, resulting in binary nucleation rates 1-3 orders of magnitude lower than those predicted by the model proposed by Vehkamaki et al. (2002), which is an updated version of Kulmala's theory. Previous studies reported that predicted $\mathrm{PM}_{2.5}$ number concentrations with the parameterization of Kulmala were lower by factors between 10 and 1000 than observations (Park et al., 2006; Elleman and Covert, 2009).

Overall, given large differences in the controlling processes for PM number, volume, and surface area predictions between urban/upwind locations and non-urban/downwind locations, the performance of various nucleation models against observations may vary, depending on characteristics of emissions, meteorology, topography of those locations, as well as the grid resolution used for model simulations (Zhang et al., 2010). In addition, recent measurements of nanoparticles with $\mathrm{D}_{p}<3 \mathrm{~nm}$ showed that the formation of small clusters of $\mathrm{H}_{2} \mathrm{SO}_{4}$ with oxidised organic molecules is a crucial first step in the nucleation of new particles, and suggest that the inclusion of organic compounds to nucleation theory is required to produce observed nucleation rates (Riccobono et al. 2014; Archer-Nicholls, 2014).

\subsubsection{Aging processes}

\section{Gas-particle mass transfer}

Aerosols can age in the atmosphere through gas-particle partitioning, and this occurs when atmospheric conditions are thermodynamically favourable for a gas to condense onto a particle. The Henry's Law coefficient $\left(\mathrm{k}_{H}\right)$ (Henry, 1803), defined as the equilibrium ratio between the aerosol and gas phases at the limit of infinite dilution, can be used to describe this interaction.

$$
k_{H}^{c p}=\lim _{c p \rightarrow 0} \frac{c_{a}}{p_{i}}
$$


where $\mathrm{p}_{i}$ is the partial pressure of species $i$ in the gas phase and $c_{a}$ the concentration in the aerosol phase in $\mathrm{mol} \mathrm{m}^{-3}$. Or, in dimensionless, defined as a ratio of the equilibrium gas-phase and aerosol concentrations:

$$
k_{H}^{c c}=\lim _{c c \rightarrow 0} \frac{c_{a}}{c_{g}}=\left(k_{H}^{c p}\right) R T
$$

where $\mathrm{c}_{g}$ is the gas-phase concentrations of a species in mol $\mathrm{m}^{-3}$. Nevertheless, Henry's law only applies to infinitely dilute solutions (i.e. ideal scenarios). For real solutions, a correction factor, called the activity coefficient $(\phi)$, is applied (Archer-Nicholls, 2014). This factor is defined such that it approaches 0 at the limit of infinite dilution (Pitzer and Simonson, 1986). The activities $a_{j}$ and $\phi_{j}$ are related by

$$
\ln a_{j}=\ln \left(\frac{x_{j} \phi_{j}}{x^{0}}\right)
$$

where $x^{0}{ }_{j}$ and $x_{j}$ are the mole fraction of the $i$-th species before and after mixing. The general form for the instantaneous mass transfer is given by:

$$
\frac{d c_{a}}{d t}=K_{m t}\left(c_{g, \infty}-\frac{c_{a, s u r f}}{k_{H}^{c c}}\right)
$$

where $\mathrm{c}_{g, \infty}$ is the background gas phase concentration and $\mathrm{c}_{a, s u r f}$ is the concentration at the surface of the aerosol. The growth is driven by the difference between the background gas phase concentration and the optimum concentration at the aerosol surface. The mass transfer coefficient $\mathrm{K}_{m t}\left(\mathrm{~s}^{-1}\right)$ differs depending on the relative size of the aerosol.

The formation and evolution of secondary organic aerosol (SOA), particulate matter formed by the chemical transformation of atmospheric organic compounds, are probably the most uncertain between all aerosol constituents. The key concept underlying modern treatments of SOA is that it is composed predominantly of semivolatile organics, allowing for the description of SOA formation in terms of gas-particle partitioning. The absorptive partitioning of semivolatiles is described by Pankow's theory (Pankow, 1994a b), defining an equilibrium partitioning coefficient $K_{p}$ : 


$$
K_{p}=\frac{P}{G M}
$$

where $G$ and $P$ are the mass concentrations (e.g. $\mu \mathrm{g} \mathrm{m}^{-3}$ ) of the semivolatile species in the gas phase and particle phase, respectively, and $M$ is the mass concentration $\left(\mu \mathrm{g} \mathrm{m}^{-3}\right)$ of the total absorbing particle phase. The partitioning coefficient $K_{p}\left(\mathrm{~m}^{3} \mu \mathrm{g}^{-1}\right)$ is thus inversely proportional to the saturation vapor pressure $\left(c^{*}\right)$ of the pure semivolatile compound. The fractional distribution $(F)$ of a semivolatile compound in the particle phase is given by

$$
F=\frac{P}{P+G}=\frac{1}{1+c^{*} / M}
$$

Hence, as the amount of absorbing material $(M)$ increases, compounds of higher volatility (higher $c^{*}$, lower $K_{p}$ ) will increasingly partition into the condensed phase.

a

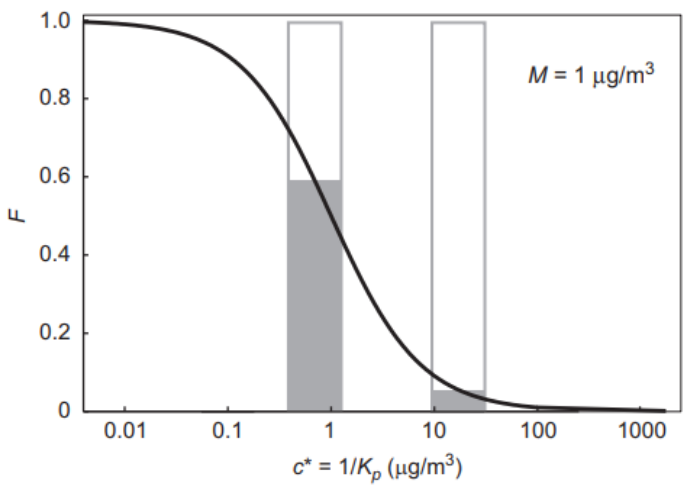

C

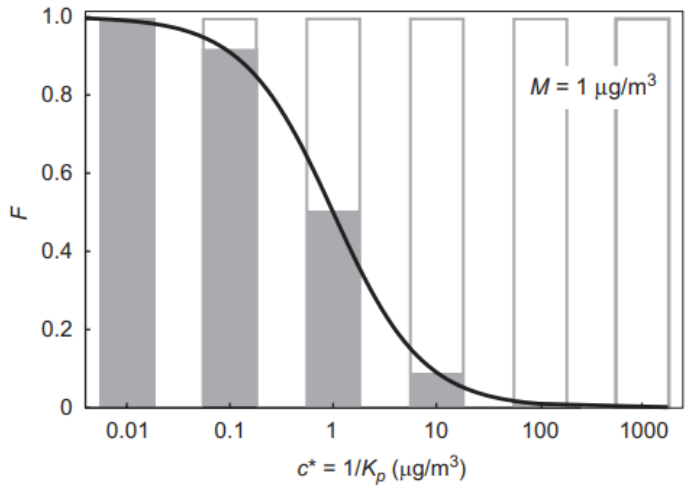

b

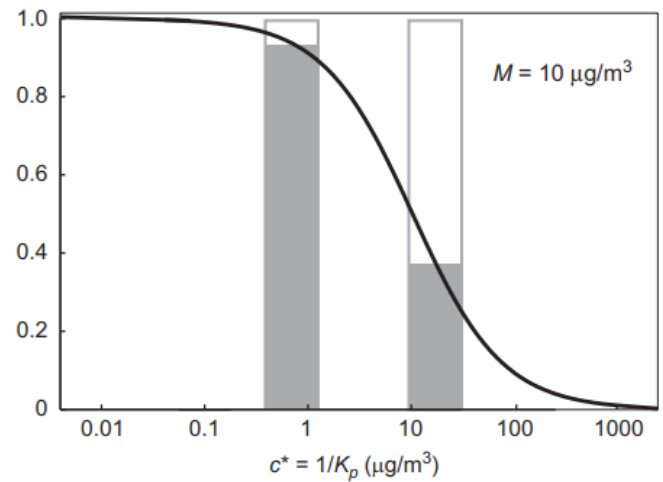

d

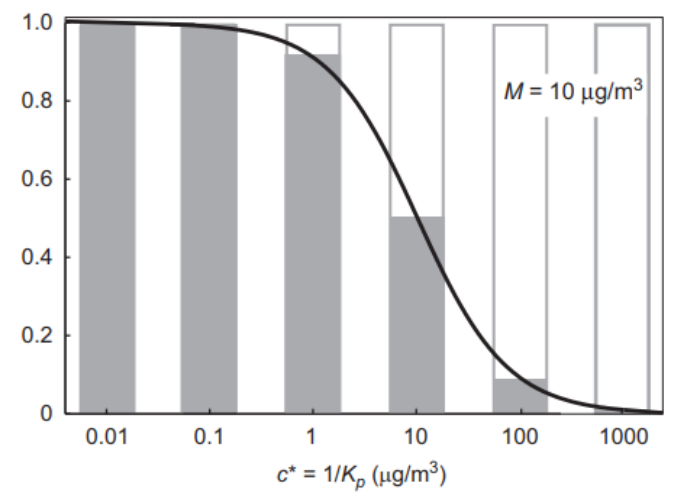

Figure 2.2: Representation of gas-particle partitioning using ( $\mathrm{a}-\mathrm{b})$ the "two-product model", and (c-d) the "volatility basis set". Partitioning at two mass loadings of organic aerosol (1 and $10 \mu \mathrm{g} \mathrm{m}^{-3}$ ) is shown for each model (figure extracted from Kroll and Seinfeld (2008)). 
SOA gas-particle partitioning can be represented using the "two-product model" Odum et al. 1996), in which the semivolatiles are represented by two model compounds with experimentally determined vapor pressures, or the "volatility basis set" (Donahue et al. 2006), which employs a larger number of lumped compounds with prescribed vapor pressures. Fig. 2.2 shows how $F$ is represented in terms of both the "two-product model" and the "volatility basis set", and how partitioning in each model is affected by a change in absorbing aerosol loading $M$.

Discrepancies between predicted and measured SOA are, in general, due to:

- SOA yields under atmospheric conditions from known SOA precursors exceed those measured in laboratory experiments;

- uncertainties in current treatments of SOA formation in models lead to biases that generally result in underpredictions of SOA loading; or

- there exist additional classes of SOA precursors that have yet to be studied in the laboratory or included in models.

However, even if SOA could be accurately described in terms of the full set of underlying reactions, a computationally expensive approach is probably infeasible within global transport models, and simpler treatments of SOA formation such as the "two-product model", or the "volatility basis set", are still necessary (Kroll and Seinfeld, 2008).

In addition, the dimensionless Knudson number $\left(\mathrm{K}_{n}\right)$, which relates the particle radius $\mathrm{r}_{p}$ to the mean free path $l$ of the surrounding fluid, is used to describe the dynamics of particle growth:

$$
K_{n}=\frac{l}{r_{p}}
$$

The mean free path being calculated as:

$$
l(T, P)=\frac{2 \mu}{p(8 M / \pi R T)^{1 / 2}}
$$

where $\mu$ is the viscosity of the fluid and $M$ the molecular weight. Three descriptions of particle dynamics are used depending on the magnitude of $\mathrm{K}_{n}$ : 
- $\mathrm{K}_{n} \geq 1$ (kinetic regime)

- $\mathrm{K}_{n} \approx 1$ (transition regime)

- $\mathrm{K}_{n} \leq 1$ (continuum regime)

\section{Coagulation}

As soon as aerosol particles are formed from the condensation of trace gases, preexisting particles can coagulate to form larger particles. Atmospheric aerosols collide and coalesce, reducing the number concentration but conserving the total mass. The basic theory of coagulation is derived from the coagulation equation of Müller (1928):

$$
\frac{\partial n_{v}}{\partial t}=\frac{1}{2} \int_{0}^{v} \beta_{v-\bar{v}, \bar{v}}^{\prime} n_{v-\bar{v}} n_{\bar{v}} d \bar{v}-n_{v} \int_{0}^{\infty} \beta_{v, \bar{v}}^{\prime} n_{\bar{v}} d \bar{v}
$$

where $v$ is the volume of the newly formed particle, $\mathrm{n}_{v}$ is the number of particles (per unit volume of air) of size $v$ and $\beta^{\prime}$ is the rate coefficient of two colliding particles. Eq. (2.14) defines the rate of change in $\mathrm{n}_{v}$ as the rate of formation of particles of size $v$ minus the rate of coagulation of particles of size $v$ with other particles (Jacobson, 2005; ArcherNicholls, 2014). As different air masses mix over time, aerosol particles coagulate and grow through condensation, and thus aerosol populations become more homogeneous and internally mixed. Yet, the heterogeneity and short lifetimes of these particles ensure that atmospheric aerosols characterization remains an ongoing challenge (NAs 2016).

\subsection{Global impacts of aerosols on meteorology and climate}

Research studies on aerosol effects and their implications for climate change were first compiled in the Intergovernmental Panel on Climate Change report in 1990. Since then, there have been numerous studies on the direct and indirect effects that aerosols have on weather and climate. The aerosol direct effect refers to how aerosols can absorb and scatter solar and thermal radiation, while the aerosol indirect effects refer to the ways how aerosols can alter cloud albedo and lifetime (Hartmann et al., 2013). The magnitude of such effects dependent on the size distribution, chemical composition, mixing state and morphology of the particles (Seinfeld et al., 2016). 


\subsubsection{Aerosol direct effect}

Part of the impacts on climate due to aerosol particles are related to how they interact with radiation. Depending on whether they scatter or absorb radiation, the net effects can be warming or cooling. The basis of how a material interacts with radiation is described by its complex refractive index $m=n-i k$. The real part $n$ describes the scattering component, whereas the absorption is largely described by the imaginary component $k$, although it can also be affected by $n$. Table 2.1 shows the refractive indices for the main aerosol constituents.

Table 2.1 - Densities and refractive indices $(n-\mathrm{i} k)$ of the indicated species. Unless otherwise noted, the refractive indices are for a wavelength of $870 \mathrm{~nm}$ (table adapted from Barnard et al. (2010).

\begin{tabular}{lccc}
\hline Species & Density $\left(\mathrm{g} \mathrm{cm}^{-3}\right)$ & $n$ & $k$ \\
\hline $\mathrm{SO}_{4}$ & 1.8 & 1.52 & 0 \\
$\mathrm{NO}_{3}$ & 1.8 & 1.5 & 0 \\
$\mathrm{NH}_{4}$ & 1.8 & 1.5 & 0 \\
${\text { Organic Matter }(\mathrm{OM})^{1}}^{1}$ & 1.4 & 1.45 & 0 \\
Elemental Carbon $(\mathrm{EC})^{2}$ & 1.8 & 1.85 & 0.71 \\
Dust $^{3}$ & 2.6 & 1.55 & 0.02 \\
water $^{2}$ & 1 & 1.33 & 0 \\
\hline
\end{tabular}

1 Kanakidou et al. (2005); refractive index from 300 to $800 \mathrm{~nm}$.

2 Bond and Bergstrom (2006); refractive index for $550 \mathrm{~nm}$.

3 Prasad and Singh (2007) and Mishra and Tripathi (2008).

In general, absorption increases as $k$ increases in magnitude, and decreases with increasing $n$. The fundamental optical properties of a particle are often described using Mie theory (Mie, 1908), in which the aerosol is assumed to be a refracting sphere (Archer-Nicholls, 2014). The dimensionless size parameter $x$ is used to relate the particulate diameter $\left(D_{p}\right)$ to the wavelength of incident light $(\lambda)$ :

$$
x=\frac{\pi D_{p}}{\lambda}
$$

Different values of $x$ define different interaction regimes: 
- $\mathrm{x} \ll 1$ (Rayleigh regime)

- $\mathrm{x} \approx 1$ (Mie regime)

- $\mathrm{x} \gg 1$ (Geometric regime)

For visible light, aerosol particles in the accumulation mode are in the Mie regime. The phase function $\mathrm{P}(\theta, x, m)$ describes the angular distribution of scattered light, defined as the ratio of scattered light in a specific direction relative to the integral of the total scattered light:

$$
\begin{gathered}
P(\theta, x, m)=\frac{I(\theta, x, m)}{\int_{0}^{\pi} I(\theta, x, m) \sin \theta d \theta} \\
\int_{0}^{2 \pi} \int_{0}^{\pi} P(\theta, x, m) \sin \theta d \theta d \phi=4 \pi
\end{gathered}
$$

where $I$ is the intensity of scattered radiation at different angles and $\theta$ is the zenith angle of the radiation. Note that this formulation assumes the particle is spherical in order to remove the dependence on the azimuthal angle $\phi . P$ is normalised such that the integral in all angles is equal to $4 \pi$. The phase function can in turn be used to calculate the asymmetry parameter $g$ :

$$
g \equiv \frac{1}{2} \frac{\int_{0}^{\pi} \cos \theta I(\theta, x, m) \sin \theta d \theta}{\int_{0}^{\pi} I(\theta, x, m) \sin \theta d \theta}=\frac{1}{2} \int_{0}^{\pi} \cos \theta P(\theta, x, m) \sin \theta d \theta
$$

Ultrafine aerosol and gas molecules in the Rayleigh regime scatter radiation symmetrically in the forward and backward directions $(g \approx 0)$. Accumulation mode particles in the Mie regime have typical values of $\mathrm{g}$ between 0.5 to 0.8 , while for larger particles, such as coarse mode aerosol or cloud droplets, $g$ tends towards 0.844 . The dependence on $x$ is such that $g$ is sensitive to the size of the aerosol (in particular it can be strongly affected by ambient RH), and wavelength, tending to decrease with increased $\lambda$ (Archer-Nicholls 2014). The absorption and scattering cross sections $\mathrm{C}_{a b s}(\mathrm{~m}, \mathrm{x})$ and $\mathrm{C}_{\text {scat }}(\mathrm{m}, \mathrm{x})$ are defined as the cross-sectional area of the aerosol that can absorb or scatter incident radiation. 
Both are functions of $m$ and $x$, and can be derived from Mie theory as described in more detail by Bohren and Huffman (1983). As the aerosol refractive index approaches to the air refractive index, both $\mathrm{C}_{\text {scat }}$ and $\mathrm{C}_{a b s}$ approach 0 :

$$
\lim _{k \rightarrow 0} C_{a b s}=0 ; \quad \lim _{m \rightarrow 1} C_{s c a t}=0
$$

Equivalent, dimensionless scattering coefficients $\mathrm{Q}_{a b s}$ and $\mathrm{Q}_{\text {scat }}$ can be defined by dividing $\mathrm{C}_{a b s}$ or $\mathrm{C}_{\text {scat }}$ by the physical cross-sectional area of the aerosol:

$$
Q_{s c a t / a b s}=\frac{4 C_{\text {scat } / a b s}}{\pi D_{p}^{2}}
$$

The extinction is defined as the sum of the scattering and the absorption, and describes the total energy removed from a beam of radiation:

$$
C_{\text {ext }}=C_{\text {scat }}+C_{a b s} ; \quad Q_{e x t}=Q_{\text {scat }}+Q_{a b s}
$$

To calculate the total radiation intercepted by a layer of aerosol particles, the above parameters need to be integrated over the full range of particle diameters in a population. If we assume all particles have the same refractive index $m$ and are described by a number size distribution function $n\left(D_{p}\right)$, the extinction coefficient $\beta_{\text {ext }}$ is given by:

$$
\beta_{\text {ext }}(\lambda)=\int_{0}^{D_{p}^{\max }} \frac{\pi D_{p}{ }^{2}}{4} Q_{e x t}(m, x) n\left(D_{p}\right) d D_{p}
$$

with similar relations for scattering coefficient $\beta_{\text {scat }}$ and absorption coefficient $\beta_{a b s}$. For a collection of particles, the extinction $\left(\beta_{\text {ext }}\right)$, scattering $\left(\beta_{\text {scat }}\right)$, and absorption $\left(\beta_{\text {abs }}\right)$ coefficients describe the amount of light removed, scattered, and absorbed, respectively (Tamar et al. 2015). The extinction coefficient $\beta_{\text {ext }}$ has units of inverse distance (e.g. $\mathrm{km}^{-1}$ ), and describes how much radiation interacts with aerosol particles per unit depth of atmosphere penetrated. For the same type of particle, the optical coefficients can be expressed as the product of the optical cross section and the particle number concentration $\mathrm{N}$, as: 


$$
\beta_{\text {ext } / \text { scat } / a b s}=N C_{\text {ext } / \text { scat } / a b s}
$$

For a population of different types of particles, the coefficients are expressed as the sum of the individual optical cross sections of each substance divided by the total volume occupied by this population (Tamar et al. 2015). Finally, the single scattering albedo, $\omega_{0}$, is defined as the ratio of scattered radiation to extinction:

$$
\omega_{0}=\frac{C_{\text {scat }}}{C_{\text {ext }}}=\frac{\beta_{\text {scat }}}{\beta_{\text {ext }}}=\frac{\beta_{\text {scat }}}{\beta_{\text {scat }}+\beta_{\text {abs }}}
$$

such that the fraction of scattered incident radiation is equal to $\omega_{0}$, and the fraction absorbed is $1-\omega_{0} . \mathrm{C}_{a b s}$ is highest (and $\omega_{0}$ is lowest) when $x \approx 1$, but drops off steeply as the particle gets larger as only the surface of the particle takes part in absorption. By integrating $\beta_{\text {ext }}$ between the ground and top of the atmosphere (TOA), the aerosol optical depth (AOD, or $\tau$ ) can be calculated as:

$$
\tau(\lambda)=\int_{0}^{T O A} \beta_{e x t}(\lambda, z) d z
$$

To find the intensity of light which will penetrate an aerosol layer, the Beer-Lambert law (Swinehart, 1962) is used:

$$
I(\lambda)=I_{0}(\lambda) e^{-\tau(\lambda)}
$$

where $I_{0}$ is the incident radiation intensity. Thus, the AOD describes an e-folding of the incident radiation intensity through the aerosol layer. Typical AODs can vary from near zero in clean environments to 1 or more in regions with high aerosol loadings. AOD is routinely measured across the world at various wavelengths by both ground-stations and satellites to give a detailed description of aerosol spatial and temporal distribution. The Ångström exponent $(\stackrel{\circ}{a})$ Angström, 1929) can be used to estimate the wavelength dependence of the extinction if AOD is known at two or more wavelengths: 


$$
\frac{\tau_{1}}{\tau_{2}}=\left(\frac{\lambda_{1}}{\lambda_{2}}\right)^{-\stackrel{\circ}{a}}
$$

where $\tau_{i}$ is the AOD at wavelength $\lambda_{i}$. Solving the Eq. 2.27 for $\stackrel{\circ}{a}$ gives:

$$
\stackrel{\circ}{a}=-\frac{\ln \left(\frac{\tau_{1}}{\tau_{2}}\right)}{\ln \left(\frac{\lambda_{1}}{\lambda_{2}}\right)}
$$

Angström (1929) demonstrated that $\stackrel{\circ}{a}$ shows a strong sensitivity to the size of the particle. For fine mode particles with diameter less than $500 \mathrm{~nm}, \stackrel{\circ}{a}$ is in the range $1.5-3$, tending towards 4 as predicted by Rayleigh scattering, as the particle gets smaller. Coarse mode particles typically have $\stackrel{\circ}{a}<1$. This information can be used to derive an approximate aerosol size distribution from remote sensing data (Archer-Nicholls, 2014). In Fig. 2.3, estimates of the aerosol radiative forcing are shown, and the contribution from aerosol constituents that absorb light are compared to those that reflect it.

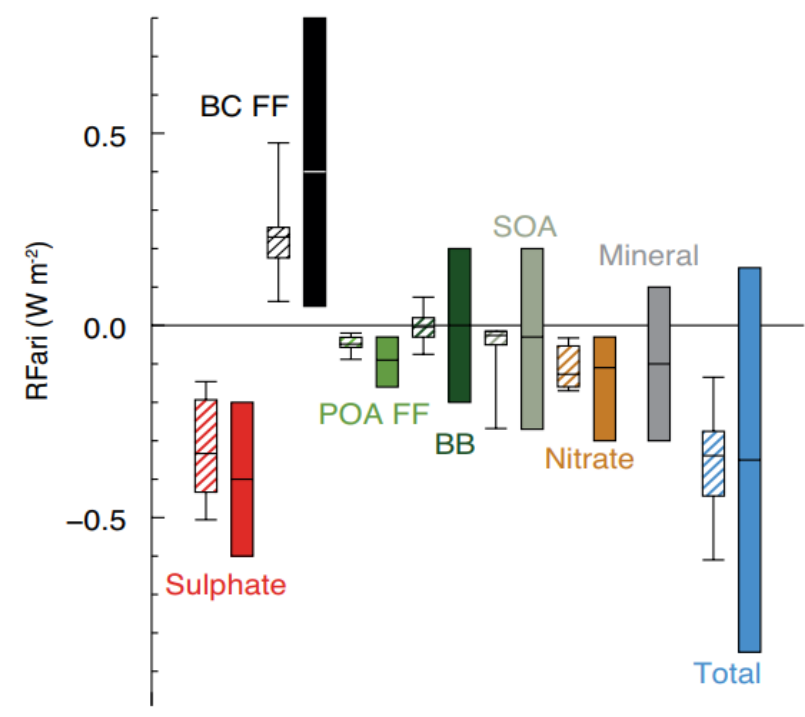

Figure 2.3: Annual mean top of the atmosphere radiative forcing due to aerosol-radiation interactions (RFari, in $\mathrm{W} \mathrm{m}^{-2}$ ) due to different anthropogenic aerosol types, for the 1750-2010 period. Hatched whisker boxes show median (line), $5^{\text {th }}$ to $95^{\text {th }}$ percentile ranges (box) and min/max values (whiskers) from AeroCom II models (Myhre et al., 2013). Solid coloured boxes show the AR5 best estimates and $90 \%$ uncertainty ranges. BC FF is for black carbon from fossil fuel and biofuel, POA FF is for primary organic aerosol from fossil fuel and biofuel, BB is for biomass burning aerosols, and SOA is for secondary organic aerosols. (figure extracted from Boucher et al. (2013)). 


\section{Recent advances and future challenges}

Of all aerosol particle physical parameters that influence scattering efficiency, the uptake of water with increasing humidity, which is controlled by the composition of the particles, is the most important. The highly variable relative humidity across the scales, and the nonlinear response of aerosol water uptake to it, introduce aerosol direct radiative forcing uncertainty. While estimates of aerosol direct radiative forcing are typically dominated by scattering aerosols, the degree of warming provided by absorbing aerosol has been an active area of research, particularly over the last decade (NA\$ 2016). The strong dependence of light absorption and scattering on aerosol composition and aging has directed more recent studies to focus on understanding the relationship between these optical properties and the aerosol source, chemical composition, physical structure and aging processes (Boucher et al. 2013). The latest IPCC report ranked black carbon as the second most important climate warming, after $\mathrm{CO}_{2}$. However, uncertainties surrounding the sources, mixing state, and optical properties of black carbon lead to large uncertainty in its impact on the absorption of solar radiation. In addition, brown carbon (organic carbon aerosol that absorbs at ultraviolet and visible wavelengths) may also make an important contribution to solar absorption and climate forcing. Initial modelling studies suggest that brown carbon could globally contribute 20-30\% of the total aerosol absorption at visible wavelengths. Still, the sources and composition of brown carbon, its distribution throughout the atmosphere as well as its absorption characteristics and how these might evolve in the atmosphere are not well known yet. Reflecting a growing understanding of aerosol sources and properties, an increasingly complex treatment in atmospheric models will reduce this gab (NAS 2016).

\subsubsection{Aerosol indirect effects}

Atmospheric aerosols play an essential role in the formation of clouds by acting as cloud condensation or ice nuclei (CCN or IN respectively), providing surfaces onto which water vapour condenses to form water droplets or ice crystals. Clouds form when water vapour in air mass becomes supersaturated, i.e. when the relative humidity $(\mathrm{RH})$ becomes greater than 100\%: 


$$
S=\frac{e}{e_{s}}=\frac{R H}{100}
$$

where $e$ is the vapour pressure of water and $\mathrm{e}_{s}$ is the saturation vapour pressure of water and $S$ is known as the saturation ratio. The saturation water vapour decreases with decreasing temperature (Archer-Nicholls, 2014).

The process by which CCN grow through condensation of water vapour to form cloud droplets is known as activation (Abdul-Razzak and Ghan, 2000). Current theories of aerosol activation are based on the Köhler equation (Köhler, 1936), which gives the general equilibrium relation between a droplet of an aqueous salt solution and its surrounding environment:

$$
S=a_{w} \exp \left(K_{e}\right)=a_{w} \exp \left(\frac{2 v_{w} \sigma_{s o l} / v}{R T r_{p}}\right)
$$

where $\mathrm{r}_{p}$ is the radius of the particle, $v_{w}$ is the partial molar volume of water and $\sigma_{s o l / v}$ the surface tension of the solution. The Kelvin term $\left(K_{e}\right)$ describes how it is easier for molecules to be retained on a flat surface than a curved one. The activity term $a_{w}$ is an effect of Raoult's law which describes how, as more solute is added to a solution, the equilibrium vapour pressure is reduced, increasing the net condensation of water vapour for a given $S$. It is defined as:

$$
a_{w}=\exp \left(-x_{s} \phi_{s}\right)=\exp \left(-\frac{v n_{s}}{n_{w}} \phi_{s}\right)
$$

where $x_{s}$ is the molar fraction, $v$ is the number of dissociated ions per molecule of the solute, $n_{w}$ and $n_{s}$ are the number densities of water and the solute respectively, and $\phi_{s}$ is the activity coefficient of the salt. If it is assumed that the droplet is homogeneous, that the solute behaves ideally and is completely soluble, and that the surface tension and density are the same as for pure water, Eq. 2.30 reduces to:

$$
S=\frac{e}{e_{s}} \approx 1+\frac{A}{r_{p}}-\frac{B}{r_{p}^{3}}
$$


where $A$ is is the coefficient of the curvature or Kelvin effect, and $B$ is the hygroscopicity, related to Raoult's Law. These are defined as:

$$
A=\frac{2 \tau_{a} M_{w}}{\rho_{w} R T} ; \quad B=\frac{v \epsilon \phi_{s} M_{w} \rho_{s}}{M_{s} \rho_{w}}
$$

where $\tau_{a}$ is the activation time, $\mathrm{M}_{w}$ and $\mathrm{M}_{s}$ are the molecular weights of water and the solute respectively, $\rho_{w}$ and $\rho_{s}$ are the densities of water and solute respectively, and $\epsilon$ is the mass fraction of soluble material in the particle Abdul-Razzak and Ghan, 2000; Archer-Nicholls, 2014). With these assumptions the overall behaviour can be seen as a competition between Kelvin and Raoult terms, as shown in Fig. 2.4.

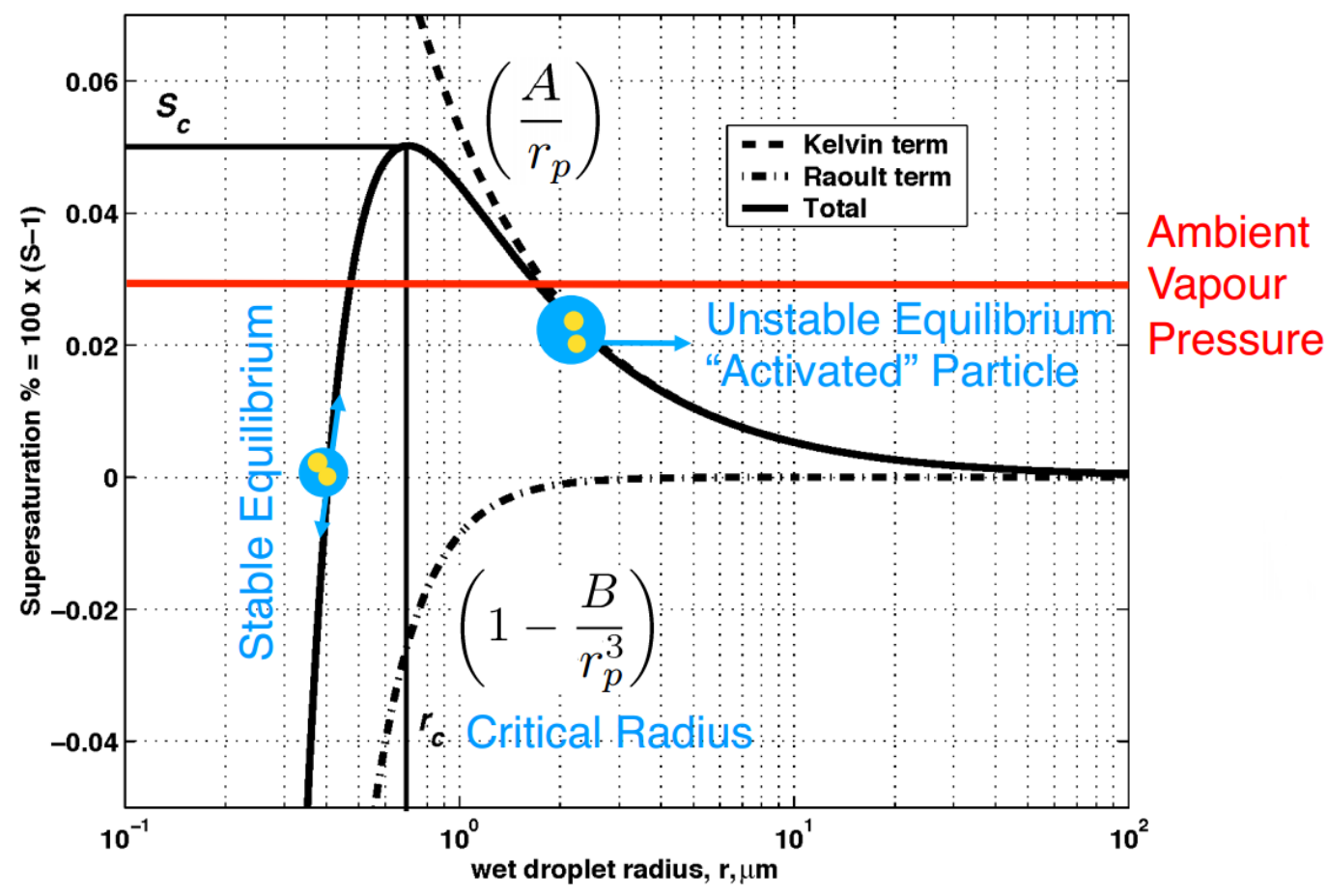

Figure 2.4: Köhler curve (thick line) as the product of the Kelvin effect and the Raoult effect (dashed lines) (figure adapted from (Stier, 2011)).

A particle with a given composition and dry radius will have a critical supersaturation $\mathrm{S}_{c}$, and a corresponding critical dry radius $\mathrm{r}_{c}$, associated with it:

$$
S_{c}=\frac{2}{\sqrt{B}}\left(\frac{A}{3 r_{p}}\right)^{3 / 2} ; \quad r_{c}=\left(\frac{3 B}{A}\right)^{1 / 2}
$$


For aerosol particles in environments where $S<S_{c}$, water will condense onto it until it grows up to the radius associated with that level of saturation, but no further. However, if at any point in time $S \geq S_{c}$, the particle will reach its critical size and from here can grow unimpeded. At this point, the particle is said to have become "activated" and will continue to grow as long as the environment remains supersaturated. In a cloud, the level of supersaturation is mainly driven by the updraft speed. A real air mass will contain a mixture of aerosol particles of varying sizes and composition, and only particles with $r_{p}>r_{c}$ when $S=S_{\max }$ will activate. The number of CCN in a given air mass that become activated when a cloud is formed is a key quantity needed to understand the climatic influences of aerosol particles on clouds, and is primarily dependent on the size distribution of the aerosol population (Archer-Nicholls, 2014).

\section{Recent advances and future challenges}

Uncertainties in our current understanding of CCN properties are due primarily to SOA, mainly because organic aerosol is still poorly characterized. An important effect of SOA formation is that internally mixed SOA contributes to the mass of aerosol particles, and therefore to their sizes. The size of the CCN has been found to be more important than their chemical composition at two continental locations, as larger particles require a lower critical supersaturation to be activated. However, the chemical composition may be important in other locations such as marine environments, where primary organic particles have been shown to be exceptionally good CCN (Boucher et al., 2013). Increased concentrations of large aerosol particles, termed giant CCN, may act as efficient collector drops and promote the formation of precipitation. In addition, the presence of large numbers of these giant CCN (e.g., generated during storms) may also deplete water vapour availability in the early stages of cloud formation, strongly affecting the sensitivity of cloud droplets to aerosol particle variations. On the other hand, particles that act as ice nuclei (IN) are rare in comparison with CCN; about one in a million aerosol particles acts as an IN. A quantitative understanding of what makes an effective ice nucleating particle and a generally accepted theory for ice nucleation is lacking. Part of this difficulty in establishing a theory is related to the surface chemical and morphological complexity of the IN. The other difficulty lies in the multiple ways that IN can catalise the formation of ice. The small number of particles that do act as IN makes measurement challenging and also has 
profound implications for clouds that contain ice (NAs 2016). The importance of biological particles acting as IN is unclear, and the anthropogenic fraction can not be estimated at this point because of a lack of knowledge about the anthropogenic fractions of organic aerosols and other aerosols acting as IN (Boucher et al., 2013). These complex dynamical interactions are not well understood and further research is needed to confirm aerosol particle influence on cloud-scale dynamics, and to embed these influences in multi-scale model that can ultimately evaluate changes in radiative balance and precipitation on regional and global scales (NAs 2016).

\subsection{Aerosol studies conducted in the Metropolitan Area of São Paulo}

Most of aerosol modelling studies in South America have focused on the Amazon rainforest, as smoke generated from biomass burning in the region can spread over significant portions of the continent, having a considerable effect on direct and indirect radiative forcing as well as on human health. Although it is well known that air pollutants from biomass burning in this region may affect the oxidative capacity of the atmosphere in urban areas in south-eastern Brazil, no major efforts have been made to investigate that effect. In addition, despite the fact that these urban areas have been reducing, through programs for emission control, the emission of primary pollutants such as $\mathrm{CO}, \mathrm{NOx}$ and $\mathrm{SO}_{2}$, secondary pollutants such as $\mathrm{O}_{3}$ but mainly $\mathrm{PM}_{2.5}$ need yet to be controlled.

On the other hand, although the use of air quality modelling combined with measurements has proved to be a powerful tool in the description of atmospheric photochemistry, there is still room for improvement in the emission inventories (Andrade et al., 2017), being this the main reason why studies related to chemistry-climate interactions as well as their impacts on air quality and human health have not yet been investigated in the MASP. Despite being the largest metropolitan area of South America and being affected by pollutant emissions from different sources, the MASP does not have a representative number of aerosol modelling studies that are broad enough in terms of aerosol physical, chemical and optical properties. Most of modelling studies have focused on the concentration of atmospheric aerosols, and were conducted using off-line models (Ynoue, 2004; Albuquerque, 2010). With the development of powerful computer systems, the simulation of chemical reactions inside mesoscale models, the so-called inline or online models (e.g. 
WRF-Chem), was made possible. Oliveira (2012) used the WRF-Chem model to investigate the impact of atmospheric aerosols on the formation of clouds and precipitation and found that an increase in primary aerosol emissions favoured a reduction in the total accumulated precipitation in the central area of MASP. Despite the formation of aerosols represents a challenge not only for their control but also for its understanding, Andrade et al. (2015) implemented a WRF-Chem based forecasting system for southeastern Brazil, yielding good skill for the MASP.

Unlike modelling studies, there are numerous field studies that have been conducted in the MASP, and can be tracked back to early 1973. Although sample collection methods varied from year to year, most of the samples were collected on the main campus of the University of São Paulo, which is situated in the south-western zone of the city Andrade et al. 2017). Studies conducted on ambient air pollution in the MASP have shown that organic carbon explains $40 \%$ of $\mathrm{PM}_{2.5}$ mass concentrations compared with $21 \%$ of black carbon, $20 \%$ of sulfates, and $12 \%$ of soil dust (Andrade et al., 2012). Through particle size distribution analysis, Albuquerque et al. (2012) have shown that aerosol growth is more intense during polluted periods. Aerosol properties such as CCN activation and aerosol optical depth (AOD) have also been analysed. Souto-Oliveira et al. (2016) reported that high night-time activation diameter values are associated with air masses passage over regions with active fires, which impacts negatively on CCN activation, as high activation diameter can often be attributable to low particle hygroscopicity. In order to identify the impact of local and remote contributions to aerosol loadings in the MASP, Miranda et al. (2017) combined aerosol properties measured at surface with vertical profiles and satellite information for events with and without smoke plume transport over the MASP. Their findings reveal significant changing of aerosol concentrations and optical parameters which were diverse from that found in scenarios dominated by local pollution. 
Chapter 3

\section{Method and Data}

This chapter presents a description of the modelling framework, emissions inputs and measurements used to evaluate the numerical simulations. In addition, statistical parameters used for model evaluation are presented at the end of the chapter.

\subsection{The Weather Research and Forecasting with Chemistry (WRF-Chem) community model}

The Weather Research and Forecasting with Chemistry (WRF-Chem) community model has been continuously developed through collaborations between a host of institutions and university groups and scientists over the past twelve years. It is a fully coupled on-line meteorology-chemistry transport mesoscale model used to simultaneously simulate meteorology, chemistry and aerosol feedback effects at a regional scale. WRF-Chem consists of a dynamics solver, the Advanced Research WRF (ARW) core, coupled to a chemistry module. The key equations and numerical schemes used by WRF-Chem are explained in this section based on Skamarock et al. (2008) and Grell et al. (2005).

\subsubsection{The Advanced Research WRF (ARW) model}

\subsubsection{Governing equations}

The ARW dynamics solver (also knows as WRF-ARW) integrates the fully compressible, non-hydrostatic Euler equations according to Ooyama (1990). Ooyama's approach describes the primitive equations of motion in terms of conservative properties such as mass and entropy; however that description is limited to the thermodynamics of reversible processes, basically condensation of water vapor and release of latent heat. The funda- 
mental hydrodynamic and thermodynamic laws of fluids are described for a set of four key prognostic (time dependent) equations: the continuity equation, which conserves mass; the equation of motion, derived from Newton's second law to conserve momentum; the thermodynamic equation, derived from the first law of thermodynamics; and a forth equation describing the time dependence of the pressure coordinate, derived from the continuity and thermodynamic equations and the equation of state (Archer-Nicholls, 2014). The equation of state is a diagnostic (not time dependent) equation derived from the ideal gas law.

$$
p \alpha=R T
$$

where $p$ is pressure, $\alpha=1 / \rho$ the specific volume, $R$ the gas constant and $T$ temperature. The prognostic equations are integrated in the ARW in conservative (flux) form for conserved variables, and non-conserved variables such as pressure and temperature are diagnosed from the prognostic conserved variables. Under these approaches, the ARW integrates a mass conservation equation and a scalar conservation equation, both of the form:

$$
\begin{gathered}
\frac{\partial \mu}{\partial t}+\nabla \cdot(V \mu)=0 \\
\frac{\partial(\mu \phi)}{\partial t}+\nabla \cdot(V \mu \phi)=0
\end{gathered}
$$

where $\mu$ is the column mass of dry air, $V$ is the velocity $(u, v, \nabla)$, and $\phi$ is a scalar mixing ratio. These equations follow the terrain-following mass vertical coordinate, " $\eta$ ", based on the methodology of Laprise (1992):

$$
\begin{aligned}
& \eta=\frac{p_{h}-p_{h t}}{\mu} \\
& \mu=p_{h s}-p_{h t}
\end{aligned}
$$

where $p_{h}$ represents the hydrostatic component of pressure at any model level between surface and top, while $p_{h s}$ and $p_{h t}$ represent the pressure values at the surface and top, respectively (see Fig. 3.1). 


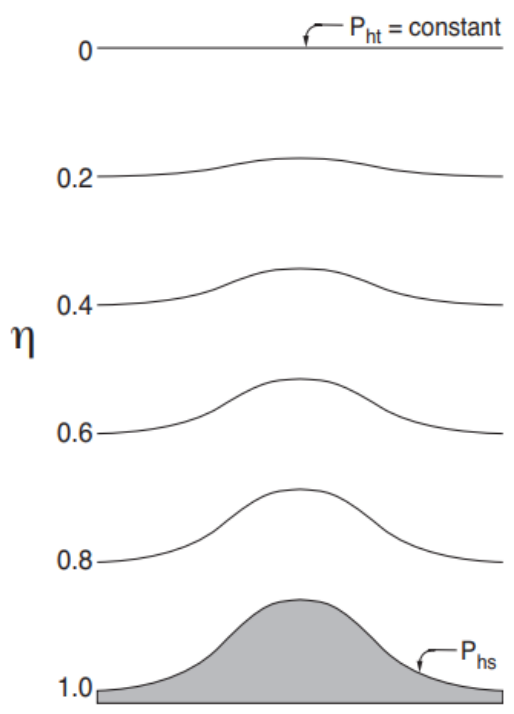

Figure 3.1: ARW $\eta$ coordinate (figure extracted from Skamarock et al. (2008)).

And are horizontally and vertically discretized in a finite volume formulation using an Arakawa-C grid staggering (Arakawa, 1966) and for the variables as shown in Fig. 3.2 .

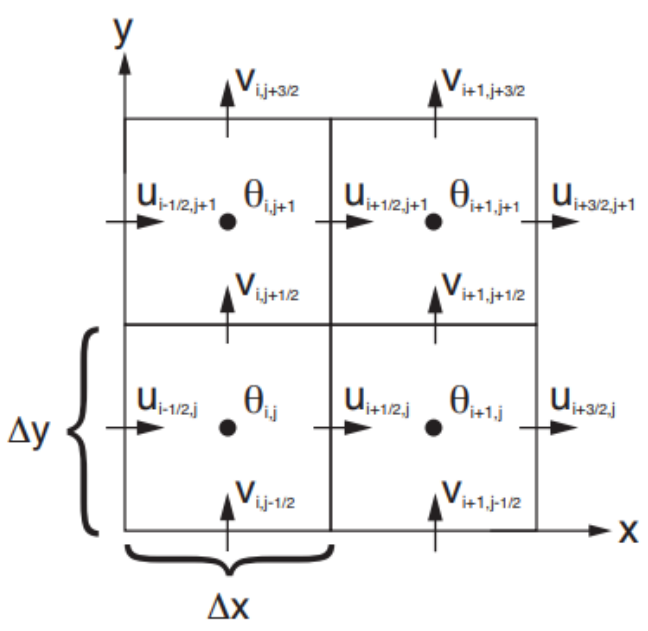

horizontal grid

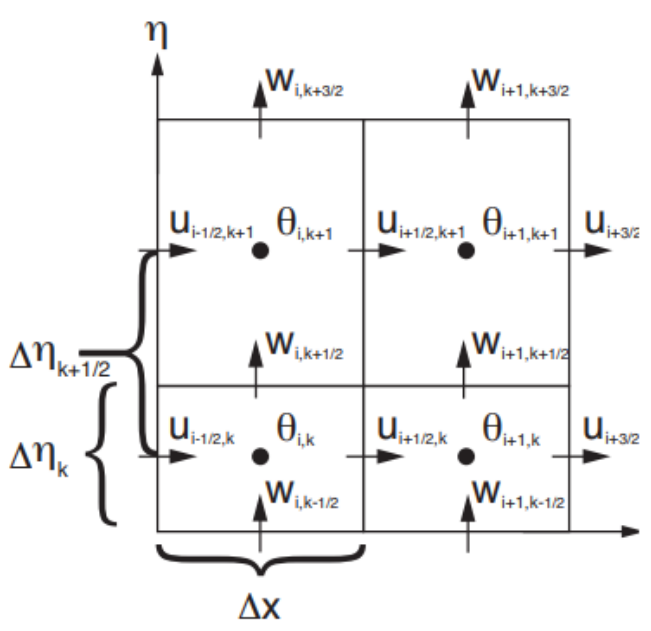

vertical grid

Figure 3.2: Arrangement of variables in a staggered Arakawa-C grid (Skamarock et al. 2008, Figure 3.2).

That is, normal velocities are staggered one-half grid length from the thermodynamic variables. The variable indices $i, j$ and $k$ indicate variable locations with $x=i \Delta x, y=j \Delta y$ and $\eta=k \Delta \eta$. The points where $\theta$ is located are defined as mass points. Likewise, locations where $u, v$ and $w$ are defined as $u$ points, $v$ points, and $w$ points, respectively. 
Approximate solutions to the non-linear Euler equations are solved using a third-order time-split Runge-Kutta scheme (Klemp et al., 2007). The integration is carried out using a fixed time step, usually defined as a function of the spatial resolution. The CourantFredrichs-Lewy condition (Courant et al. 1928), that connects the temporal and spatial resolutions, is used to guarantee the dynamical stability of the solver.

$$
C=u \frac{\Delta t}{\Delta x}
$$

where $u$ is the magnitude of the velocity. The condition $C_{\max } \leq 1$ is tolerated for explicit solvers, while for implicit methods, such as those used by WRF, the time step may be larger and remain stable. For the ARW, the time step (in seconds) should be approximately six times the grid distance (in kilometers) (Skamarock et al., 2008).

\subsubsection{Physics schemes}

In the WRF model, the available physics schemes can be split into the following six basic categories

- Radiation

- Microphysics

- Land-surface model

- Surface Layer

- Planetary Boundary Layer

- Cumulus clouds

\section{Radiation}

The radiation schemes provide atmospheric heating rates due to radiative flux divergence and surface downward longwave and shortwave radiation for the ground heat budget. Longwave radiation includes infrared or thermal radiation absorbed and emitted by gases and surfaces, whereas shortwave radiation includes visible and surrounding wavelengths that make up the solar spectrum, the upward flux being the reflection due to surface 
albedo. Radiation schemes respond to model-predicted cloud and water vapor distributions, as well as specified carbon dioxide, ozone, and other gas concentrations. All the radiation schemes in WRF are column schemes, and the fluxes correspond to those in infinite horizontally uniform planes, approximation that is less accurate at high horizontal resolutions (Skamarock et al., 2008). The radiation schemes selected in this study included the Rapid Radiative Transfer Model (RRTM) (Mlawer et al., 1997) and the Rapid Radiative Transfer Model for General Circulation Model applications (RRTMG) (Iacono et al., 2008) for longwave radiation, whereas the scheme of Goddard (Chou and Suarez, 1994) and the RRTMG for shortwave radiation. The RRTM uses pre-set tables to accurately represent the longwave interaction of $\mathrm{CO}_{2}, \mathrm{O}_{3}$, water vapour, clouds and other gases, as well as accounting for cloud optical depth. The RRTMG, a new version of the RRTM scheme, is linked to some aerosol schemes to calculate the effects of aerosol particles on both shortwave and longwave radiative transfer (Archer-Nicholls, 2014). The Goddard scheme includes 11 spectral bands and considers diffuse and direct solar radiation components in a two-stream approach that accounts for scattered and reflected components (Skamarock et al., 2008). As the RRTMG, the Goddard scheme is also linked to aerosol schemes to account for aerosol effects, in this case on shortwave spectrum.

\section{Microphysics}

Microphysics schemes include explicitly resolved water vapor, cloud, and precipitation processes. In addition, ice-phase and mixed-phase processes can be included depending on the scheme. Mixed-phase processes are those that result from the interaction of ice and water particles, such as riming that produces graupel or hail. As a general rule, for grid cell size less than $10 \mathrm{~km}$, where updrafts may be resolved, mixed-phase schemes should be used, particularly in convective or icing situations. For coarser grids the added expense of these schemes is not worth it because riming is not likely to be well resolved. Sedimentation process and saturation adjustment are also included in the microphysics schemes (Skamarock et al., 2008). There are two descriptions of the cloud hydrometeor size distribution: bin schemes, which describe the size distribution of hydrometeors in discrete bins, and bulk schemes, which assume a gamma particle size distribution ArcherNicholls, 2014). The microphysics schemes selected in this study included the scheme of Lin (Lin et al. 1983) and the Morrison two-moment (Morrison et al. 2009). Both the 
Lin and Morrison schemes account for mixed phase processes, carrying variables for liquid cloud droplets, rain, cloud ice, snow and hail/graupel. While the scheme of Lin is a single moment scheme, with the number density estimated using an exponential size distribution function, the prediction of two-moment (number concentration and mixing ratio) is treated using gamma functions, with the associated intercept and slope parameters derived from the predicted mixing ratio and number concentrations (Skamarock et al., 2008; ArcherNicholls, 2014). In order to evaluate aerosol effects on clouds, both schemes have been coupled with aerosol schemes within the model.

\section{Land-surface model}

To provide heat and moisture fluxes over land points and sea-ice points, the landsurface models (LSMs) use atmospheric information from the surface layer scheme, radiative forcing from the radiation scheme, and precipitation forcing from the microphysics and convective schemes, together with internal information on the land's state variables and land-surface properties. These fluxes provide a lower boundary condition for the vertical transport calculated in the PBL schemes. The LSMs provide no tendencies, but do update the land's state variables which include the ground (skin) temperature, soil temperature profile, soil moisture profile, snow cover, and possibly canopy properties. In addition, there is no horizontal interaction between neighboring points in the LSMs, so it can be regarded as a one-dimensional column model for each WRF land grid-point, and many LSMs can be run in a stand-alone mode. The land-surface model selected in this study is the Unified Noah land-surface model (Chen and Dudhia, 2001). This scheme models the soil in 4 layers, down to a depth of 2 meters, carrying variables for temperature, water and water and ice. The scheme can also account for the effects of vegetation, surface emissivity and fractional snow cover to provide sensible and latent heat fluxes for the PBL schemes (Archer-Nicholls, 2014).

\section{Surface Layer}

These schemes calculate friction velocities and exchange coefficients that enable the calculation of surface heat and moisture fluxes by the LSMs and surface stress by the PBL schemes. Tendencies are not provided by surface layer schemes, and only the stabilitydependent information about the surface layer is supplied to the LSMs and PBL schemes. 
Over water surfaces, the surface fluxes and surface diagnostic fields are computed in the surface layer scheme itself. Each surface layer option is tied to particular PBL options, some of which require the thickness of the surface layer in the model to be representative of the actual surface layer (e.g. 50-100 m). The surface layer schemes selected in this study included the Monin-Obukhov scheme (Chou and Suarez, 1994) and the Revised Mesoscale Model version 5 Monin-Obukhov scheme (Jiménez et al., 2012). The Monin-Obukhov similarity theory is widely used to compute the surface turbulent fluxes, providing information on the profiles within the surface layer that are used to diagnose meteorological variables at their typical observational height such as the wind at $10 \mathrm{~m}$ or the temperature and moisture at $2 \mathrm{~m}$. The Revised Monin-Obukhov scheme, a new version of the Monin-Obukhov scheme, provides a self-consistent formulation valid for the full range of atmospheric stabilities, producing a more abrupt afternoon transition than the old version. The main difference between the two schemes is that while the old scheme tends to show a period with a neutral surface layer before the stable conditions are reached, the new one does not suffer from this limitation and shows a sharper transition, which is more in agreement with observational evidence and new parameterizations (Jiménez et al., 2012).

\section{Planetary Boundary Layer}

Vertical sub-grid-scale fluxes due to eddy transports are accounted for by the planetary boundary layer (PBL) scheme, not just within the well-mixed boundary layer and the stable layer where the flux profiles are determined, but also in upper layers, thus providing atmospheric tendencies of temperature, moisture (including clouds), and horizontal momentum in the entire atmospheric column. The surface fluxes are provided by the surface layer and land-surface schemes. The PBL schemes are one-dimensional, and assume a clear scale separation of a few hundred meters below which boundary layer eddies may start to be resolved, and in these situations the scheme should be replaced by a local sub-grid turbulence scheme such as the Turbulent Kinetic Energy (TKE) diffusion scheme. The PBL scheme selected in this study is the Yonsei University (YSU) scheme (Hong et al., 2006). The YSU scheme is a non-local scheme that explicitly calculates TKE, estimating vertical turbulent fluxes based on the mean profiles of turbulent mixing. The scheme resolves better multi-scale eddies, and is more applicable for simulating convective and unstable PBLs. The choice of the PBL scheme can have a large impact on model results; however, 
it is difficult to determine, in advance, what is the best choice that would need to be used before conducting research with WRF-Chem (Archer-Nicholls, 2014).

\section{Cumulus clouds}

Cumulus schemes are intended to represent subgrid-scale effects of convective and/or shallow clouds due to unresolved updrafts and downdrafts and compensating motion outside the clouds. They operate only on individual columns where the scheme is triggered and provide vertical heating, moistening profiles and the convective component of surface rainfall. These schemes are idealised for coarse grid sizes (e.g., $\geq 10 \mathrm{~km}$ grid cell size), being necessary to properly release latent heat on a realistic time scale in the convective columns. Sometimes, however, they have been found to be helpful in triggering convection in 5-10 km grid applications, but should not be used when the model can resolve the convective eddies itself (e.g., $\leq 5 \mathrm{~km}$ grid cell size) (Skamarock et al., 2008). The cumulus schemes selected in this study included the Grell 3-D scheme (Grell and Devenyi, 2002) and the Multi-Scale Kain-Fritsch (MSKF) scheme (Zheng et al., 2016). The Grell 3-D scheme includes a cumulus advection option enabling subsistence to be spread to neighbouring columns, allowing its use at finer resolutions. Even then, no cumulus scheme should be used at resolutions less than $2 \mathrm{~km}$, as the model can be expected to resolve cumulus convection explicity (Archer-Nicholls, 2014). The MSKF scheme includes subgrid-scale cloud-radiation interactions, a simple linear method using cloud updraft mass fluxes impacting grid-scale vertical velocity, and an entrainment methodology based on the lifting condensation level, and is found to improve in overall the high-resolution simulation of longwave and shortwave radiation associated with cloud patterns, producing precipitation patterns and intensity that are closer to the observations (Zheng et al., 2016).

\subsubsection{WRF chemistry extension}

For the air pollutants simulations, the online approach using the WRF chemistry extension (WRF-Chem), in its versions 3.6 and 3.7.1, was applied. The WRF-Chem is widely used to simultaneously simulate meteorological processes, chemistry and aerosol feedback effects on a regional scale. Both WRF and WRF-Chem are completely consistent, using the same transport schemes, grid, time step and physics schemes for subgrid-scale transport Grell et al., 2005; Skamarock et al., 2008). 


\section{Chemistry-aerosol mechanisms}

For the chemistry, the Regional Acid Deposition Model version 2 (RADM2) Chang et al. 1989) and the 2005 Carbon Bond mechanism (CB05) (Yarwood et al., 2005) with additional chloride chemistry (Sarwar et al., 2007) were applied. The RADM2 was coupled with the existing Modal for Aerosol Dynamics in Europe/Secondary Organic Aerosol Model (MADE/SORGAM) Ackermann et al., 1998; Schell et al., 2001), whereas the CB05 was coupled with the Modal for Aerosol Dynamics in Europe/Volatility Basis Set (MADE/VBS) (Ackermann et al., 1998; Ahmadov et al., 2012). The RADM2 includes 59 species and 157 reactions, whereas the extended CB05 includes 97 species and 191 reactions, with more than 60 volatile organic compounds and 120 associated reactions. Both MADE/SORGAM and MADE/VBS use a three-mode aerosol representation - Aitken $(<$ $0.1 \mu \mathrm{m})$, accumulation $(0.1-1 \mu \mathrm{m})$ and coarse $(>1 \mu \mathrm{m})$. In addition, MADE/VBS uses an advanced secondary organic aerosol (SOA) module based on a four-bin VBS approach with the SOA gas-particle partitioning following Pankow's theory (Pankow, 1994a b). Nucleation processes are based on the mathematical formulations described in Kulmala et al. (1998); condensation processes are based on Binkowski and Shankar (1995); and coagulation processes are based on Whitby et al. (1991) and Binkowski and Shankar (1995).

In MADE, submicrometer aerosol particles are represented by two overlapping intervals, assuming a log-normal distribution within each mode as follows:

$$
n\left(\ln D_{p}\right)=\frac{N}{\sqrt{2 \pi} \ln \sigma_{g}} \exp \left[-\frac{1}{2} \frac{\left(\ln D_{p}-\ln D_{p g}\right)^{2}}{\ln ^{2} \sigma_{g}}\right]
$$

where $N$ is the number concentration $\left(\mathrm{m}^{-3}\right), \mathrm{D}_{p}$ the particle diameter, $\mathrm{D}_{p g}$ the median diameter, and $\sigma_{g}$ the standard deviation of the distribution. The $\mathrm{k}_{t h}$ moment of the distribution is defined as:

$$
M_{k}=\int_{-\infty}^{\infty} D_{p}{ }^{k} n\left(\ln D_{p}\right) d\left(\ln D_{p}\right)=N D_{p g}{ }^{k} \exp \left[\frac{k^{2}}{2} \ln ^{2} \sigma_{g}\right]
$$

where $\mathrm{M}_{0}$ is the total number of aerosol particles, $\mathrm{M}_{2}$ is proportional to the total particulate surface area, and $\mathrm{M}_{3}$ is proportional to the total particulate volume, all of them within the mode suspended in a unit volume of air (Grell et al., 2005). 


\subsubsection{Aerosol effects in WRF-Chem}

To account for the aerosol direct effect, aerosol radiative properties such as aerosol optical depth, single scattering-albedo and asymmetry factors are initially calculated based on the approach devised by Fast et al. (2006) according to Mie theory (Mie, 1908). Those properties are then transferred to the RRTMG shortwave radiation scheme in order to calculate the corresponding radiative forcing. The aerosol effects on photolytic rates for major gaseous species such as $\mathrm{O}_{3}$ and $\mathrm{NO}_{2}$ are linked to the Fast Troposphere Ultraviolet Visible photolysis module through the use of predicted concentrations of aerosols, including ammonium, sulfate, nitrate, OC, EC, SOAs, sea salt and dust (Wang et al., 2015). The overall impact of aerosol indirect effects in WRF-Chem is accounted for by linking interactive aerosol modules, as implemented by Gustafson et al. (2007) and Chapman et al. (2009). The CDNC is predicted based on the activated aerosols within the Morrison 2-moment microphysics scheme. Then, that information serves as input to the RRTMG shortwave radiation scheme, thus affecting the calculated droplet mean radius and cloud optical depth. In addition, the feedback effects of clouds on aerosol size and composition via aqueous-phase chemistry (Sarwar et al., 2011) and wet scavenging processes (Easter et al. 2004) are treated.

Aerosols are activated based on the approach described by Abdul-Razzak and Ghan (2000). The activation of aerosols is based on a maximum supersaturation determined from a Gaussian spectrum of updraft velocities and bulk hygroscopicity of each aerosol compound. CCN are calculated at given maximum supersaturation values $(0.02,0.05,0.1$, $0.2,0.5$ and $1 \%$ ) from the sum obtained over all lognormal particle modes (Tuccella et al. 2015). Aging processes by coagulation of particles can alter the particle hygroscopicity, converting small hydrophobic particles into larger and hydrophilic ones, thus increasing the CCN activation of aerosols. Likewise, large hydrophilic particles may lower their hygroscopicity by incorporating small hydrophobic particles, leading to less activated particles. As coating effects are not treated in the model, the overall impact of these interactions is primarily accounted for by the chemical composition, through the volume-weighted average hygroscopicity of each aerosol component. The main physics, chemistry and emission options used to conduct the numerical simulations, as well as their corresponding references, are listed in Table 3.1 . 


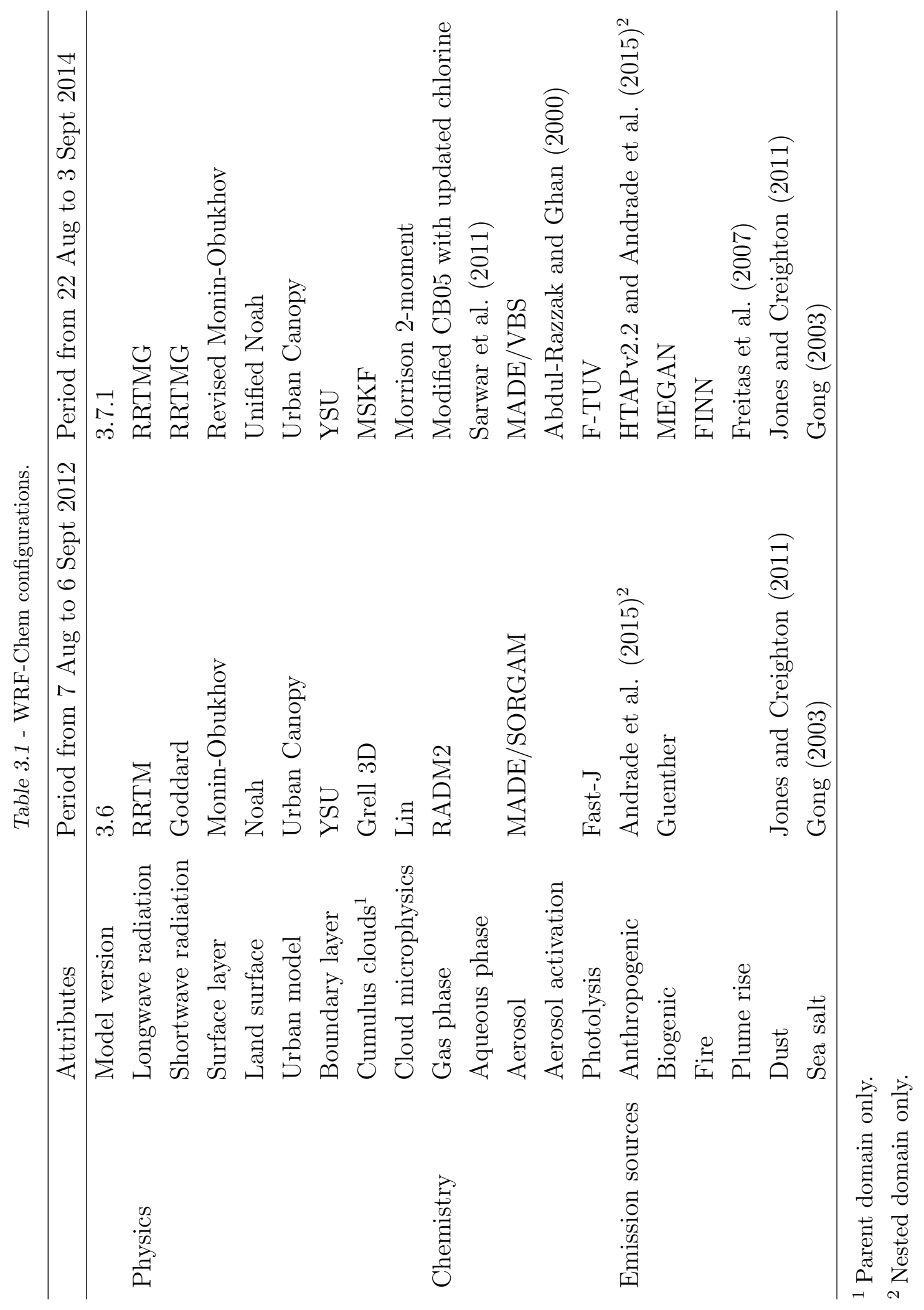




\subsubsection{Boundary and initial conditions}

As a regional model, WRF-Chem must be driven by suited inflow boundary and initial conditions. These boundary and initial conditions are typically data taken from global models, and to scale the larger forcings down into the domain, WRF uses a relaxation technique based on the work of Davies (1976). Then, further nests can be defined within WRF to achieve finer resolutions. There are two run modes in WRF-Chem to interpolate the output of the parent domain to be used as boundary condition in the nested domain: 1way or 2-way. In 1-way nesting, the parent domain provides the lateral boundary conditions to feed the boundaries of the nest domain but no information is passed back to the parent from the nest. In 2-way nesting, there is a feedback between both domains, and the new boundary conditions are smoothed and interpolated back to the parent from the nest (Skamarock et al., 2008; Archer-Nicholls, 2014).

For meteorological processes, the lower resolution model simulations were driven by Global Forecast System (GFS) analyses? and for chemistry by Model for OZone and Related chemical Tracers version 4/Goddard Earth Observing System Model version 5 (MOZART-4/GEOS-5) field² both providing input data every $6 \mathrm{~h}$.

\subsubsection{Model setup}

For this investigation, six sets of WRF-Chem simulations were carried out including different model settings. Three of them were carried out between 7 August and 6 September 2012, and were designed to evaluate the impact of vehicular emissions on the formation of fine particles. The other three, were carried out between 17 August and 3 September 2014, and were designed to quantify the contribution of biomass burning sources to the aerosol burdens. Both study periods are within the burning season in the central-west region of Brazil (from August to October), from where biomass burning emissions can be efficiently transported to urban areas in the southeastern part of the country during that season. The simulations performed for the period of 2012 were conducted over three nested domains at horizontal resolutions of $75 \mathrm{~km}, 15 \mathrm{~km}$ and $3 \mathrm{~km}$, whereas those performed for the period of 2014 were conducted over two nested domains at horizontal resolutions of $25 \mathrm{~km}$ and $5 \mathrm{~km}$. As can be seen in Fig. 3.3, the fine domains in both cases were defined as the atmosphere

\footnotetext{
${ }^{1}$ https://rda.ucar.edu/datasets/ds335.0/?hash=access

2 https://www.acom.ucar.edu/wrf-chem/mozart.shtml
} 
over the south-eastern São Paulo State, focusing on the MASP. Of each group of three simulations, one simulation was conducted to evaluate the model performance (hereafter referred to as baseline simulations with the fine-grid simulation denoted as BASE), and the other two were conducted to evaluate emission scenarios (hereafter referred to as sensitivity simulations with the fine-grid simulations denoted as NAE and NFB for the period from 7 August to 6 September 2012, and as BBE and 3BBE for the period from 17 August to 3 September 2014).
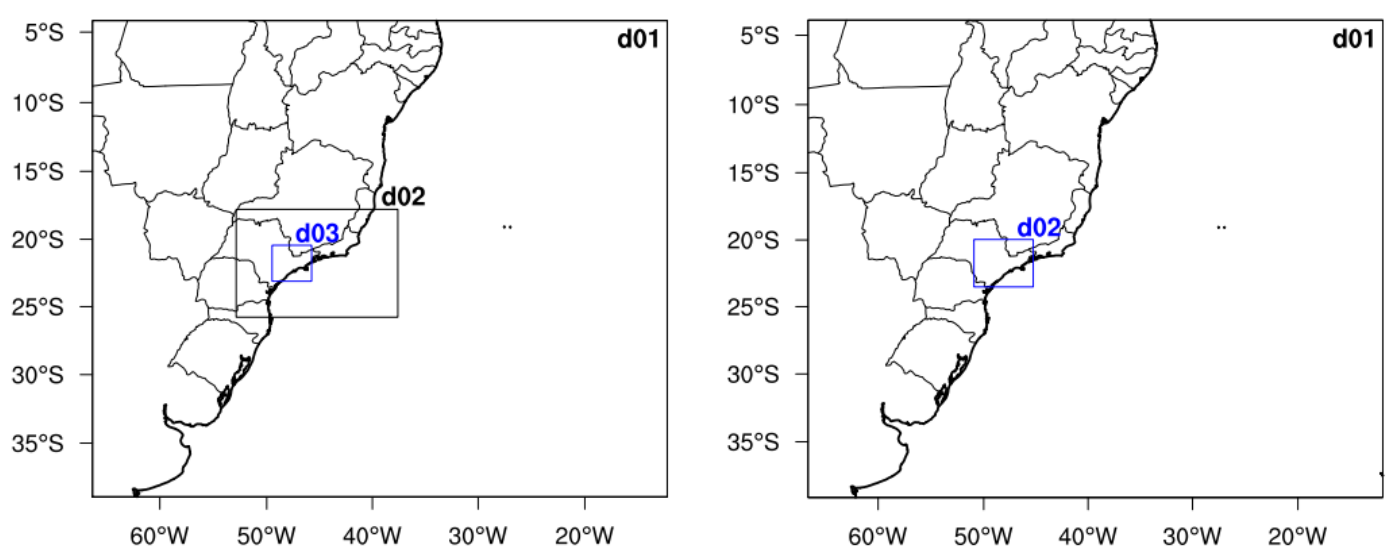

Figure 3.3: The triple (left) and double (right) nested domains for WRF-Chem modelling. The coarsest domains (d01) cover the south-eastern region of South America, whereas the finest domains (d03 and d02 for the case studies in 2012 and 2014, respectively) cover the MASP and surrounding urban areas.

As mentioned earlier, the BASE simulation for both study periods was performed to evaluate the model performance, and included emission modules and aerosol effects set up for each case. The NAE simulation was performed to evaluate the formation potential of secondary aerosols from the primary emission of gases from on-road vehicles, whereas the NFB simulation was performed to evaluate the impact of aerosols on ozone photochemistry. NAE and NFB were both coupled with primary gas emission modules, however only NFB was coupled with aerosol emission modules. The aerosol-radiation feedback module was turned on and off for NAE and NFB, respectively.

The BBE and 3BBE simulations were performed to quantify the biomass burning contribution to fine particles concentration, employing different scaling factors ( 1 and 3 for BBE and 3BBE, respectively) for FINN particulate and ozone precursor emissions. The enhancement factor of 3 was applied to produce reasonable AOD within the model, and is 
based on previous studies conducted over South America that suggested scaling factors of 1.3 to 5 Archer-Nicholls et al., 2015, Pereira et al., 2016). The use of the scaling factor of 3 together with the FINN baseline emissions (scaling factor of 1 ) provides a possible range of fire impacts estimates, through considering the uncertainties in the FINN fire emissions over South America. The need for scaling factors highlights the uncertainties involved in calculating biomass burning emissions (Ichoku et al., 2012; Archer-Nicholls et al., 2015). All emissions are emitted from the surface with the exception of fire emissions which are added at the model levels previously settled on by the plume rise model.

Model performance was evaluated by comparing observations with model results from the baseline simulations. In addition, spatial distributions of absolute and relative differences between the baseline and sensitivity simulations were used in order to quantify and characterise the changes in aerosol and ozone concentrations due to changes in the emissions. In this case, the differences are averaged for specific times (for the period from 7 August to 6 September 2012) as well as over five-day periods (for the period from 17 August to 3 September 2014). Table 3.2 summarises the simulation design for nested simulations, together with the statistical evaluation periods. The model setup scheme for the simulations can be seen in Fig. 3.4 .

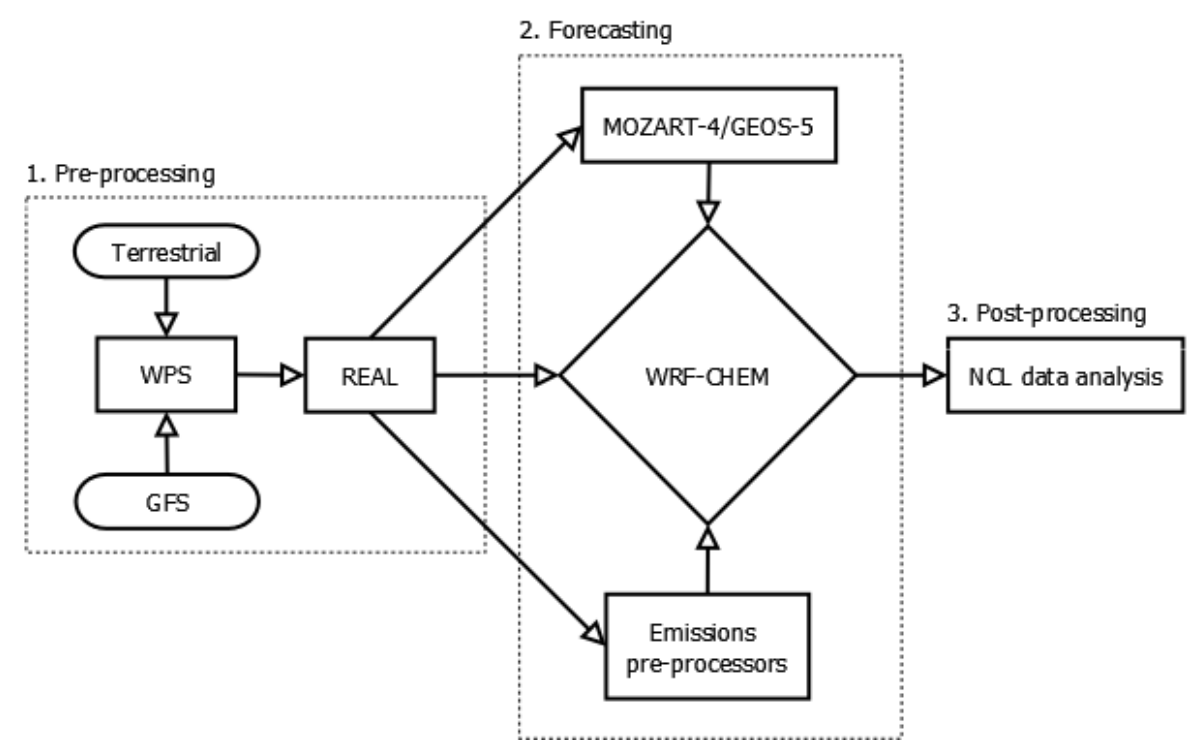

Figure 3.4: WRF-Chem simulations flowchart. The WRF-Chem model consists of the Preprocessing, an initialization routine for real datasets, and of the Forecasting; i.e. the meteorological model with chemistry extension. For manipulating model outputs, some NCAR Command Language (NCL) routines have been developed for this study. 


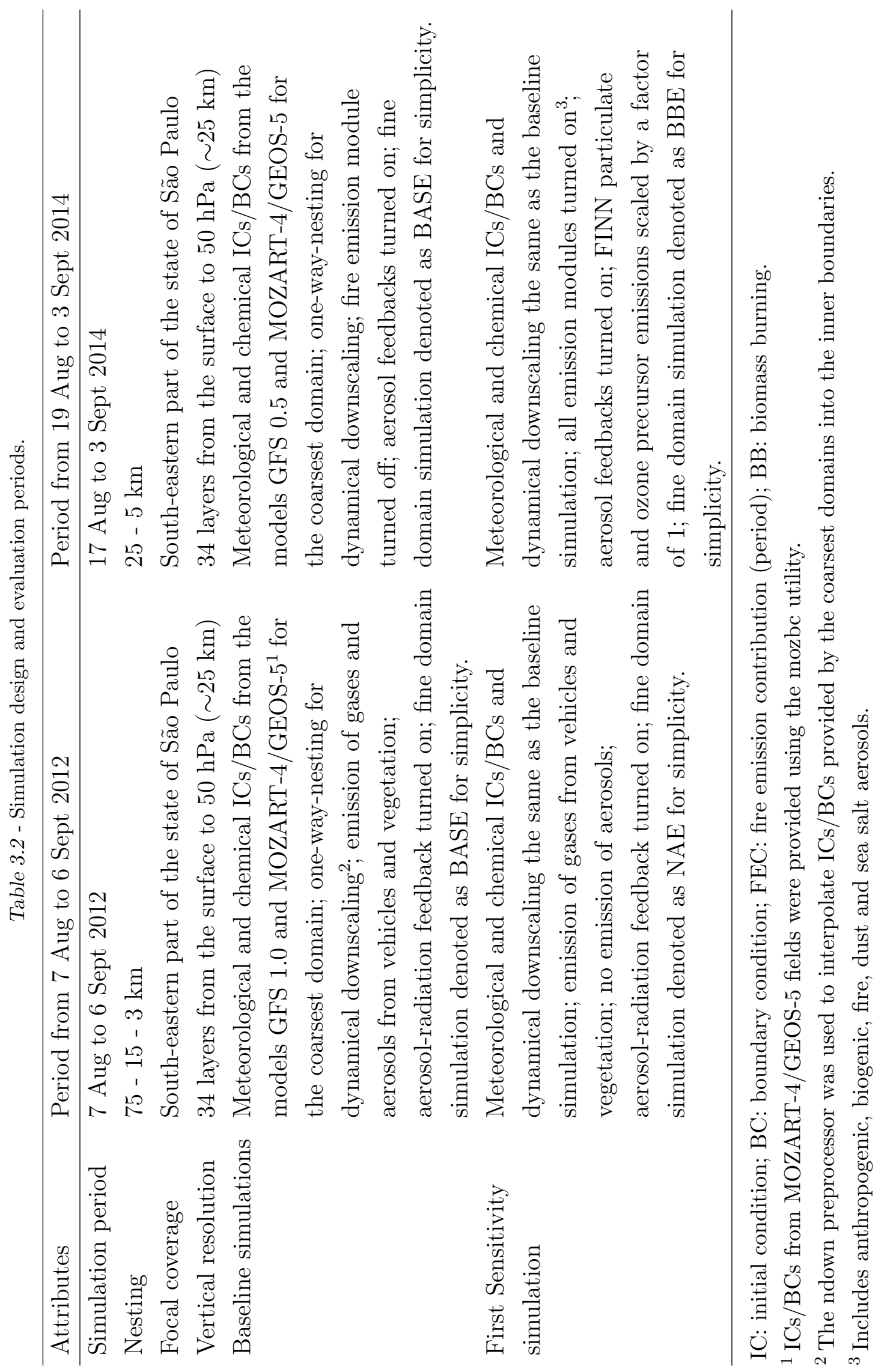




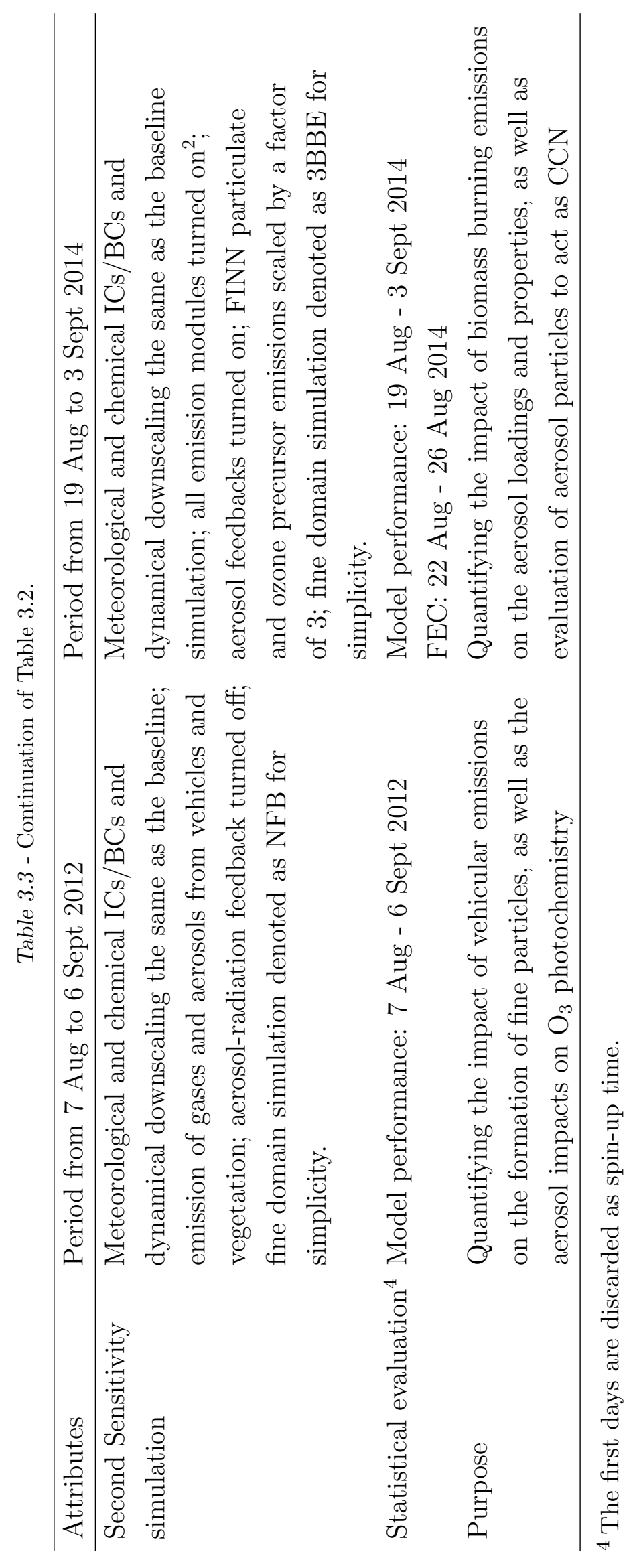




\subsection{Emissions}

\subsubsection{Anthropogenic emissions}

Anthropogenic emissions included seven sectors of human activities: power, industry, residential, agriculture, ground transport, aviation and shipping. For the parent domains, the emissions were taken from the Hemispheric Transport of Air Pollution version 2.2 (HTAPv2.2) emission inventory (Janssens-Maenhout et al., 2015). The HTAPv2.2 is a compilation of different regional gridded inventories, as well as available sources based on nationally reported emission data sets for the 2000-2010 period. The HTAPv2.2 emissions for South America are based on the Emissions Database for Global Atmospheric Research version 4.3 and are provided as monthly grid maps spatially distributed on a common grid with a resolution of $0.1^{\circ} \times 0.1^{\circ}$ (latitude $\mathrm{x}$ longitude). For the nested domains, a mixture of top-down and bottom-up emissions inventories was used, following the approach proposed by Hoshyaripour et al. (2016).
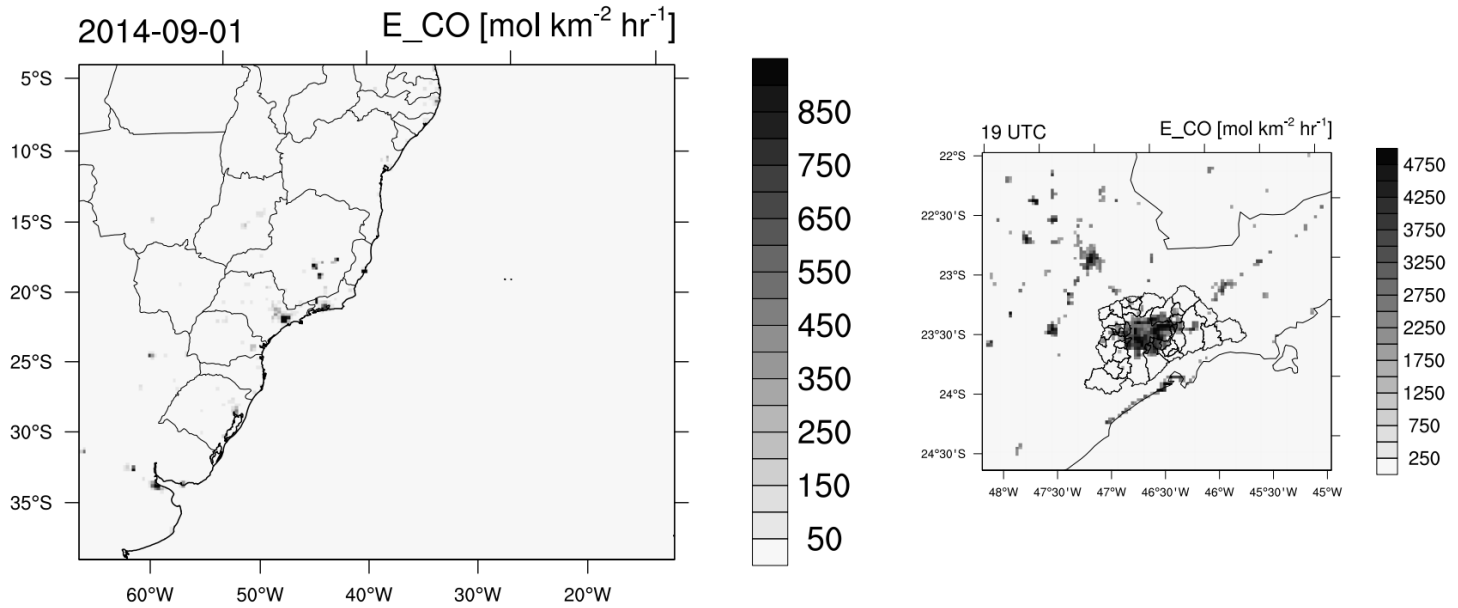

Figure 3.5: Spatial distribution of CO emission rates in the $25 \mathrm{~km}$ (left) and $3 \mathrm{~km}$ (right) modelling domains. Emissions in the coarse domain are based on the HTAPv2.2 estimates, whereas emissions in the fine domain are calculated following the approach of Andrade et al. (2015).

Anthropogenic emissions from sectors other than ground transport (such as industrial and residential) were calculated from top-down emissions taken from the HTAPv2.2, whereas the emissions from ground transport (specifically on-road vehicles) were derived from the bottom-up transport emission model described by Andrade et al. (2015). That 
model combines information on emission factors for different vehicle types (motorcycles, light-duty vehicles and heavy-duty vehicles) and different fuel types (gasohol, ethanol, ethanol-blended gasohol and diesel) with information on road maps and vehicle counts from tunnel experiments performed in the MASP (Andrade et al., 2015). To scale the topdown and bottom-up emissions into the parent and nested modelling domains, we used the mass-conserving emissions pre-processors anthro_emisł $\rfloor^{3}$ (Barth et al., 2015) and Another Assimilation System for WRF-Chem (AAS4WRF) (Vara-Vela et al., 2016, 2017), respectively. The spatial distributions of $\mathrm{CO}$ emission rates in the $25 \mathrm{~km}$ and $3 \mathrm{~km}$ modelling domains are shown in Fig. 3.5 .

\subsubsection{Fire emissions}

Fire emissions were taken from the Fire INventory of the US National Center for Atmospheric Research (NCAR), hereafter referred to as the FINN, as described by Wiedinmyer et al. (2011). The FINN provides daily emissions from open biomass burning, including wildfires, agricultural fires, and prescribed burning, on a global basis and at a resolution of $1 \mathrm{~km}^{2}$. The plume rise algorithm for fire emissions, implemented in WRF-Chem by Grell et al. (2011), is based on the 1-D time-dependent cloud model developed by Freitas et al. (2007). This 1-D model is embedded in each grid column of the WRF-Chem grid cells that contain fire spots. The lower and upper limits of the injection height are calculated based on the fire category (biome burned) provided by the fire emission model, as well as on the heat flux fields inferred from WRF-Chem. Both limits are then returned to WRFChem and taken into account to split the total fire emissions into flaming and smouldering phases, the flaming fraction being emitted between the elevated injection heights, whereas the smouldering fraction is incorporated into the lowest model level (Freitas et al., 2007; Archer-Nicholls et al., 2015). The spatial distribution of the total burned area in the 25 $\mathrm{km}$ modelling domain during the period from 22 August to 26 August 2014 is shown in Fig. 3.6. The fire_emis 5 preprocessor was used to create the fire emissions files as required by WRF-Chem.

\footnotetext{
${ }^{3}$ Available at https://www.acom.ucar.edu/wrf-chem/download.shtml

${ }^{4}$ Available at https://github.com/alvv1986/AAS4WRF

${ }^{5}$ Available at http://bai.acom.ucar.edu/Data/fire/
} 
(a) Tropical forest

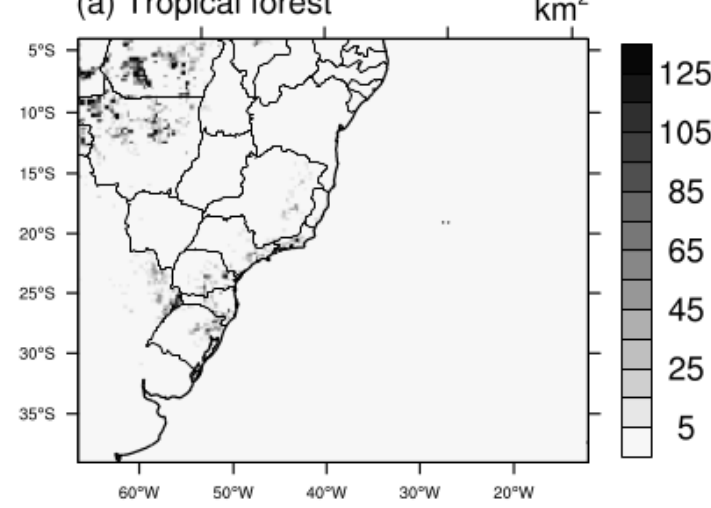

(c) savanna

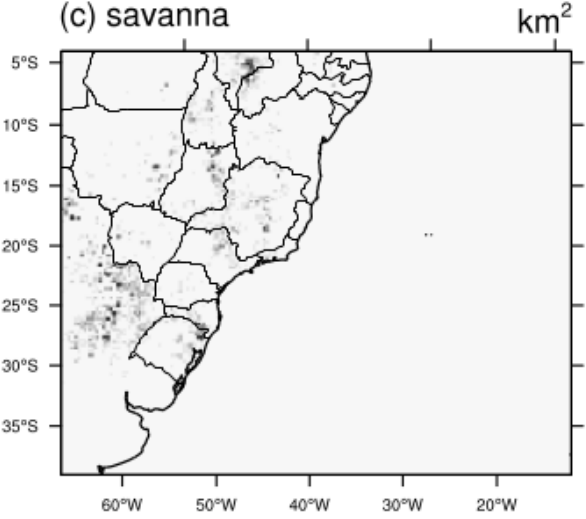

(b) Extra tropical forest

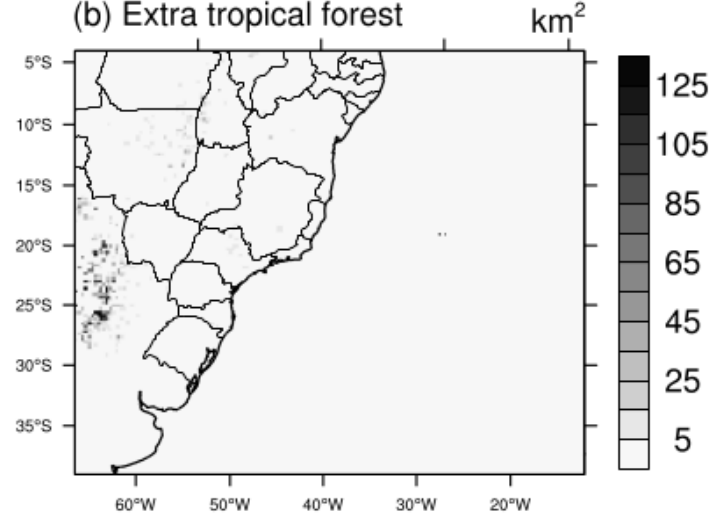

(d) grassland

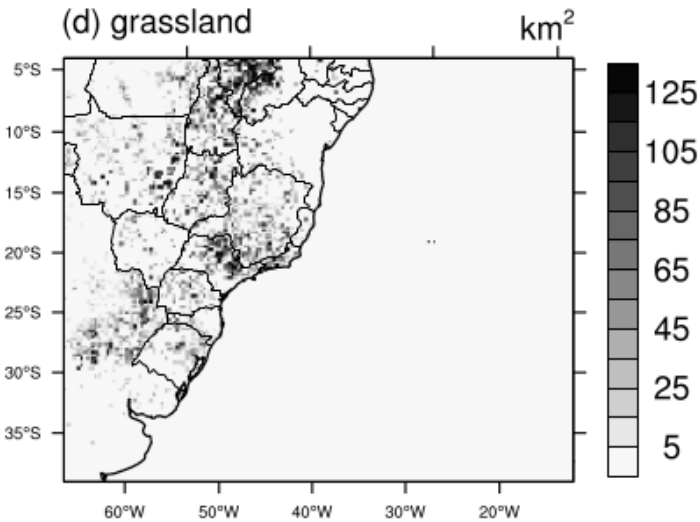

Figure 3.6: Spatial distribution of the total burned area in the $25 \mathrm{~km}$ modelling domain during the period from 22 August to 26 August 2014. The panels show the distribution of the total burned area for each FINN biome.

\subsubsection{Biogenic emissions}

Biogenic emissions were calculated on-line using the Guenther scheme (Guenther et al., 1993, 1994) and the Model of Emissions of Gases and Aerosols from Nature version 2 (MEGAN2) (Guenther et al., 2006). Based on driving variables such as the ambient temperature, solar radiation, Leaf Area Index (LAI), and plant functional type (PFT), MEGAN2 estimates net terrestrial biosphere emission rates for different trace gases and aerosols with a global coverage of $1 \mathrm{~km}^{2}$ spatial resolution. Four canopy types are considered in MEGAN2 for the calculation of emission factors, except for isoprene emissions where a separate map of emission factors is used (see Fig. 3.7). The bio_emis: ${ }^{6}$ preprocessor was used to prepare the MEGAN2 input for WRF-Chem.

\footnotetext{
${ }^{6}$ Available at https://www.acom.ucar.edu/wrf-chem/download.shtml
} 

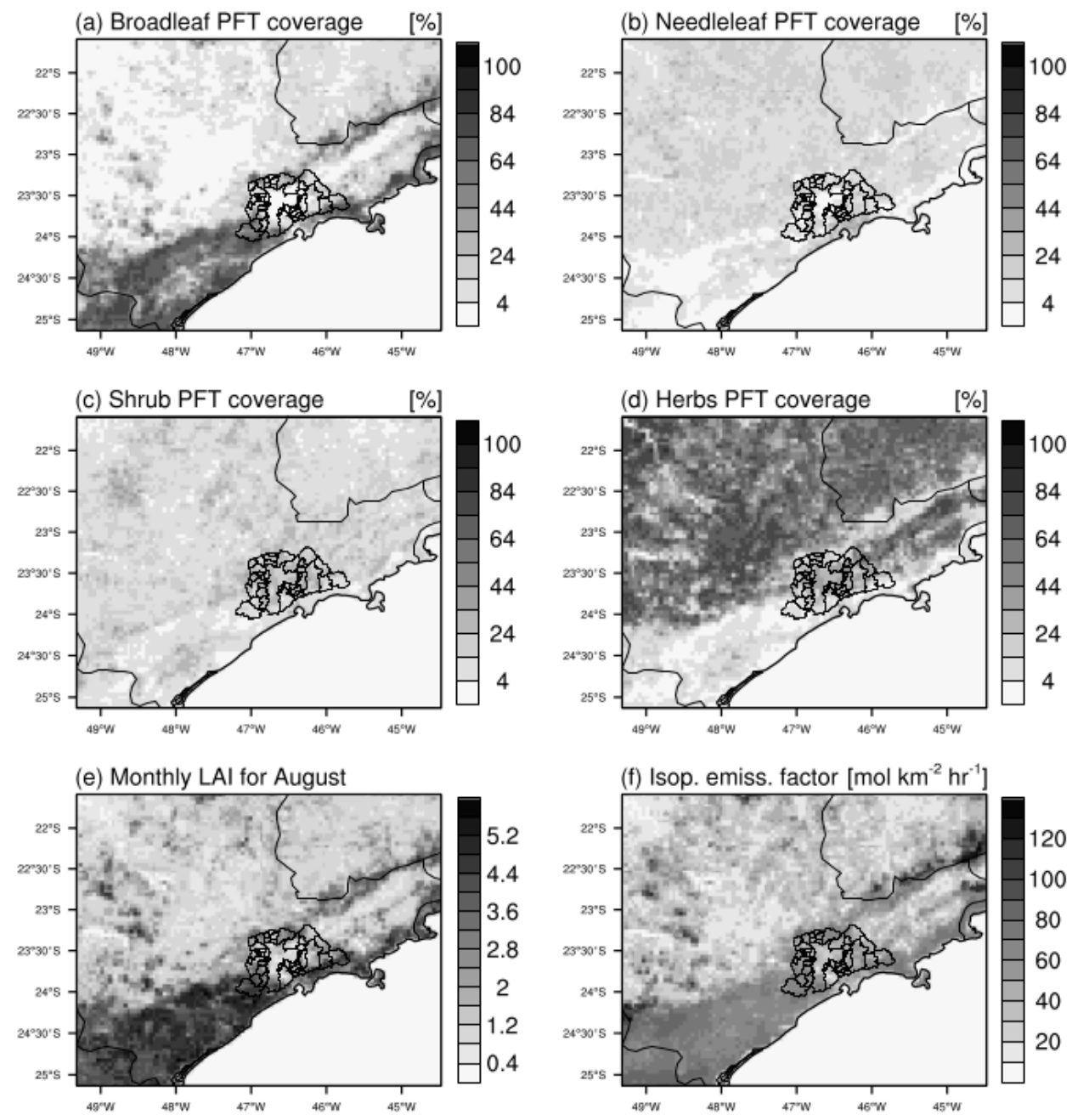

Figure 3.7: Spatial distributions of MEGAN2 canopy types (panels a, b, c and d), LAI (e) and isoprene emission factor (f) in the $5 \mathrm{~km}$ modelling domain.

\subsubsection{Dust and sea salt emissions}

Dust emissions are calculated on-line following the works of Ginoux et al. (2001) and Jones and Creighton (2011). The calculation of Ginoux et al. (2001) for the uplifting of dust particles is based on information on the surface wind speed, wetness, and information on soil characteristics. The parameterization of sea salt aerosol source function of Gong (2003) is an extended parameterization of Monahan et al. (1986), which scales the generation of marine aerosols from mechanical disruption of wave crests by the wind and sea surface covered by whitecaps. 


\subsection{Measurements}

\subsubsection{The NUANCE-SPS project}

The aerosol measurements used in this thesis were mostly taken from the FAPESP thematic project entitled "Narrowing the uncertainties on aerosol and climate changes in São Paulo State: NUANCE-SPS", through two field campaigns carried out over the MASP between 2011 and 2015. The NUANCE-SPS campaigns, orchestrated by the Institute of Astronomy, Geophysics and Atmospheric Sciences of the University of São Paulo (IAGUSP), aimed to improve the current knowledge of the chemistry and transport processes of the pollutants emitted in the MASP and in other areas of the state of São Paulo. All the samplings were obtained at $15 \mathrm{~m}$ above ground level, on the top of the main IAG-USP building $\left(23.559^{\circ} \mathrm{S}, 46.733^{\circ} \mathrm{W}\right.$; hereafter referred to as the IAGU site), which is inside a small green-park (approximately $7.4 \mathrm{~km}^{2}$ ), with local traffic during the day and surrounded by major roads with intense traffic by light and heavy-duty vehicles (Nogueira et al., 2014). This point is located approximately $45 \mathrm{~km}$ from the Atlantic Ocean.

During the NUANCE-SPS campaigns, aerosol samplings were carried out during winter (dry season), from 7 August to 6 September 2012 and from 19 August to 3 September 2014. A Dichotomous sampler, as described by Wedding et al. (1980), was used in order to collect $\mathrm{PM}_{2.5}$ and $\mathrm{PM}_{10}$ concentrations. In addition, a Micro-Orifice Uniform Deposit Impactor (MOUDI), as described by Marple et al. (1986), was used in order to collect particle mass concentrations, and a differential mobility particle sizer (DMPS), as described by Winklmayr et al. (1991), was used in order to collect particle number concentrations. The rotating MOUDI collected particles in 10 different stages with nominal $50 \%$ cut-off diameters: $10,5.6,3.2,1.8,1.0,0.56,0.32,0.18,0.1$ and $0.06 \mu \mathrm{m}$. Particles smaller than $0.06 \mu \mathrm{m}$ were collected in a subsequent stage designated the after-filter. The DMPS collected particles in 22 size bins, with diameters in the range of 9-450 nm. Samples were collected every $12 \mathrm{~h}$ with the MOUDI and every $5 \mathrm{~min}$ with the DMPS. The samples collected with the MOUDI impactor were deposited on a polycarbonate membrane filter with $0.4 \mu \mathrm{m}$ porous and for the Dichotomous sampler the substrate was a teflon membrane filter with $2 \mu \mathrm{m}$ porous. The after-filter in the MOUDI impactor is a $33 \mathrm{~mm}$ teflon membrane filter, which was not submitted to the reflectance analysis. The collected membrane filters sampled with the Dichotomous and MOUDI samplers were analysed for the identification 
of trace elements through X-ray diffraction analysis, mass concentration through gravimetric analysis, and black and organic carbon through reflectance and thermo analysis using a thermal-optical transmittance (TOT) (Birch and Cary, 1996). Ion concentrations were evaluated through the ion chromatography analysis of the soluble material collected on the membrane filters (sulphate, nitrate, ammonium, sodium, and chloride).

CCN were counted with a single-column continuous-flow streamwise thermal gradient chamber (Roberts and Nenes, 2005; Lance et al., 2006). The total polydisperse CCN number concentration is measured as a function of time and supersaturation. One measurement cycle included CCN measurements at supersaturation values of $0.2,0.4,0.6,0.8$ and $1.0 \%$, each being measured for 5 min (Almeida et al., 2014). Given that DMPS and CCN data were derived from different counter instruments, correction factors were previously applied in order to determine the PNC spectrum in the 450-1000 nm range, as well as to constrain the activated ratio $(\mathrm{AR})$ to a value $\leq 1$. Further details on DMPS data calibration and correction factors can be found in Souto-Oliveira et al. (2016).

Table 3.4 - Description of the NUANCE-SPS aerosol sampling campaign performed at the IAGU site and other data sets included in the model evaluation.

\begin{tabular}{lllll}
\hline Database & Parameter & frequency & Period & Device \\
\hline NUANCE-SPS & Particle mass conc. & $12 \mathrm{~h}$ & both & Rotating MOUDI \\
& Particle number conc. & $5 \mathrm{~min}$ & 2014 & DMPS aerosol spectra \\
& CCN conc. & $1 \mathrm{sec}$ & 2014 & CCN chamber \\
& PM $_{2.5}$ and $\mathrm{PM}_{10}$ conc. & $12 \mathrm{~h}$ & 2012 & Dichotomous sampler \\
& EC and OC conc. $^{2}$ & $12 \mathrm{~h}$ & both & Sunset OC-EC analyser \\
& Aerosol extinction coeff. & Daily & 2014 & Elastic/Raman Lidar $^{2}$ \\
& & & & system $^{3}$ \\
CETESB & PM $_{2.5}, \mathrm{PM}_{10}, \mathrm{O}_{3}, \mathrm{~T}$, & Hourly & both & Various \\
& RH, WS and WD & & & \\
GPCP $^{4}$ & Precipitation & Daily & 2014 & \\
MERGE $^{4}$ & Precipitation & Daily & 2014 & \\
MODIS $^{4}$ & AOD & Daily & 2014 & \\
\hline
\end{tabular}

${ }^{1}$ Includes aerosol mass size distribution for $\mathrm{EC}, \mathrm{SO}_{4}, \mathrm{NO}_{3}, \mathrm{NH}_{4}, \mathrm{Na}$ and $\mathrm{Cl}$.

${ }^{2} \mathrm{PM}$ collected on a MiniVol sampler.

${ }^{3}$ The system was set up at the USP Institute for Energy Research and Nuclear Science, which is approximately $900 \mathrm{~m}$ from the IAGU site.

${ }^{4}$ Datasets used for the evaluation of the $25 \mathrm{~km}$ baseline simulation. 
Vertical profiles of aerosol extinction were retrieved using a lidar system supplying vertical distributions of aerosol backscatter and extinction coefficients, obtained from elastic backscatter and Raman channels at 532 and $607 \mathrm{~nm}$, respectively. Table 3.4 lists the aerosol instrumentation deployed at the IAGU measurement site. In addition, ambient data from the CETESB's air quality monitoring network and the IAG-USP's meteorological station (hereafter also referred as AF-IAG) were also considered for numerical simulations evaluation. The locations of measurement sites are depicted in Fig. 3.8 whereas geographic coordinates and a list of pollutants and meteorological parameters monitored at each site is available in Table 3.5 .

Table 3.5 - Description of measurement sites.

\begin{tabular}{lllll}
\hline Site $^{1}$ & Initials & Latitude & Longitude & Species measured \\
\hline Agua Funda $^{2}$ & AGFU & -23.6500 & -46.6167 & $\mathrm{~T}, \mathrm{RH}, \mathrm{WS}, \mathrm{WD}, \mathrm{Precip}^{3}$ \\
Cerqueira Cesar & CERQ & -23.5531 & -46.6723 & $\mathrm{PM}_{10}, \mathrm{NO}_{2}$ \\
Congonhas & CONG & -23.6159 & -46.6630 & $\mathrm{PM}_{10}, \mathrm{PM}_{2.5}$ \\
IAG-USP & IAGU & -23.5590 & -46.7330 & $\mathrm{PM}_{10}, \mathrm{PM}_{2.5}$, and aerosol \\
& & & & properties from the NUANCE-SPS \\
Ibirapuera & IBIR & -23.5914 & -46.6602 & $\mathrm{O}_{3}, \mathrm{PM}_{2.5}, \mathrm{NO}_{2}$ \\
Interlagos & INTE & -23.6805 & -46.6750 & $\mathrm{O}_{3}, \mathrm{PM}_{10}, \mathrm{~T}_{1} \mathrm{RH}, \mathrm{WS}, \mathrm{WD}, \mathrm{NO}_{2}$ \\
IPEN-USP & IPEN & -23.5662 & -46.7374 & $\mathrm{O}_{3}, \mathrm{PM}_{2.5}, \mathrm{NO}_{2}$ \\
Mooca & MOOC & -23.5497 & -46.5984 & $\mathrm{O}_{3}, \mathrm{PM}_{10}$ \\
Nossa S. do O & NSDO & -23.4796 & -46.6916 & $\mathrm{O}_{3}, \mathrm{PM}_{10}$ \\
Parque D. Pedro & PQDP & -23.5448 & -46.6276 & $\mathrm{O}_{3}, \mathrm{PM}_{10}$ \\
Pinheiros & PINH & -23.5610 & -46.7016 & $\mathrm{O}_{3}, \mathrm{PM}_{2.5}, \mathrm{PM}_{10}$ \\
Parelheiros & PARE & -23.7762 & -46.6970 & $\mathrm{PM}_{2.5}, \mathrm{PM}_{10}$ \\
Santana & STAA & -23.5055 & -46.6285 & $\mathrm{PM}_{10}$ \\
Santo Amaro & STOA & -23.6545 & -46.7095 & $\mathrm{PM}_{10}$ \\
\hline
\end{tabular}

${ }^{1}$ With the exception of AGFU and IAGU, all the rest of sites are part of the CETESB network. ${ }^{2}$ IAG-USP-affiliated meteorological station.

${ }^{3}$ T, RH, WS, WD, and Precip denote temperature, relative humidity, wind speed, wind direction, and precipitation, respectively.

${ }^{4}$ Aerosol properties collected during the campaigns are listed in Table 3.4 .

\subsubsection{Other data sets}

Concentrations of $\mathrm{PM}_{2.5}, \mathrm{PM}_{10}$ and $\mathrm{O}_{3}$, as well as meteorological data, were obtained from the São Paulo Environmental Protection Agency monitoring network and the IAG- 
USP meteorological station. In addition to in situ and lidar measurements, information on precipitation and AOD derived from satellite data were also considered in the numerical simulations evaluation (see Table 3.4).

\subsection{Statistical parameters}

In the comparison between model results and observations, we used the statistical indices recommended for PM analyses (Boylan and Russell, 2006; Zhang et al., 2006; EPA |. 2007) including mean fractional bias (MFB), mean fractional error (MFE), normalised mean bias (NMB) and normalised mean error (NME), as well as other indices that can provide meaningful information such as mean bias (MB) and correlation coefficient (R), as defined in Appendix Table A.1. In some cases, data were compared against the Global Precipitation Climatology Project (GPCP) database and against the MERGE technique (Rozante et al., 2010). For ease of model-satellite data comparison, satellite and model data were both initially re-gridded onto a common grid with a resolution of $0.25^{\circ} \times 0.25^{\circ}$ (latitude $\times$ longitude) and then averaged in time and space over the grid.

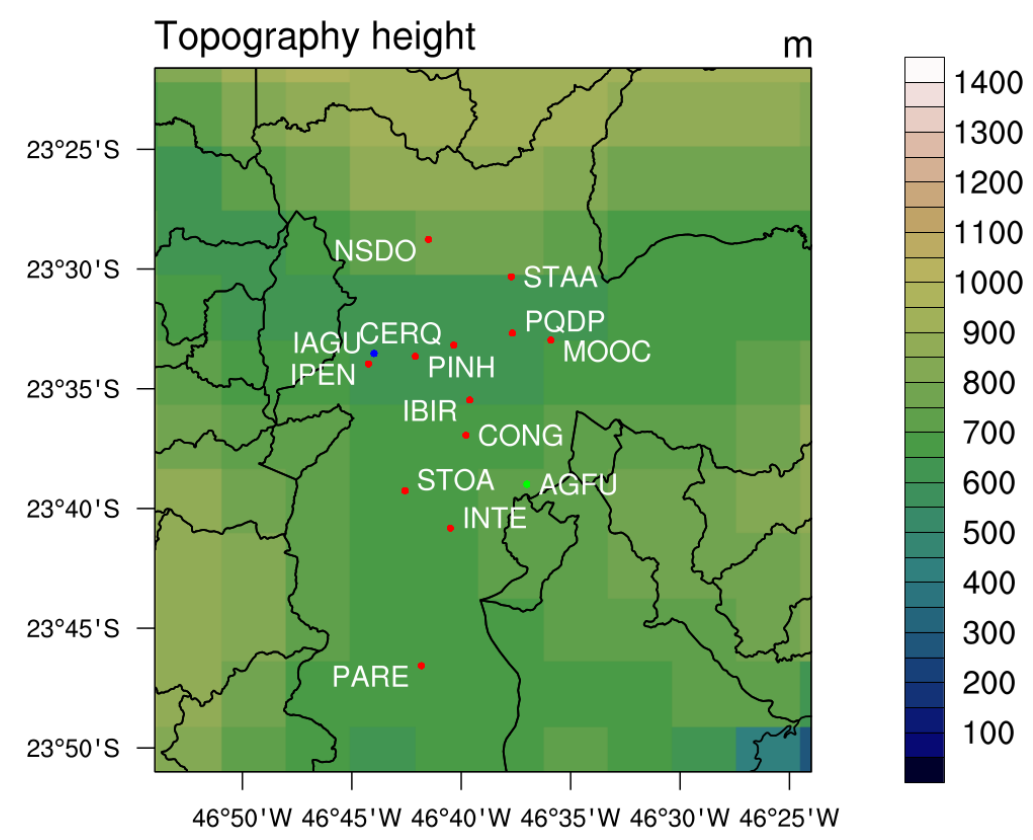

Figure 3.8: Zoom-in map for the $5 \mathrm{~km}$ modelling domain showing WRF topography height and the location of all measurement sites within the MASP. Red dots represent CETESB sites, whereas the blue and green dots represent, respectively, the locations of the NUANCE-SPS sampling campaigns and IAG-USP's meteorological station (AGFU). 
Chapter 4

\section{Results}

This chapter presents the performance results of model simulations, in addition to evaluation of the contribution of different emission sources to the $\mathrm{PM}_{2.5}$ loadings in the MASP. In Section 4.1, the model performance will be evaluated by comparing observations with the baseline model simulations. Next, in Section 4.2, the impact of different emission sources on aerosol loadings will be evaluated by comparing model results from the baseline model simulations with those from the sensitivity model simulations. The impact of aerosol particles on ozone photochemistry will be discussed in Section 4.3.

\subsection{Model evaluation}

\subsubsection{Meteorology}

Period from 7 August to 6 September 2012

Table 4.1 summarizes the performance statistics for meteorological parameters over the MASP, considering the baseline simulation for the $3 \mathrm{~km}$ modelling domain. In general, the WRF-Chem simulation captures reasonably well the daily variations of most of the evaluated parameters throughout the study period (see Fig. 4.1). For temperature and wind speed and direction, the MB and MFB are positive, thereby an overestimation occurs most of the time. Conversely, these same performance statistics, i.e. MB and MFB, are negative for relative humidity, which is coherent since temperature and relative humidity are negatively correlated. In both cases, the smaller MB and MFB indicate bias compensation between under predictions of maximum values and over predictions of minimum values, mostly observed in the second half of the study period when a semi-stationary frontal system was acting close to MASP. In the case of winds, the WRF-Chem model performs 
better on wind direction compared to wind speed for which less accurate values of $\mathrm{R}$, $\mathrm{MFB}$ and MFE are found. Based on the performance statistics and comparing the two sites individually by meteorological parameters, the results for temperature show a better model performance at AGFU for most of the statistics; for relative humidity, AGFU has higher MB and MFB, but slightly better MFE, $\mathrm{RMSE}_{U B}$ and R; for wind speed, the model performance is also better at AGFU for most of the statistics, except $\mathrm{RMSE}_{U B}$ and R; and finally, for wind direction, the results show that the model performs better at INTE in terms of MB, MFB and MFE (see Table 4.1 for performance statistics). Large differences in MB and MFB for both wind speed and wind direction is clearly due to overestimations of wind speed at INTE and of wind direction at AGFU, respectively, as they are poorly reproduced by the model (in full sight from Fig. 4.1). Since the sites INTE and AGFU, classified as urban and suburban categories respectively, have different features in terms of land cover, roughness, emissions, etc., then the accuracy of the WRF-Chem model in representing local meteorology depends largely on how well these fields are represented within the model.

According to the monthly climate reports from the IAG-USP's Climate Research Group (GrEC), the observed precipitation rates were lower than the climatological value in MASP (anomaly of -38.6 mm) and over most of the São Paulo State during August 2012. Negative precipitation anomalies were caused by the intensification of the South Atlantic Subtropical High (SASH). These conditions established an easterly wind anomaly pattern at the 850 $\mathrm{hPa}$ level. Conditions were unfavorable for relative humidity coming from the Amazon due to the Low Level Jet (LLJ) and less intense Trade winds in the Tropical Atlantic (GrEC, 2012b). However, the action of frontal systems favored the rain accumulation in September 2012, mainly in western São Paulo State where greater amounts were observed. Precipitation events were predominantly observed during the second half of the month. In this case, the wind pattern showed an opposite configuration than the observed in August 2012 as a result of the weakening of the SASH (GrEC, 2012a). The IAG-USP's meteorological station recorded an accumulated precipitation of about $1.3 \mathrm{~mm}$ on three days of occurrence (28 August, 30 August and 4 September 2012) and an easterly wind pattern with a median intensity of $2 \mathrm{~m} \mathrm{~s}^{-1}$ during the period between 7 August and 6 September 2012. Fig. 4.2 shows the hourly accumulated precipitation and relative humidity observed at the IAG-USP's meteorological station. 

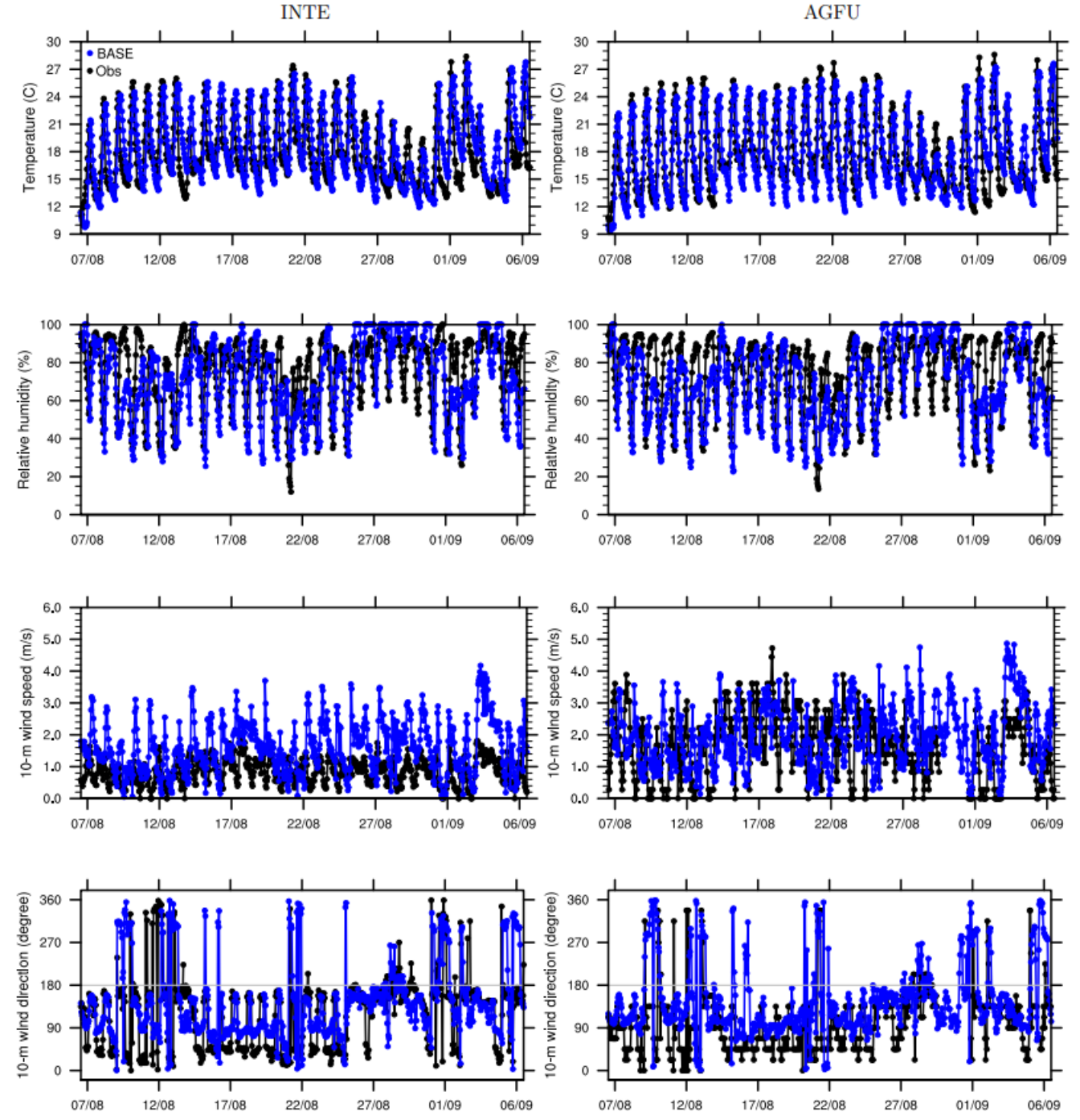

Figure 4.1: The observed and predicted (BASE) hourly variations of 2-m temperature, 2-m relative humidity, $10-\mathrm{m}$ wind speed and 10-m wind direction at two CETESB sites in the MASP during the period from 7 August to 6 September 2012.

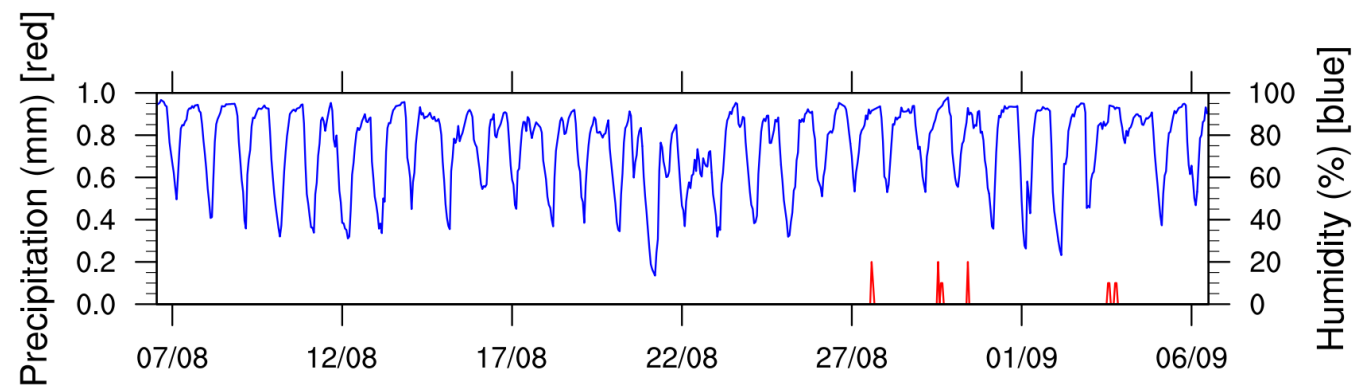

Figure 4.2: Hourly accumulated precipitation and relative humidity observed at the AGFU site during the period from 7 August to 6 September 2012. 
Table 4.1 - Performance statistics for WRF-Chem meteorological predictions for the period from 7 August to 6 September 2012 .

\begin{tabular}{lllllll}
\hline Variable & Site & $\mathrm{R}$ & $\mathrm{RMSE}_{U B}$ & $\mathrm{MB}$ & $\mathrm{MFB}$ & $\mathrm{MFE}$ \\
\hline $\mathrm{T} 2\left[{ }^{\circ} \mathrm{C}\right]$ & AGFU & 0.76 & 2.86 & 0.44 & 0.86 & 12.95 \\
& INT & 0.66 & 3.55 & 0.86 & 3.01 & 15.37 \\
$\mathrm{RH} 2[\%]$ & AGFU & 0.63 & 19.47 & -6.42 & -9.02 & 23.69 \\
& $\mathrm{INT}$ & 0.60 & 20.64 & -5.05 & -6.88 & 23.98 \\
$\mathrm{WS10}\left[\mathrm{m} \mathrm{s}^{-1}\right]$ & AGFU & 0.44 & 0.89 & 0.31 & 26.76 & 70.62 \\
& INT & 0.37 & 1.16 & 0.77 & 55.65 & 71.61 \\
\hline
\end{tabular}

$\mathrm{T} 2$ : temperature at $2 \mathrm{~m}$; RH2: relative humidity at $2 \mathrm{~m}$; WS10: wind speed at $10 \mathrm{~m}$; WD10: wind direction at $10 \mathrm{~m}$; MB: mean bias; MFB: mean fractional bias; MFE: mean fractional error; $\mathrm{RMSE}_{U B}$ : root mean square error UB; R: correlation coefficient.

Period from 19 August to 3 September 2014

To study the impact that the long-range transport of fire emissions may have on aerosol particles in the MASP, meteorological conditions, especially wind speed and wind direction, were analysed. Comparisons between the observed and predicted hourly variations for 2 $\mathrm{m}$ temperature, $2 \mathrm{~m}$ relative humidity, $10 \mathrm{~m}$ wind speed and $10 \mathrm{~m}$ wind direction (see Fig. 4.3 show that the model performs well in terms of trends. Nevertheless, it tends to underpredict temperature and relative humidity, the average MB over all sites being $0.01^{\circ} \mathrm{C}$ and $2 \%$ lower than the respective observed values, whereas it overpredicts wind speed, the average MB being $0.57 \mathrm{~m} \mathrm{~s}^{-1}$ higher than the observed value. Wind direction is predicted to be more easterly compared with the observed fields, south-easterly winds largely dominated by the influence of sea breezes. Individual calculations of performance statistics are presented in Table 4.2 .

Although winds were not generally favourable for air pollutants transport from fire areas, shifts in wind direction, foremost from south-easterly to north-westerly, over a five-day period (from 22 August to 26 August) favoured such transport and thereby the enhancement of aerosol loadings into the MASP. In another favourable event (from midday 31 August to midnight 1 September), wind speeds increased to $8 \mathrm{~m} \mathrm{~s}^{-1}$ and the number of fire events was proportionally higher in comparison with the total study period. However, there were multiple precipitation events related to the passage of a low-pressure system 
that spread rapidly over the MASP, contributing significantly to the removal of gases and particles. Except during those two periods, the winds were not favourable for transport from fire regions. There were precipitation events on some days within the second half of the study period (27 August to 3 September 2014).
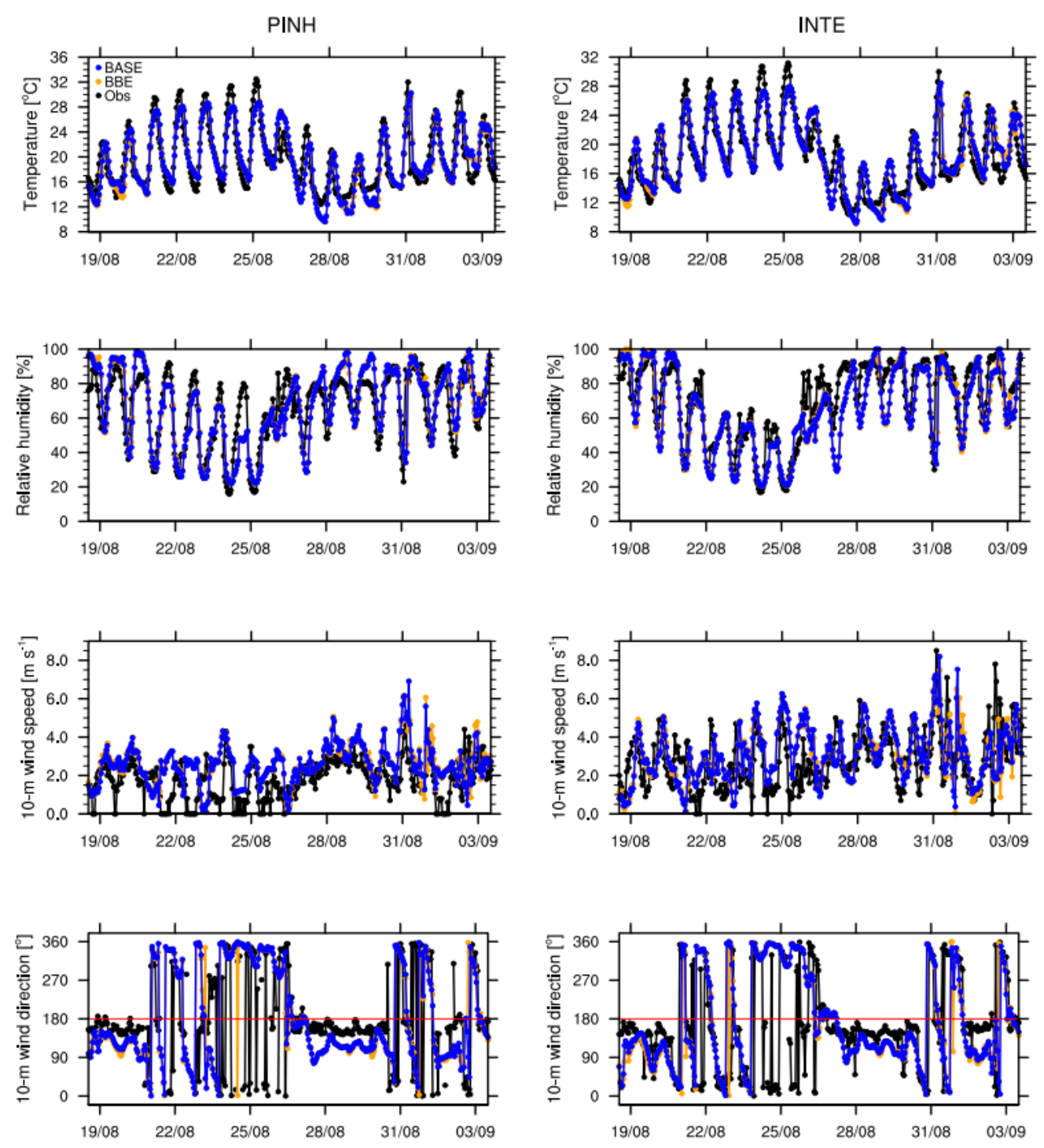

Figure 4.3: The observed and predicted (blue and orange dots for the BASE and BBE simulations, respectively) hourly variations of 2-m temperature, 2-m relative humidity, 10-m wind speed and 10-m wind direction at two CETESB sites in the MASP during the period from 19 August to 3 September 2014.

Precipitation predictions agreed well with ground- and satellite-based measurements. The model evaluation for the $25 \mathrm{~km}$ baseline simulation shows a good domain mean performance statistics with MBs and NMBs within $0.7 \mathrm{~mm}^{\text {day }}{ }^{-1}\left(0.4 \mathrm{~mm}\right.$ day $^{-1}$ against the 
MERGE data and $0.7 \mathrm{~mm}$ day $^{-1}$ against the GPCP database) and within $30 \%$ (17\% against the MERGE data and $30 \%$ against the GPCP database), respectively. The differences are attributable to different spatial coverage and combination of rainfall estimates, and may have led to bias compensation. Fig. 4.4 compares precipitation data obtained from the IAG-USP meteorological station with the amounts of rainfall on the corresponding grid-points for the $5 \mathrm{~km}$ modelling domain and for the MERGE data (see Table 4.2 for performance statistics).

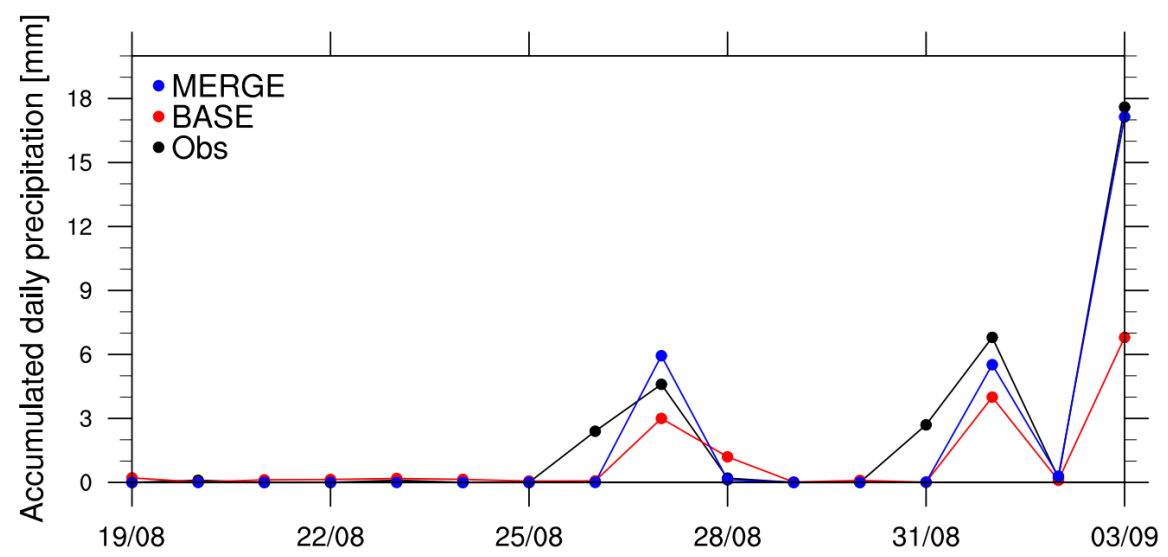

Figure 4.4: Accumulated daily rainfall measured at AGFU (black dots) compared with those estimated from the MERGE satellite data (blue dots) and BASE simulation (red dots).

Table 4.2 - Performance statistics for WRF-Chem meteorological predictions for the period from 19 August to 3 September 2014.

\begin{tabular}{lllllll}
\hline Variable & Site & $\mathrm{R}$ & $\mathrm{RMSE}$ & $\mathrm{MB}$ & $\mathrm{MFB}$ & $\mathrm{MFE}$ \\
\hline $\mathrm{T} 2\left[{ }^{\circ} \mathrm{C}\right]$ & PINH & 0.84 & 2.71 & -0.09 & -0.93 & 11.17 \\
& INTE & 0.85 & 2.58 & 0.07 & 0.34 & 11.06 \\
$\mathrm{RH} 2[\%]$ & PINH & 0.81 & 12.84 & 0.83 & 0.88 & 16.79 \\
& INTE & 0.83 & 13.78 & -4.79 & -7.77 & 16.26 \\
WS10 $\left[\mathrm{m} \mathrm{s}^{-1}\right]$ & PINH & 0.42 & 1.36 & 0.79 & 46.36 & 64.98 \\
& INTE & 0.40 & 1.59 & 0.34 & 13.40 & 49.74 \\
Precip $[\mathrm{mm}]$ & AGFU & 0.89 & 3.06 & -1.26 & 51.29 & 148.03 \\
\hline
\end{tabular}

Precip: accumulated daily precipitation; RMSE: root mean square error. 


\subsubsection{Chemical compounds concentrations}

Period from 7 August to 6 September 2012

Table 4.3 presents the performance statistics for gaseous and particulate chemical species over the MASP, taking also into consideration the baseline simulation for the 3 $\mathrm{km}$ modelling domain. Figs. 4.5, 4.6, and 4.7 show the observed and predicted temporal variations of $\mathrm{PM}_{10}, \mathrm{PM}_{2.5}$ and $\mathrm{O}_{3}$ concentrations at 10, 3 and 6 sites in the MASP, respectively, with some measurement sites sharing the same grid point for comparisons due to the geographical proximity (e.g. the sites IAGU and IPEN both separated by about $900 \mathrm{~m}$ ). These figures suggest that predicted concentrations did not present any significant spatial variation in the downtown MASP and were generally underestimated when compared to measurements. This under prediction could be associated with an underestimation on the vehicular emissions as well as other emission sources such as emissions coming from industry that are disregarded in this study. In addition, predicted surface winds more intense than those observed led to a dilution of aerosol particles in the MASP. The high concentrations of $\mathrm{PM}_{2.5}$ and $\mathrm{PM}_{10}$ observed at the beginning and at the end of the study period, whose variability and trends were reasonably well captured by the model, could be related with the emission of high aerosol loadings due to traffic incidents as well as the establishment of lower PBL heights, commonly observed under post-frontal situations. The results for this simulation (BASE) show that, in general, the predicted PBL heights (not shown here) have a regular diurnal variation in the downtown MASP with averaged daily values around $500 \mathrm{~m}$ at both the beginning and the end, and of up to $700 \mathrm{~m}$ in the middle of the study period, when lower concentrations of aerosols were observed.

WRF-Chem performs best and worst at INTE and NSDO, both urban sites located in the southern and northern MASP, respectively. Compared to $\mathrm{PM}_{10}$ performance, the predictions for $\mathrm{PM}_{2.5}$ do not show an improved performance with relatively larger MFB and MFE, possibly due to the major complexity of the representation of secondary aerosols formation, which comprise an important fraction of the $\mathrm{PM}_{2.5}$. Predicted $\mathrm{PM}_{2.5}$ concentrations are identical in both IAGU and IPEN as these two sites are sharing the same model grid point; however, the model performs slightly better at IAGU. The worst performance statistics are found for CONG. It is important to indicate that the sites IPEN and IAGU are located in a small green-park (about $7.4 \mathrm{~km}^{2}$ ) inside the main campus of the 

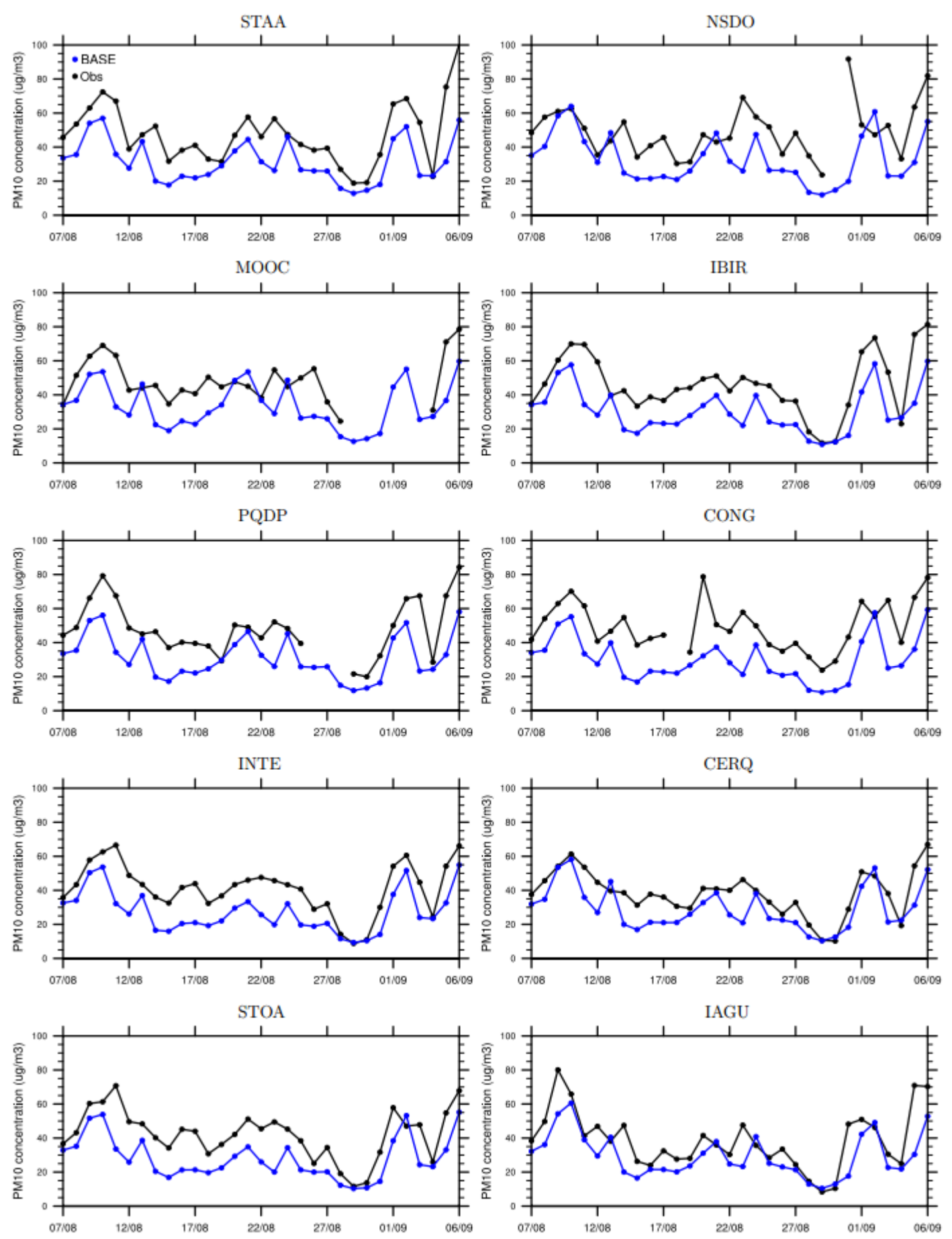

Figure 4.5: The observed and predicted daily variations of $\mathrm{PM}_{10}$ concentrations at ten sites in the MASP for the $3 \mathrm{~km}$ modelling domain.

University of São Paulo in the western MASP, whereas CONG is located in a fully urban area with scarce vegetation in the central region of the city. On the other hand, the model reproduces well the daily variations of $\mathrm{O}_{3}$ (with $\mathrm{R}$ ranging from 0.60 for NSDO to 0.66 for INTE), capturing its decrease during nighttime scavenging periods consistently. However, 

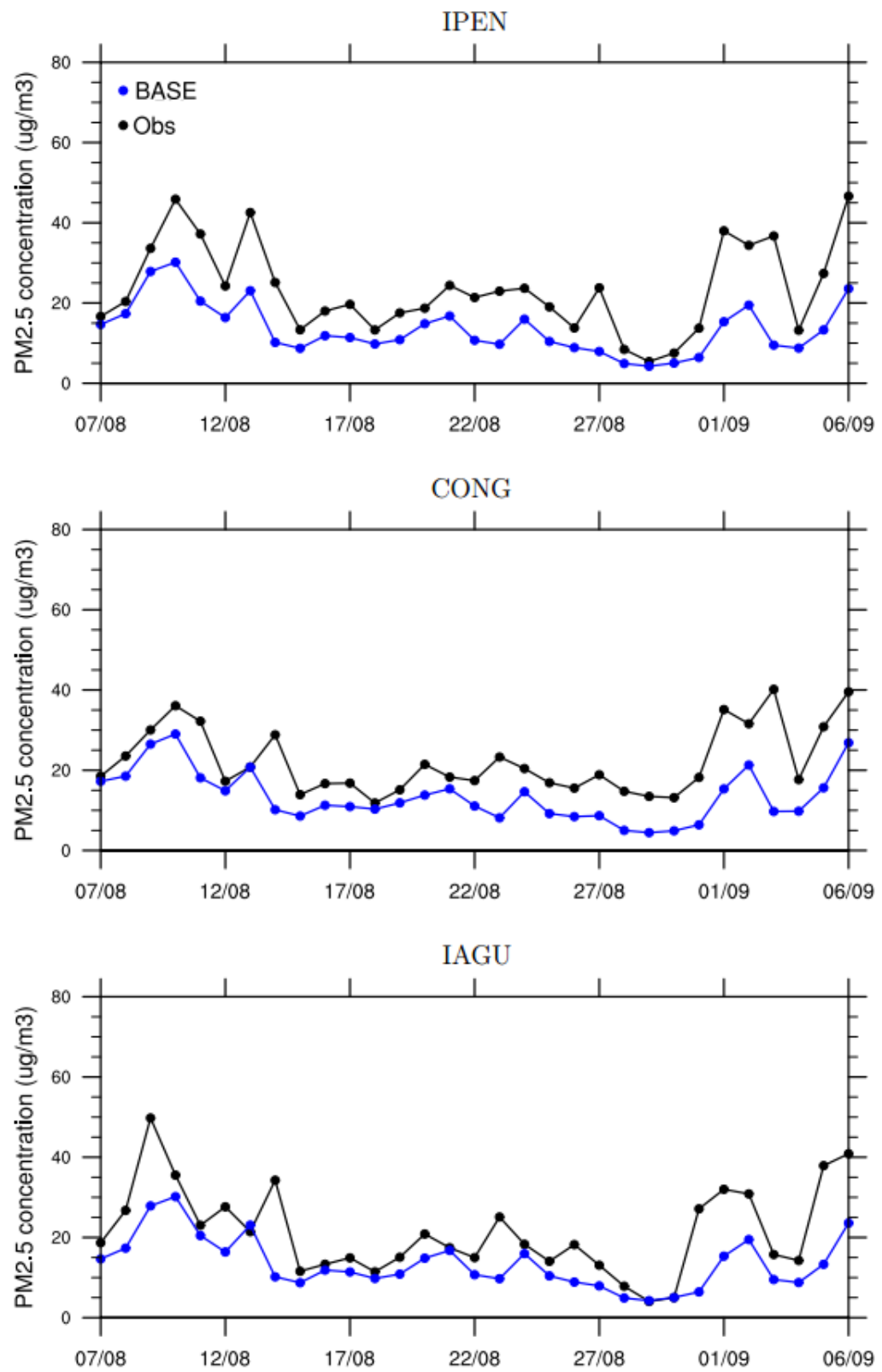

Figure 4.6: The observed and predicted daily variations of $\mathrm{PM}_{2.5}$ concentrations at three sites in the MASP for the $3 \mathrm{~km}$ modelling domain.

it is not able to represent adequately some high $\mathrm{O}_{3}$ episodes, clearly underestimating the maximum concentrations, mostly observed in the second half of the study period. MB is negative for most of the sites, ranging from -12.45 for IBIR to $10.48 \mu \mathrm{g} \mathrm{m}^{-3}$ for PQDP. Finally, the daily cycles of $\mathrm{CO}$ and NOx are also reasonably well represented, especially for $\mathrm{CO}$, with maximum concentrations corresponding to the rush hours; nonetheless, as found for the other species, the WRF-Chem underestimates the observed concentrations, which is directly related to an underestimation of vehicle emissions as they are, by far, the 

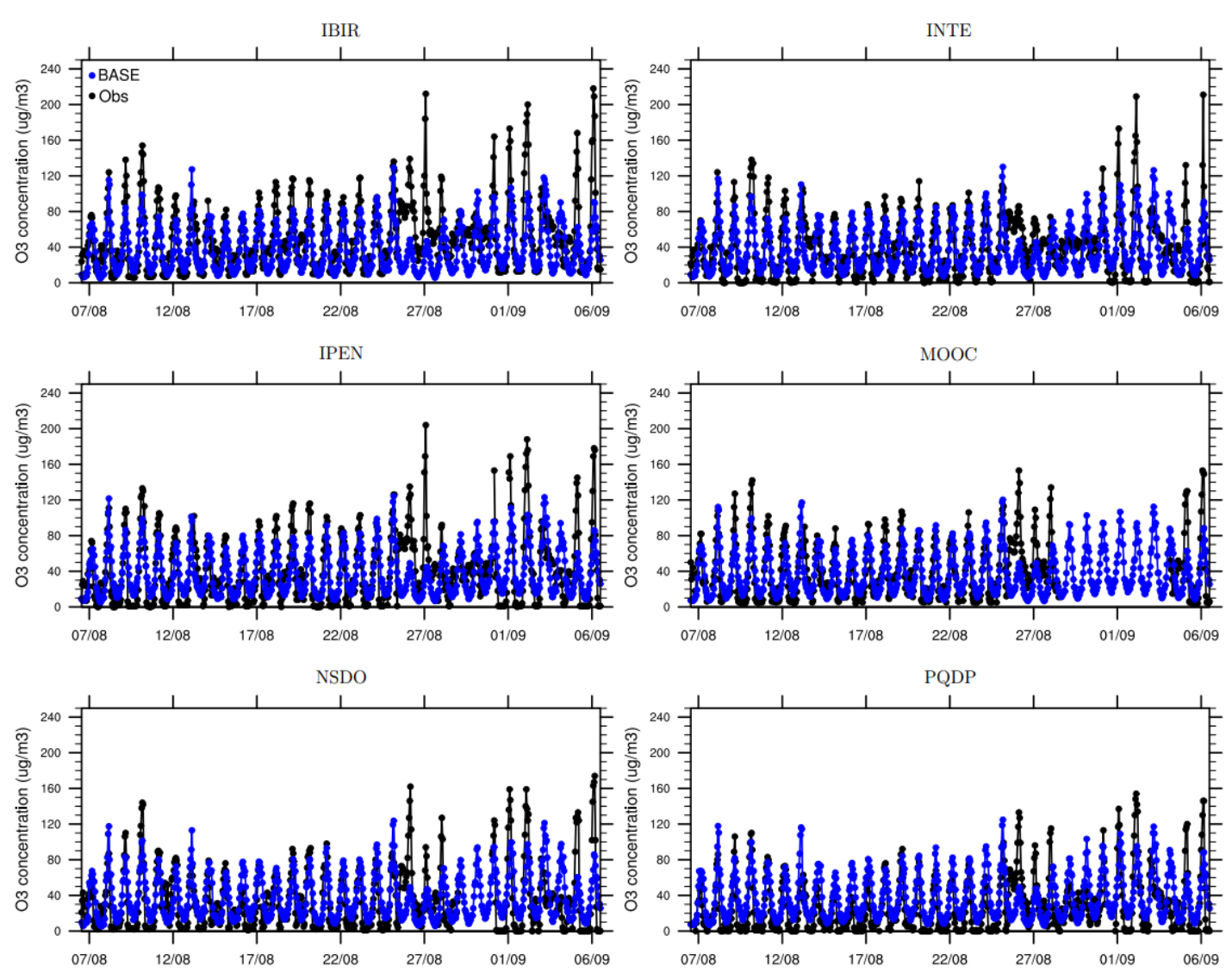

Figure 4.7: The observed and predicted hourly variations of $\mathrm{O}_{3}$ concentrations at six sites in the MASP for the $3 \mathrm{~km}$ modelling domain.

most important sources of anthropogenic emissions in the MASP.

In general, the model captures the temporal variations of all the evaluated PM aerosols, with $\mathrm{R}$ greater than 0.5 and $\mathrm{RMSE}_{U B}$ less than $12,8,3$, and $2 \mu \mathrm{g} \mathrm{m}{ }^{-3}$ for $\mathrm{PM}_{10}, \mathrm{PM}_{2.5}$, OC and EC, respectively, but underestimates the observed PM concentrations, with the $\mathrm{MB}$ and MFB both negative. The statistics used to quantify the model performance in the representation of PM concentration, show that, overall, most of prediction-observation pairs present good correlation coefficients, mainly those for $\mathrm{PM}_{10}$, but with negative biases and standard deviations lower than those for observations (see Fig. 4.9). The WRF-Chem performance for both $\mathrm{PM}_{10}$ and $\mathrm{PM}_{2.5}$ is satisfactory based on the PM model performance criteria proposed by Boylan and Russell (2006), which is defined as "the level of accuracy that is considered to be acceptable for modelling applications" and met when both MFE $\leq 75 \%$ and $-60 \leq \mathrm{MFB} \leq 60 \%$. All of the $\mathrm{PM}_{10}$ and $\mathrm{PM}_{2.5}$ results are well within the recommended model performance criteria (gray polygon in Fig. 4.8), indicating that the 
model is capable of reproducing, with acceptable ranges for bias and error, the observed $\mathrm{PM}_{10}$ and $\mathrm{PM}_{2.5}$ concentrations. Nevertheless, the MFB and MFE for $\mathrm{OC}$ and $\mathrm{EC}$ do not meet such criteria showing the difficulty of the model to simulate the mass of these PM compounds. The underestimation of $\mathrm{OC}$, and thus of $\mathrm{PM}_{2.5}$ and $\mathrm{PM}_{10}$, is related to several factors including underestimation of POA emissions, inaccuracy of SOA formation, inaccurate meteorological predictions, among others.

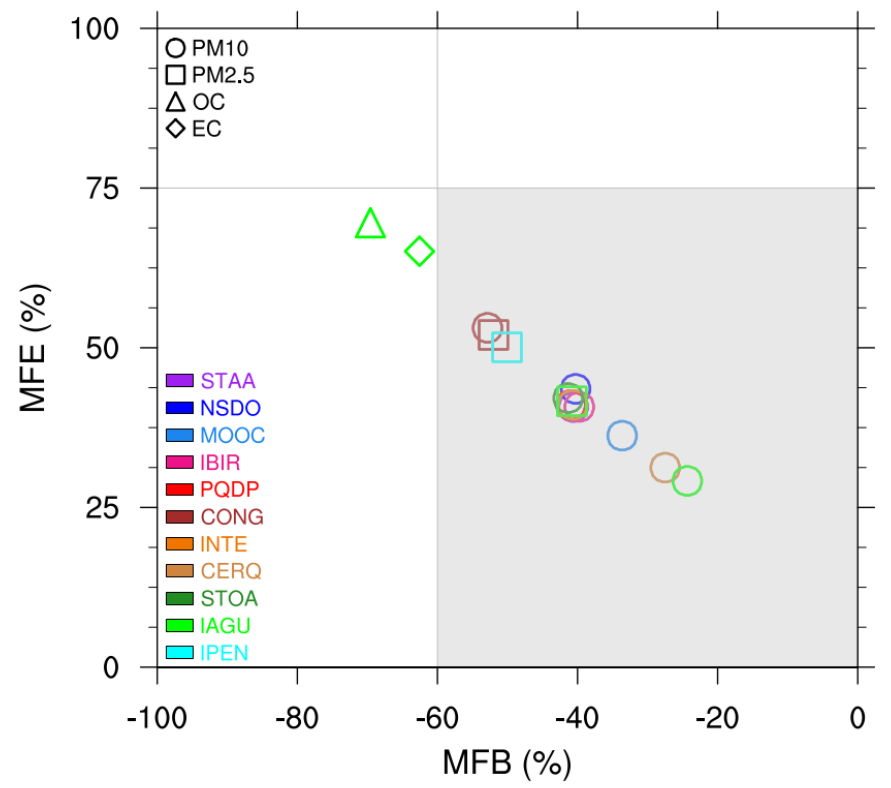

Figure 4.8: Mean fractional bias (MFB) and mean fractional error (MFE) of different dailyaverage PM variables: $\mathrm{PM}_{10}, \mathrm{PM}_{2.5}$, $\mathrm{OC}$ and EC. Each point on the scatter plot, displayed with a marker (PM variable) and a color (site), represents the WRF-Chem performance considering the criteria proposed by Boylan and Russell (2006) (gray polygon in the figure).

Fig. 4.10 shows the predicted average surface distribution of $\mathrm{PM}_{2.5}, \mathrm{PM}_{10}$ and $\mathrm{PM}_{2.5}: \mathrm{PM}_{10}$ ratio for the $3 \mathrm{~km}$ modelling domain, respectively. Red dots and cyan numbers represent the locations and the observed mean PM concentrations (or mean PM concentration ratios) at the measurement sites, respectively. Major contributions of $\mathrm{PM}_{2.5}$ to the total $\mathrm{PM}_{10}$ concentration were observed mainly over offshore continental areas (see the panel (c) in Fig. 4.10). High $\mathrm{PM}_{2.5}: \mathrm{PM}_{10}$ concentration ratios would be firstly associated with the transportation of fine particles and gases from upwind regions, followed by a production of fine particles from biogenic emissions.

Additional comparisons between the observed and predicted concentrations of $\mathrm{OC}$ and EC at IAGU (the only site with measurements of OC and EC) are shown in Fig. 4.11. 


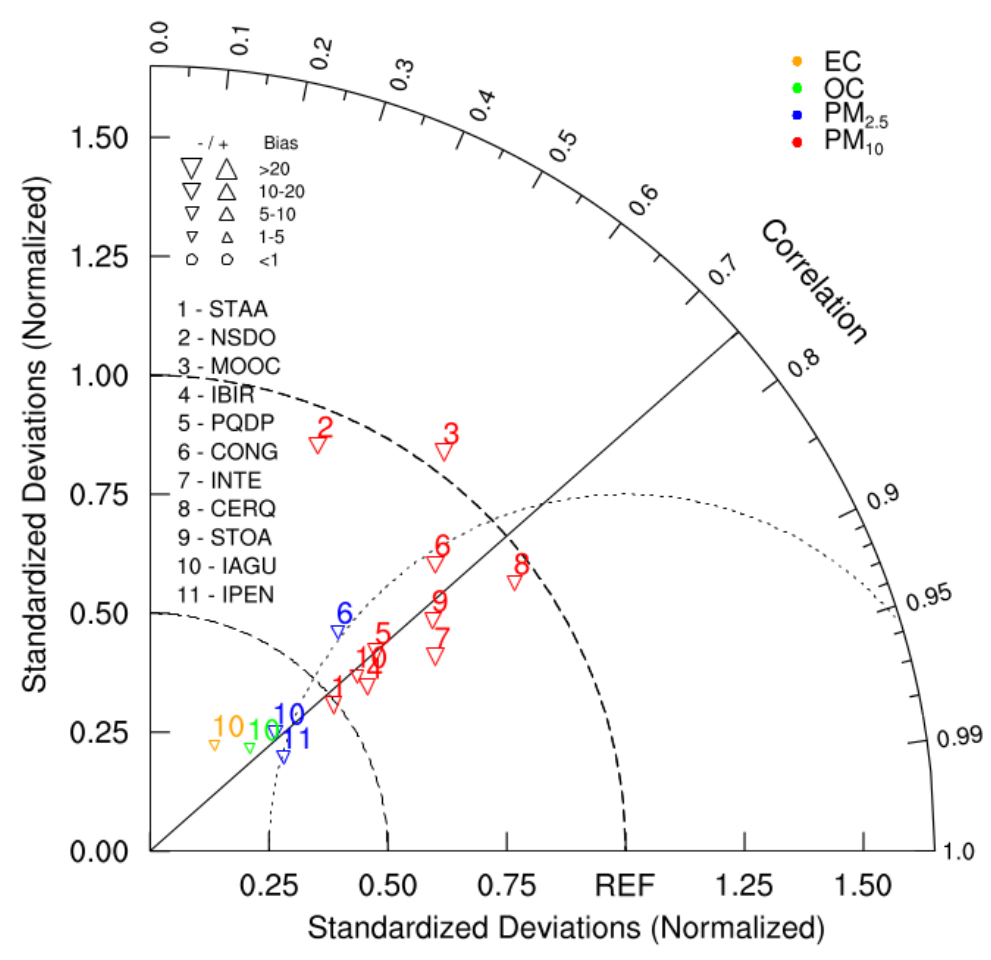

Figure 4.9: Taylor diagram (Taylor, 2001) showing the individual correlation coefficients, mean biases, and normalized standard deviations for the $\mathrm{PM}_{10}, \mathrm{PM}_{2.5}$, $\mathrm{OC}$ and $\mathrm{EC}$ concentrations.

Underpredicted OC concentrations could be associated with an underestimation of SOA, probably due to the absence of oxidation of monoterpenes and a limited treatment of anthropogenic VOCs oxidation in the RADM2 mechanism, as discussed by Tuccella et al. (2012). The SORGAM aerosol module considers the formation of anthropogenic SOAs from the oxidation of alkane, alkene and aromatic VOCs as well as the biogenic SOA formation from the oxidation of alpha-pinene, limonene and isoprene VOCs. Recent studies coupling non-traditional SOA models (VBS approaches) in WRF-Chem show improvements in the predicted SOA concentrations, although these are still lower than those observed (Li et al. 2011a; Ahmadov et al., 2012; Shrivastava et al., 2013). 
Table 4.3 - Performance statistics for WRF-Chem chemical predictions for the period from 7 August to 6 September 2012.

\begin{tabular}{|c|c|c|c|c|c|c|}
\hline Variable & Site & $\mathrm{R}$ & $\mathrm{RMSE}_{U B}$ & $\mathrm{MB}$ & MFB & $\mathrm{MFE}$ \\
\hline \multirow[t]{10}{*}{$\mathrm{PM}_{10}\left[\mu \mathrm{g} \mathrm{m}^{-3}\right]$} & NSDO & 0.40 & 16.04 & -15.58 & -40.27 & 43.55 \\
\hline & STAA & 0.78 & 11.16 & -16.05 & -40.60 & 40.72 \\
\hline & PQDP & 0.75 & 10.55 & -15.60 & -40.96 & 41.05 \\
\hline & MOOC & 0.59 & 11.23 & -13.24 & -33.63 & 36.24 \\
\hline & CERQ & 0.80 & 8.12 & -8.90 & -27.48 & 31.23 \\
\hline & IAGU & 0.76 & 10.83 & -9.13 & -24.33 & 29.15 \\
\hline & IBIR & 0.79 & 10.46 & -15.12 & -39.75 & 40.75 \\
\hline & $\mathrm{CONG}$ & 0.70 & 10.39 & -19.02 & -52.85 & 53.11 \\
\hline & STOA & 0.77 & 9.02 & -14.01 & -41.33 & 42.12 \\
\hline & INTE & 0.82 & 8.06 & -13.45 & -40.67 & 41.06 \\
\hline \multirow[t]{3}{*}{$\mathrm{PM}_{2.5}\left[\mu \mathrm{g} \mathrm{m}^{-3}\right]$} & IAGU & 0.72 & 6.26 & -7.82 & -40.80 & 41.62 \\
\hline & IPEN & 0.81 & 6.79 & -8.75 & -50.07 & 50.07 \\
\hline & $\mathrm{CONG}$ & 0.65 & 7.43 & -9.94 & -52.00 & 52.00 \\
\hline $\mathrm{OC}\left[\mu \mathrm{g} \mathrm{m}^{-3}\right]$ & IAGU & 0.70 & 2.74 & -3.94 & -69.57 & 69.57 \\
\hline $\mathrm{EC}\left[\mu \mathrm{g} \mathrm{m}^{-3}\right]$ & IAGU & 0.52 & 1.66 & -1.62 & -62.56 & 65.10 \\
\hline \multirow[t]{6}{*}{$\mathrm{O}_{3}\left[\mu \mathrm{g} \mathrm{m}^{-3}\right]$} & NSDO & 0.60 & 28.55 & 4.15 & 41.51 & 82.33 \\
\hline & PQDP & 0.62 & 25.49 & 10.48 & 64.02 & 88.12 \\
\hline & MOOC & 0.63 & 25.53 & -3.19 & 7.00 & 59.88 \\
\hline & IPEN & 0.63 & 29.60 & -1.79 & 27.22 & 76.53 \\
\hline & IBIR & 0.62 & 29.94 & -12.45 & -18.66 & 59.98 \\
\hline & INTE & 0.66 & 25.61 & -2.30 & 14.66 & 70.27 \\
\hline \multirow[t]{2}{*}{ NOx $[\mathrm{ppb}]$} & IPEN & 0.43 & 33.40 & 7.06 & 67.49 & 94.52 \\
\hline & IBIR & 0.40 & 27.30 & -24.57 & -42.13 & 71.11 \\
\hline \multirow[t]{2}{*}{$\mathrm{CO}[\mathrm{ppm}]$} & IPEN & 0.51 & 0.59 & -0.14 & 4.98 & 83.88 \\
\hline & IBIR & 0.57 & 0.54 & -0.39 & -70.04 & 77.97 \\
\hline
\end{tabular}

R: correlation coefficient; $\mathrm{RMSE}_{U B}$ : root mean square error; MB: mean bias; MFB: mean fractional bias; MFE: mean fractional error. 

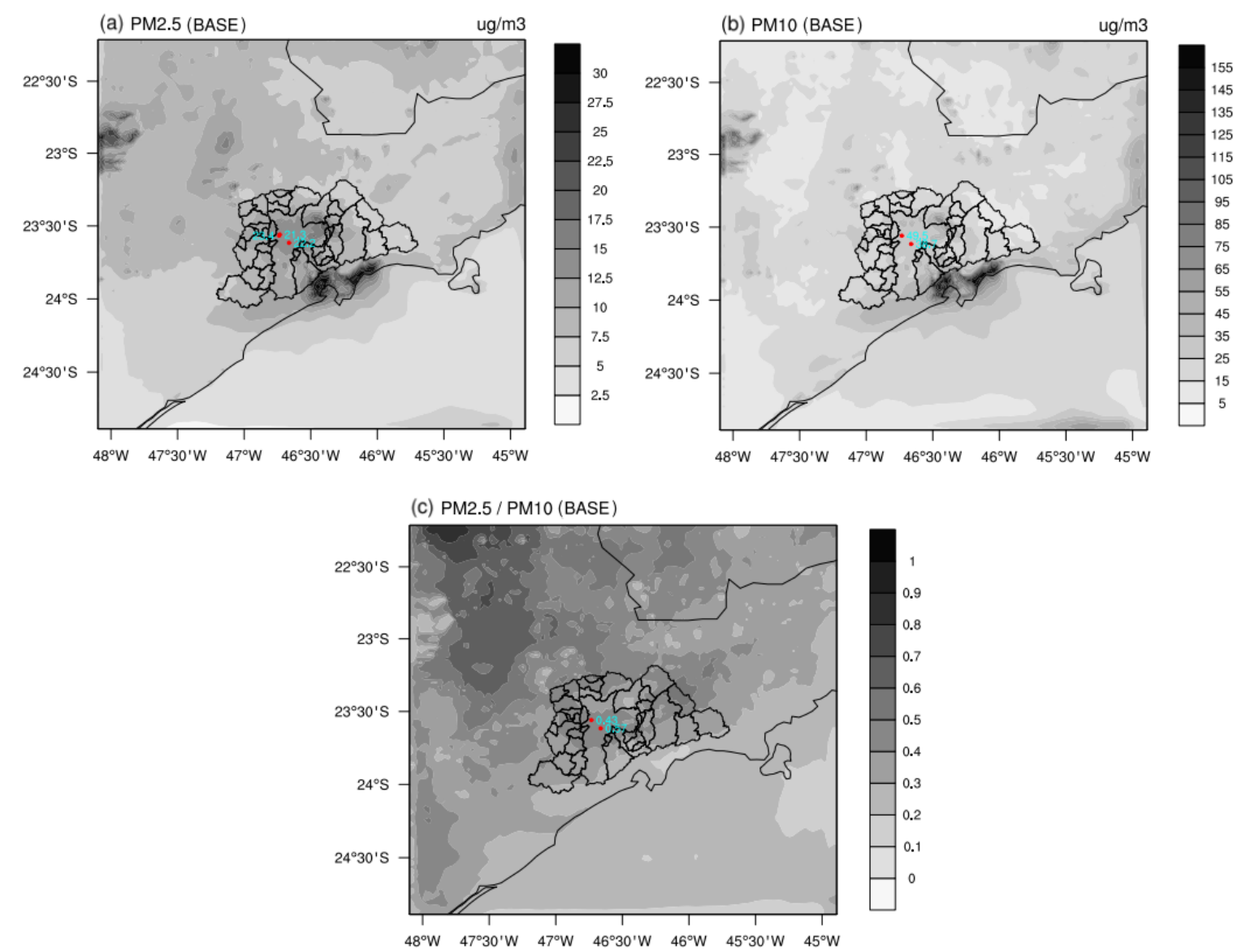

Figure 4.10: The predicted average surface distribution of (a) $\mathrm{PM}_{2.5}$, (b) $\mathrm{PM}_{10}$ and (c) $\mathrm{PM}_{2.5}: \mathrm{PM}_{10}$ for the whole study period in the $3 \mathrm{~km}$ modelling domain. Red dots represent the locations of the measurement sites with information on PM, whereas cyan numbers represent the observed average PM concentrations in those sites: $23.4 \mu \mathrm{g} \mathrm{m}^{-3}$ in IPEN, $21.3 \mu \mathrm{g} \mathrm{m}^{-3}$ in IAGU and $22.2 \mu \mathrm{g} \mathrm{m}^{-3}$ in CONG for $\mathrm{PM}_{2.5}, 49.5 \mu \mathrm{g} \mathrm{m}^{-3}$ in IAGU and $38.7 \mu \mathrm{g} \mathrm{m}^{-3}$ in CONG for $\mathrm{PM}_{10}$, and 0.43 in IAGU and 0.57 in CONG for $\mathrm{PM}_{2.5}: \mathrm{PM}_{10}$. 

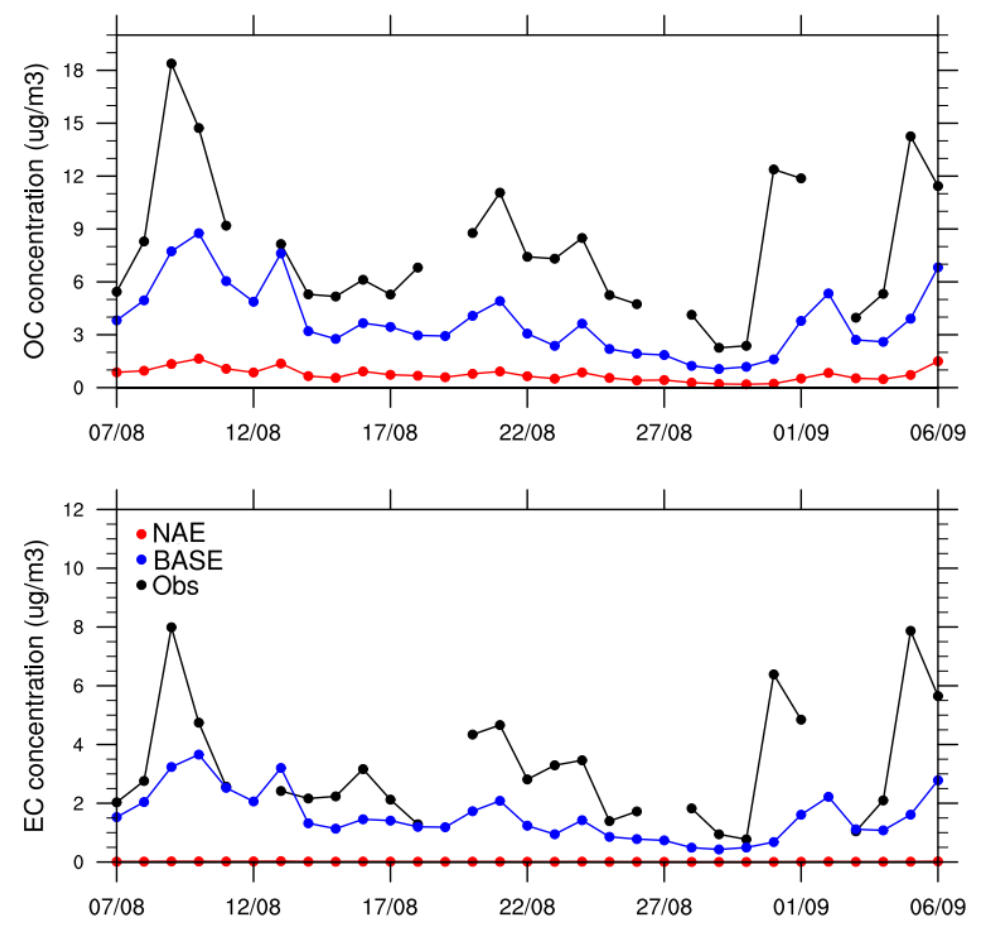

Figure 4.11: The observed and predicted (blue and red dots for BASE and NAE simulations, respectively) daily variations of OC and EC concentrations at the IAGU site during the period from 7 August to 6 September 2012. 
Period from 19 August to 3 September 2014

Figs. 4.12, 4.13 and 4.14, respectively, compare the observed near-surface $\mathrm{PM}_{10}$, $\mathrm{PM}_{2.5}$ and $\mathrm{O}_{3}$ concentrations with the concentrations predicted in the BASE simulation (blue dots in the figures). In general, the model tracked the temporal variations of those pollutants concentrations reasonably well, mainly during the first half of the study period (19 August to 26 August 2014) when there were no precipitation events. However, it frequently underestimated the maximum concentrations, indicating either inaccurate meteorological predictions (e.g., PBL height) or underestimation of the emissions, or a combination of both. For the concentrations of $\mathrm{PM}_{2.5}, \mathrm{PM}_{10}$ and $\mathrm{O}_{3}$, the average MBs were $1.02,-2.87$ and $-5.32 \mu \mathrm{g} \mathrm{m}^{-3}$, and the average NMBs were $4.30,-4.79$ and $-12.45 \%$, respectively. Individual indices are available in Table 4.4. Each point on the scatter plot in Fig. 4.16, displayed with a marker (PM variable) and a colour (monitoring site), represents the PM baseline performance in terms of NMB and NME for the period from 19 August to 3 September 2014.
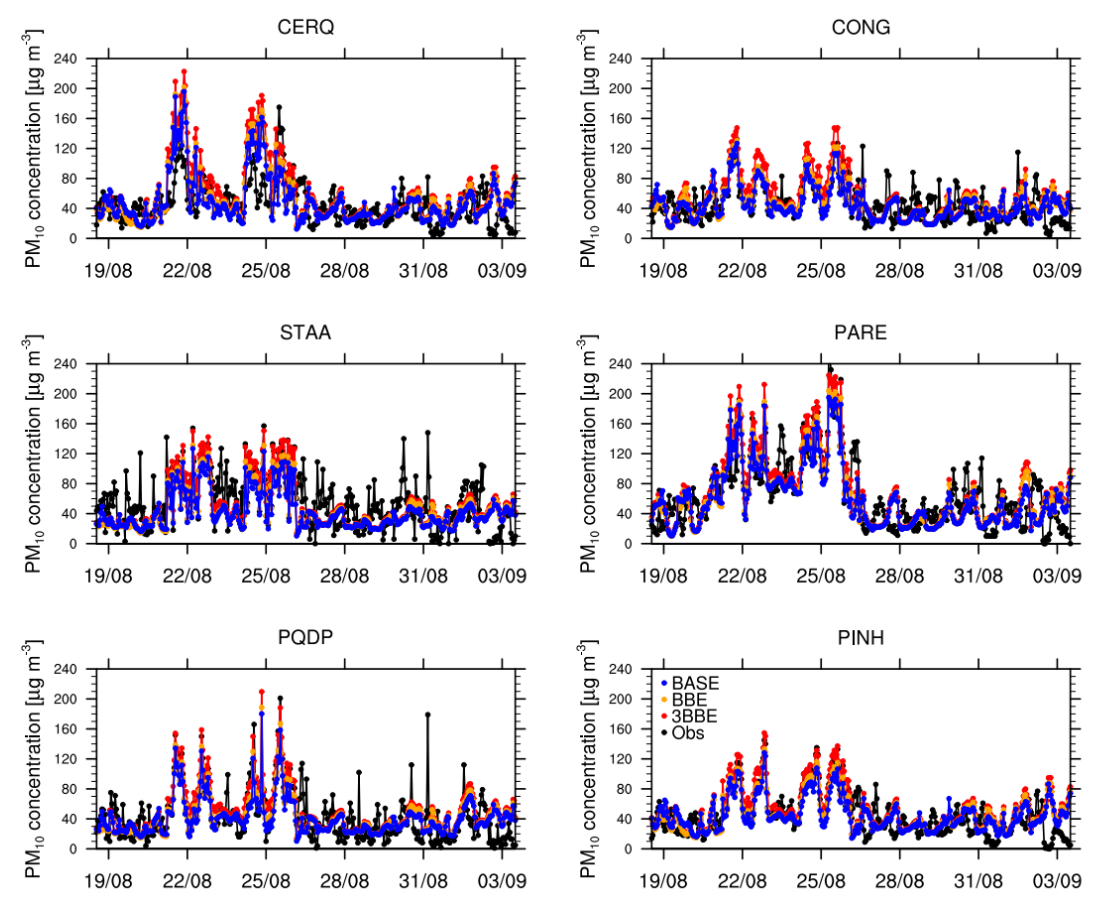

Figure 4.12: Hourly variations in $\mathrm{PM}_{10}$ concentrations during the period from 19 August to 3 September 2014, showing observed values (black dots) and predicted values (blue, orange and red dots, respectively, for the simulations BASE, BBE and 3BBE). 

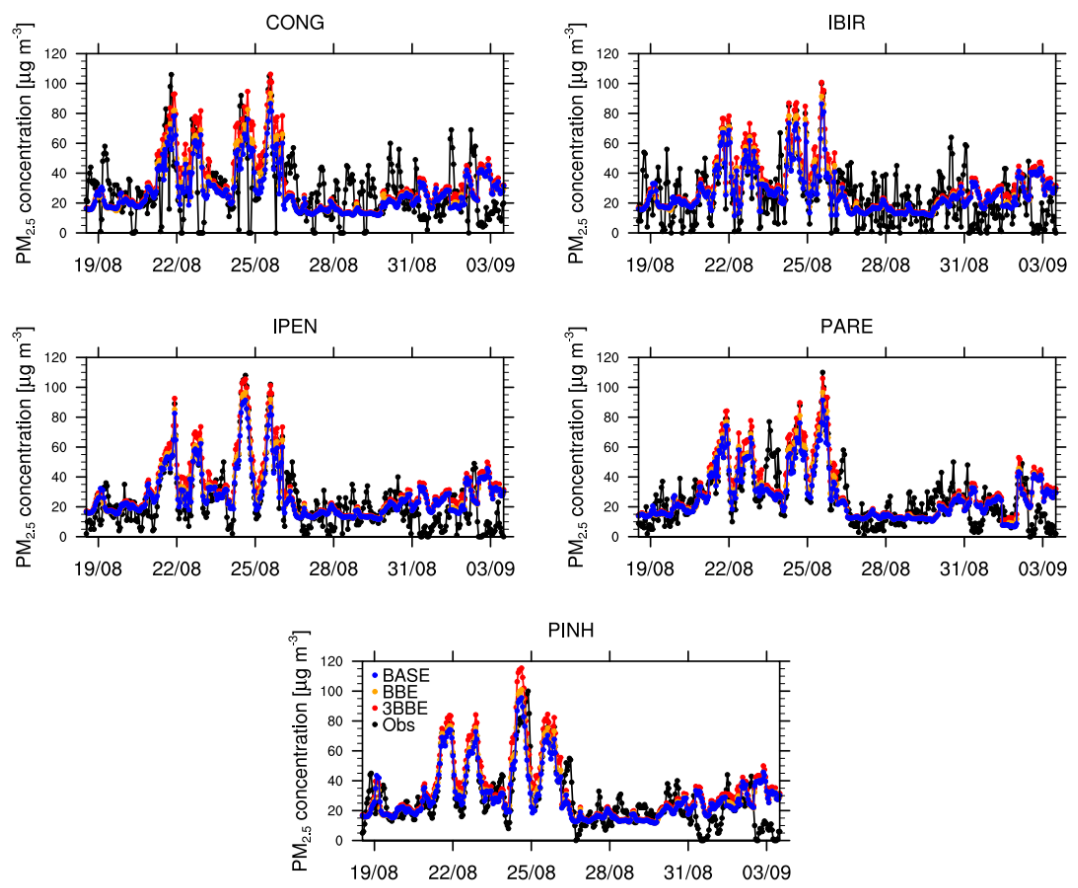

Figure 4.13: Hourly variations in $\mathrm{PM}_{2.5}$ concentrations during the period from 19 August to 3 September 2014, showing observed values (black dots) and predicted values (blue, orange and red dots, respectively, for the simulations BASE, BBE and 3BBE).
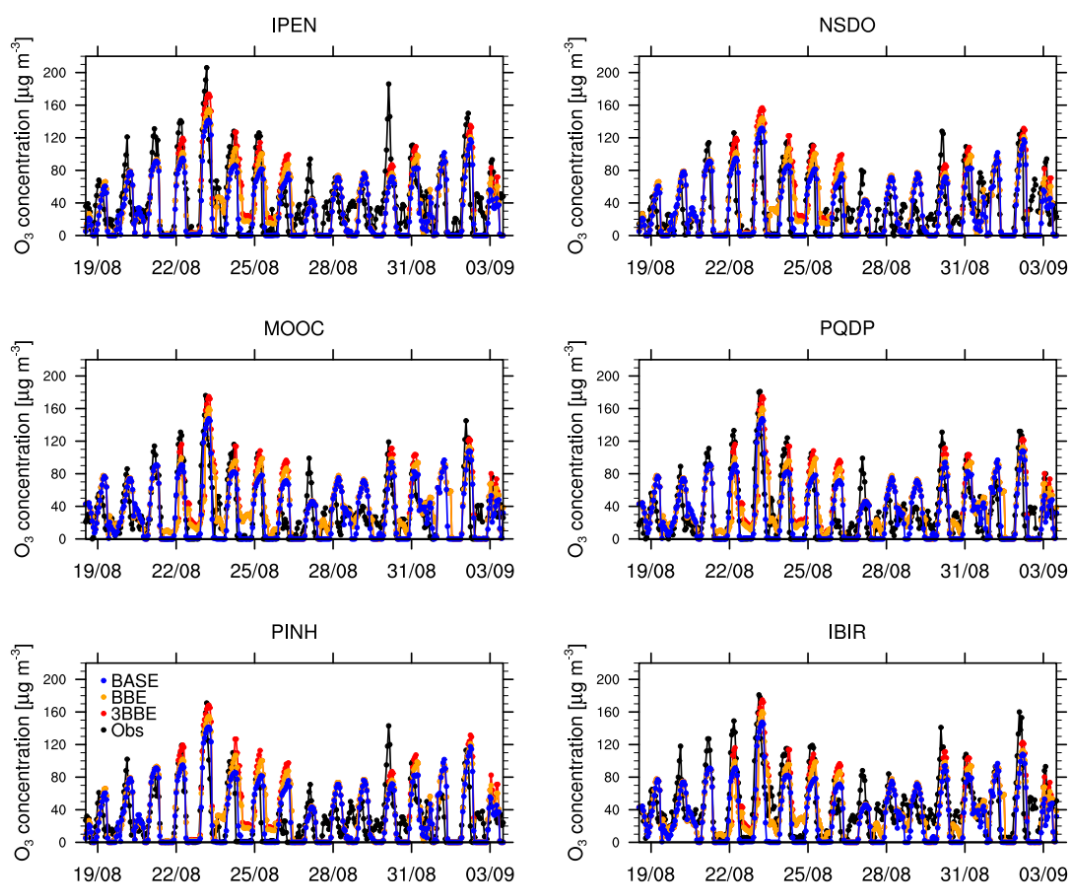

Figure 4.14: Hourly variations in $\mathrm{O}_{3}$ concentrations during the period from 19 August to 3 September 2014, showing observed values (black dots) and predicted values (blue, orange and red dots, respectively, for the simulations BASE, BBE and 3BBE). 
Comparisons between the observed and predicted concentrations of EC at the IAGU site are shown in Fig. 4.15. The considerable underprediction of EC might be due to underestimates of EC emissions in the fire emissions inventory. As reported by Pereira et al. (2016), the FINN tends to underestimate the smoke emission loading in the eastern portion of the Amazon rainforest.

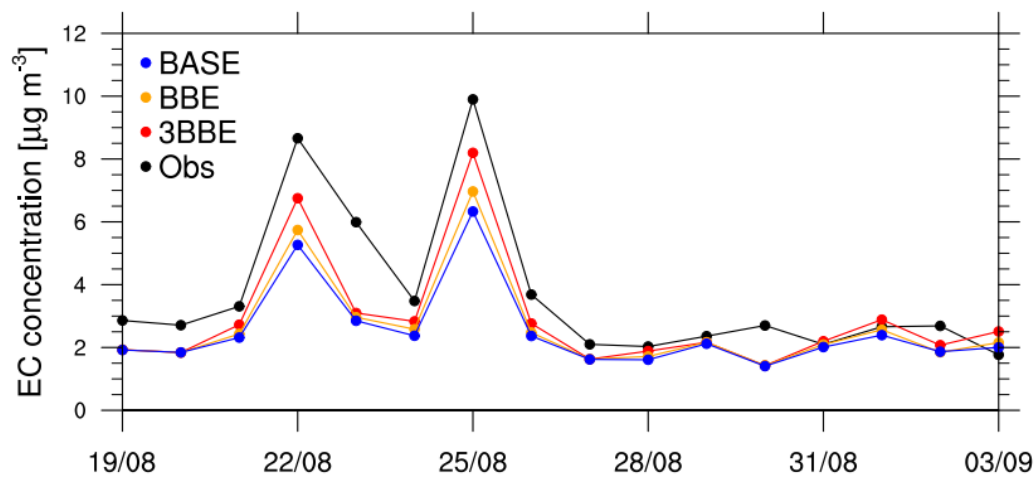

Figure 4.15: Daily variations in EC concentrations at IAGU during the period from 19 August to 3 September 2014, showing the observed values (black dots) and predicted values (blue, orange and red dots, respectively, for the simulations BASE, BBE and 3BBE).

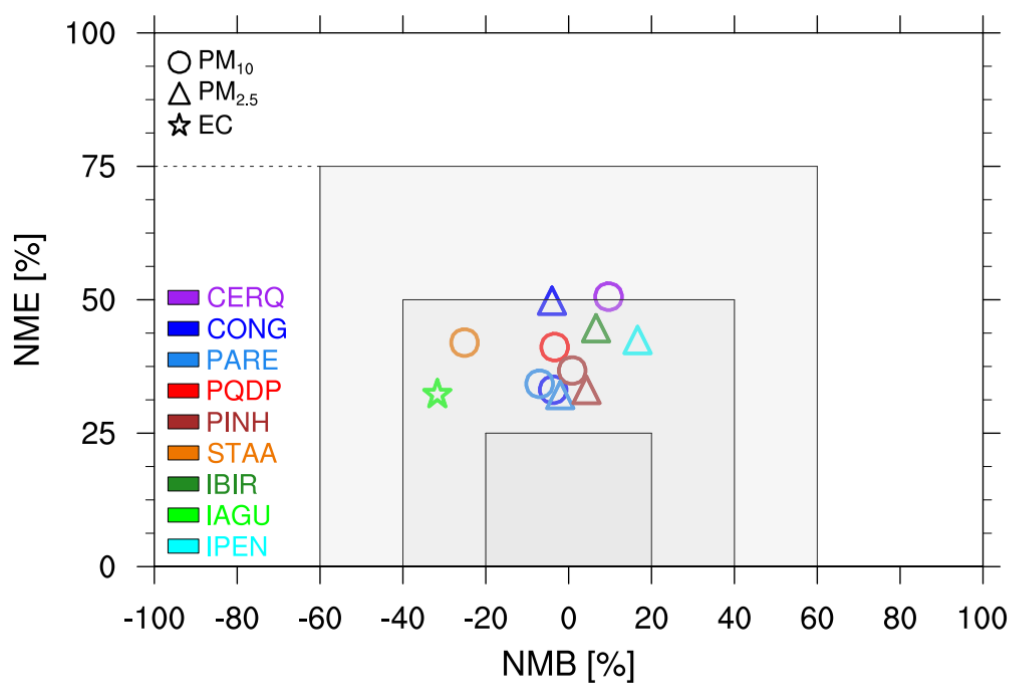

Figure 4.16: PM soccer plots (NMB vs. NME) for the BASE simulation during the period from 19 August to 3 September 2014. 
Table 4.4 - Performance statistics for WRF-Chem chemical predictions for the period from 19 August to 3 September 2014.

\begin{tabular}{|c|c|c|c|c|c|c|}
\hline Variable & Site & $\mathrm{R}$ & RMSE & $\mathrm{MB}$ & MFB & MFE \\
\hline \multirow[t]{6}{*}{$\mathrm{PM}_{10}\left[\mu \mathrm{g} \mathrm{m}^{-3}\right]$} & CERQ & 0.49 & 30.48 & 4.35 & 8.30 & 48.91 \\
\hline & $\mathrm{CONG}$ & 0.60 & 20.37 & -1.74 & -0.71 & 39.12 \\
\hline & STAA & 0.62 & 30.63 & -14.17 & -16.40 & 55.78 \\
\hline & PARE & 0.79 & 29.17 & -4.62 & -2.28 & 47.74 \\
\hline & PQPD & 0.69 & 24.11 & -1.44 & 11.63 & 48.74 \\
\hline & PINH & 0.67 & 21.58 & 0.38 & 8.81 & 42.77 \\
\hline \multirow[t]{5}{*}{$\mathrm{PM}_{2.5}\left[\mu \mathrm{g} \mathrm{m}^{-3}\right]$} & CONG & 0.44 & 19.23 & -1.17 & 8.55 & 57.97 \\
\hline & IBIR & 0.66 & 14.60 & 1.66 & 27.06 & 59.53 \\
\hline & IPEN & 0.80 & 13.19 & 3.96 & 32.78 & 54.42 \\
\hline & PARE & 0.80 & 11.98 & -0.55 & 8.94 & 42.82 \\
\hline & PINH & 0.78 & 12.91 & 1.21 & 14.36 & 41.90 \\
\hline $\mathrm{EC}\left[\mu \mathrm{g} \mathrm{m}^{-3}\right]$ & IAGU & 0.96 & 1.63 & -1.17 & -32.43 & 33.99 \\
\hline \multirow[t]{6}{*}{$\mathrm{O}_{3}\left[\mu \mathrm{g} \mathrm{m}^{-3}\right]$} & IPEN & 0.74 & 30.57 & -13.47 & -70.81 & 114.48 \\
\hline & NSDO & 0.66 & 29.36 & -2.80 & -8.35 & 120.27 \\
\hline & MOOC & 0.73 & 25.79 & -1.82 & 0.42 & 107.45 \\
\hline & PQDP & 0.72 & 26.64 & -0.35 & 9.40 & 112.44 \\
\hline & PINH & 0.69 & 27.04 & -0.21 & -29.11 & 118.52 \\
\hline & IBIR & 0.73 & 29.32 & -13.28 & -78.75 & 102.60 \\
\hline
\end{tabular}

R: correlation coefficient; RMSE: root mean square error; MB: mean bias; MFB: mean fractional bias; MFE: mean fractional error; NMB: normalised mean bias; NME: normalised mean error.

\subsubsection{Size distribution and chemical composition}

\section{Period from 7 August to 6 September 2012}

The observed and predicted aerosol mass size distributions averaged over the same sampling time period (16 days along the study period) are shown in Fig. 4.17. Over the downtown MASP, both observed and predicted fine particles from accumulation mode account for majority of the total $\mathrm{PM}_{2.5}$ mass. Since the formation-growth processes of aerosols in question are explicitly treated in the Aitken and accumulation modes, the predicted concentrations for particles larger than $1 \mu \mathrm{m}$ are assumed to be zero. In this case, the mass of particles larger than $1 \mu \mathrm{m}$ is allocated to the $\mathrm{PM}_{2.5}$ aerosol variable. 


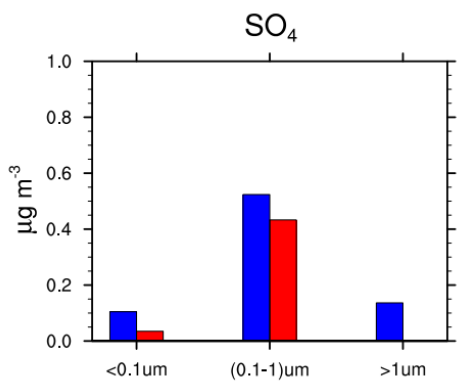

$\mathrm{Na}$

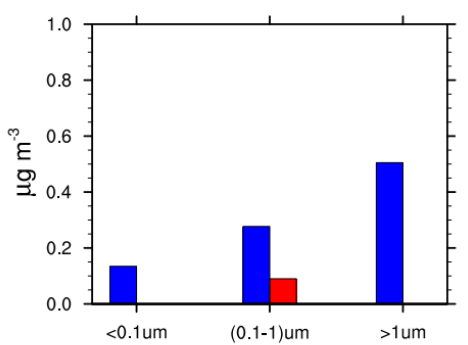

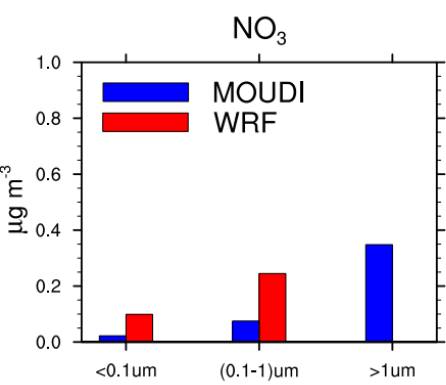

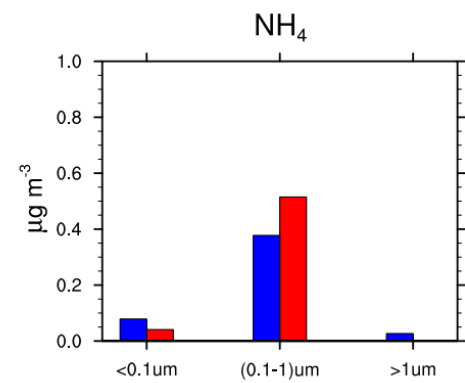

$\mathrm{Cl}$

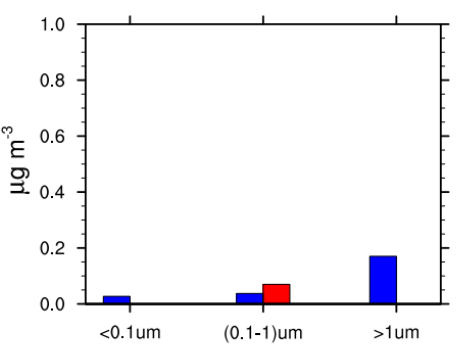

$\mathrm{PM}_{10}$

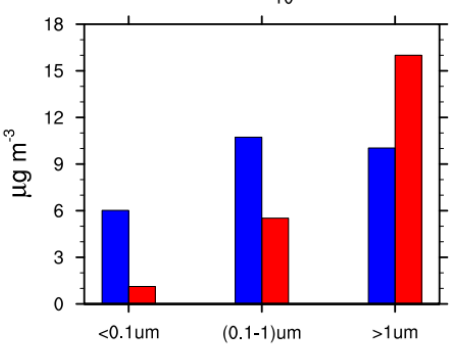

Figure 4.17: The observed and predicted average aerosol mass size distribution for $\mathrm{SO}_{4}, \mathrm{NO}_{3}$, $\mathrm{NH}_{4}, \mathrm{Na}, \mathrm{Cl}$, and other $\mathrm{PM}_{10}$ constituents at IAGU. The observed aerosol distributions were collected in ten size classes using a rotated impactor (MOUDI) and joined adequately according to the three modes used by the MADE aerosol scheme: Aitken $(<0.1 \mu \mathrm{m})$, accumulation $(0.1-1 \mu \mathrm{m})$ and coarse $(>1 \mu \mathrm{m})$. The five inorganic ions carried in MADE are only calculated for the Aitken and accumulation modes. The WRF's $\mathrm{PM}_{10}$ aerosol variable does not include neither OC nor EC for this comparison.

The comparison between the observed and predicted average contributions for the main identified aerosol constituents at IAGU is shown in Fig. 4.18. Both the observed and predicted $\mathrm{OC}$ and $\mathrm{EC}$ make up the largest fraction of $\mathrm{PM}_{2.5}$ mass with contributions of 55 and $40 \%$, respectively. In addition, it was found that the predicted SOA concentrations contribute $17 \%$ of the predicted total OC concentration at this measurement site. Various global and regional scale SOA simulations have been conducted using mass-based yield and partitioning coefficients, but they have underestimated the SOA concentrations by roughly an order of magnitude, especially over urban regions (Matsui et al., 2014). Using the same SOA formation approach employed by this study, and a conversion factor of 1.6 to convert the emissions of OC to organic matter (OM), Tuccella et al. (2012) found simulated SOA:OM ratios in the 5-40\% range against the observed range of 50-80\%. Although the predicted average $\mathrm{PM}_{2.5}$ concentration $\left(14.48 \mu \mathrm{g} \mathrm{m}^{-3}\right.$ ) was lower than observed (22.32 $\mu \mathrm{g} \mathrm{m}^{-3}$ ), the mean aerosol chemical composition was reasonably well represented by the model (see Fig. 4.18). 


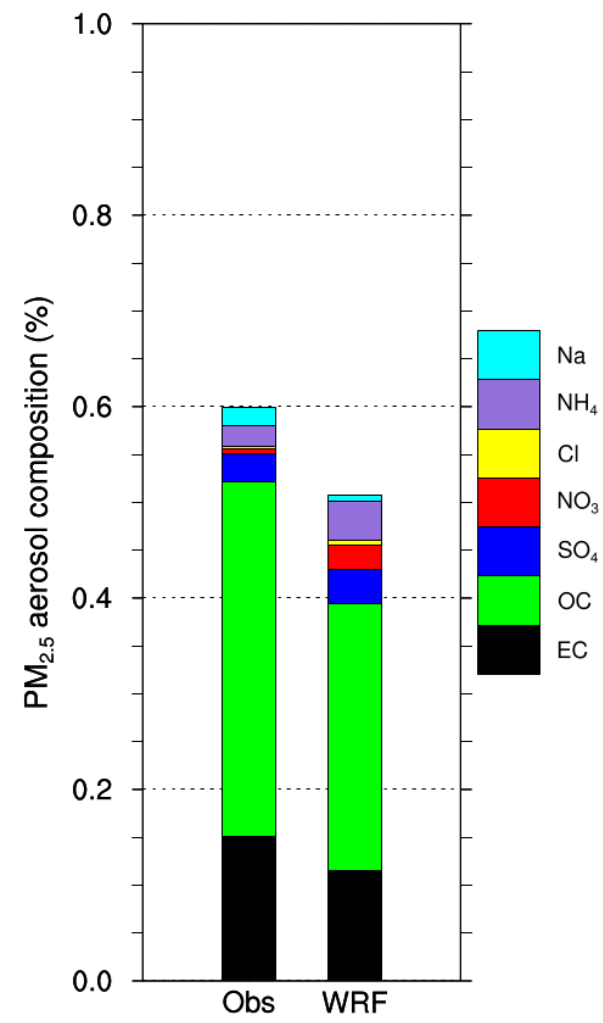

Figure 4.18: The observed and predicted average contributions for the main identified constituents of $\mathrm{PM}_{2.5}$ at IAGU.

\section{Period from 19 August to 3 September 2014}

Figs. 4.19 and 4.20 depict the predicted particle mass and number concentrations, respectively, using available observations. For comparison purposes, the particle masses in each MOUDI bin were grouped into the MADE modes according to their size limits. In addition, due to limited measurements of mass size distribution, the observed and predicted particle mass concentrations were compared based on the MOUDI sampling period, which included only one day within the fire emission contribution period prior to the shift in meteorological conditions. Based on WRF-Chem nomenclature, nu0 and ac0 are used here to refer to PNC in the Aitken and accumulation modes, respectively. The comparison of particle number data from the model against DMPS data revealed a good agreement in terms of temporal evolution (see the left panels in Fig. 4.20). However, some peaks attributed to very specific small-scale features, mainly in the second half of the study period, were not fully captured by the model. The predicted PNC showed lower variability than did the observed PNC (see the bottom right panel in Fig. 4.20), the differences being attributable in large part to uncertainties in the estimation of nucleation rates and of 
primary emissions of aerosol particles, the latter considered to be the key factor for $\mathrm{CCN}$ production within the planetary boundary layer (PBL), as described by Tuccella et al. (2015) and Spracklen et al. (2006).
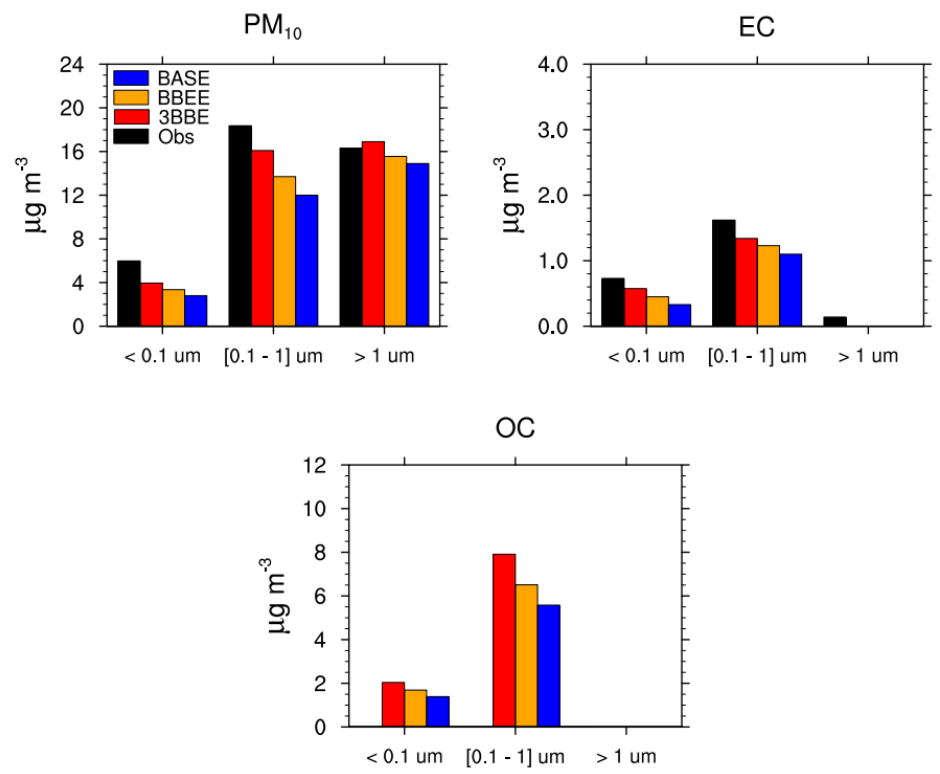

Figure 4.19: Observed and predicted particle mass concentration of average $\mathrm{PM}_{10}$ (top left) and EC (top right), together with the predicted average OC (bottom). The mass concentrations in each MOUDI bin were first grouped according to the three modes used in the MADE aerosol module, after which they were averaged for the MOUDI sampling period (eight days during the study period).

The model evaluation for $\mathrm{PM}_{2.5}$ chemical composition, in terms of light absorption at ultraviolet and visible wavelengths, focused only on the two most important aerosol components: EC (observed and predicted) and OC (predicted only). The predicted OC and EC composed the largest fraction of the total $\mathrm{PM}_{1}$ mass at the IAGU site, with individual contributions of $49.2 \%$ and $9.6 \%$, respectively, compared with only $8.8 \%$ for the observed EC. In addition, the predicted SOA at the IAGU site were found to correspond to $24 \%$ of the predicted OC (11.8\% of the total $\mathrm{PM}_{1}$ mass). A previous study, also conducted over the MASP (Vara-Vela et al., 2016), reported that the predicted SOA accounted for $17 \%$ of the OC mass. Although those proportions represent average contribution during August for different but proximal years (2012 and 2014), the approximately 7\% higher SOA contribution obtained in this study is attributable to the use of a non-traditional SOA model rather than a traditional SOA model, as those used by Vara-Vela et al. (2016) and Tuccella et al. (2012), together with the use of an extended and updated biogenic 
emissions model.
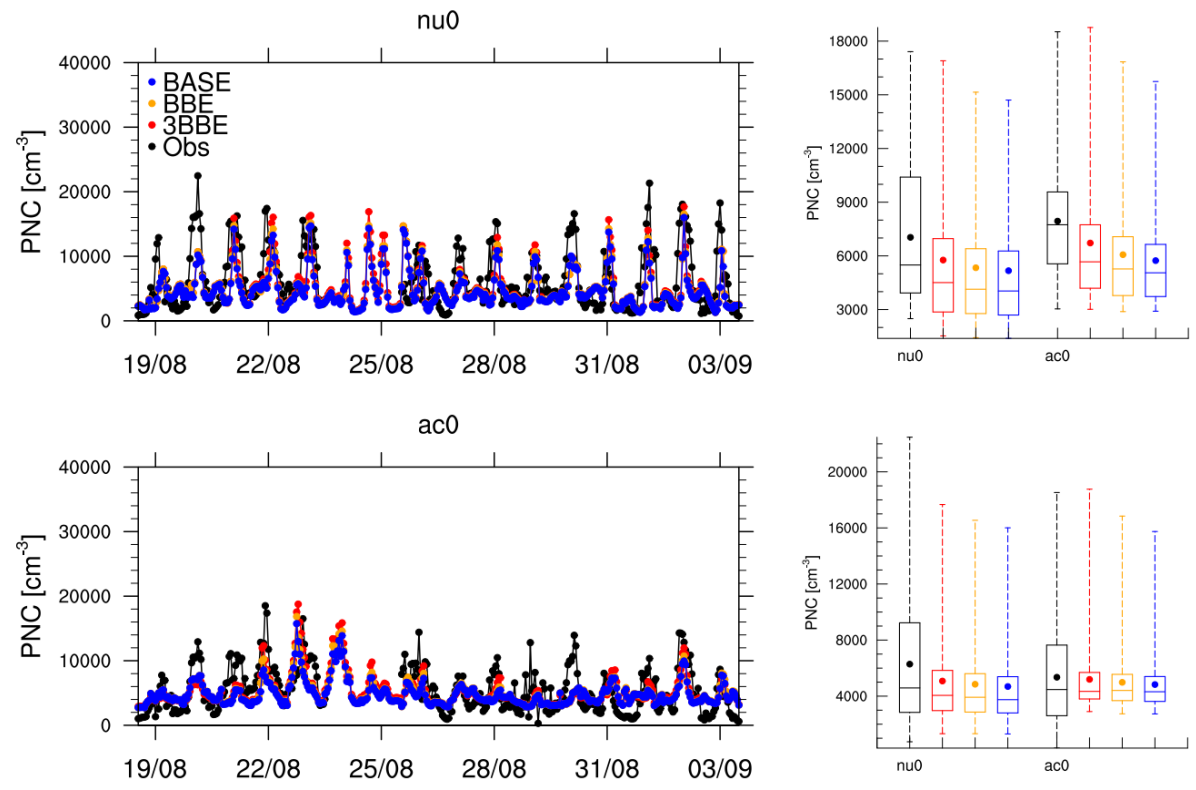

Figure 4.20: Time series (left) and box-whisker plots (right) of PNC, in the Aitken mode (nu0) and in the accumulation mode (ac0), at the IAGU site showing observed values (in black) and predicted values (in blue, orange and red, respectively, for the simulations BASE, $\mathrm{BBE}$ and $3 \mathrm{BBE}$ ). The box-whisker plots show the interquartile ranges for the periods from 22 August to 26 August 2014 (top) and from 19 August to 3 September 2014 (bottom).

\subsubsection{CCN activation and optical properties}

Period from 19 August to 3 September 2014

Aerosols can be activated depending on the supersaturation, aerosol composition, and particle size. Although the relative importance of these parameters may vary greatly in different environments and locations, there is general agreement that the activation of CCN at a given supersaturation depends primarily on the particle size, followed by the chemical composition and mixing state (Che et al., 2017). In the present study, activation of CCN was assessed by comparing the observed and predicted AR values at supersaturations of $0.2 \%$ and $1.0 \%$. The AR was calculated, with PNC integrated over bins and modes, as follows:

$$
A R=\frac{C C N}{P N C}
$$


with a particle diameter $\leq 1 \mu \mathrm{m}$. The AR, thus calculated, was employed for determining the efficiency of aerosol particles in acting as CCN, following the examples of previous studies of the atmosphere over the MASP conducted by Almeida et al. (2014) and SoutoOliveira et al. (2016). Time series and box-whisker plots of CCN concentrations at IAGU are shown in the Fig. 4.21, and Fig. 4.22 shows the same for ARs. The CCN comparisons show that the model represented the spread of CCN relatively well at both supersaturations, confirming the importance of supersaturation in the magnitude of the CCN activation. Underestimation of the predicted CCN was directly related to an underestimation of the predicted PNC. Global and regional modelling studies have suggested that CCN production depends largely on the primary emission of aerosol particles (Spracklen et al. 2006; Merikanto et al., 2009; Tuccella et al., 2015). Depending on the aerosol composition, particle hygroscopicity may or not catalyse the activation of CCN. In the WRF-Chem, CCN activation depends on the volume-weighted average hygroscopicity of each aerosol component (e.g. salt, sulfate, nitrate, ammonium and SOA, which are the aerosol particles that react readily with water).
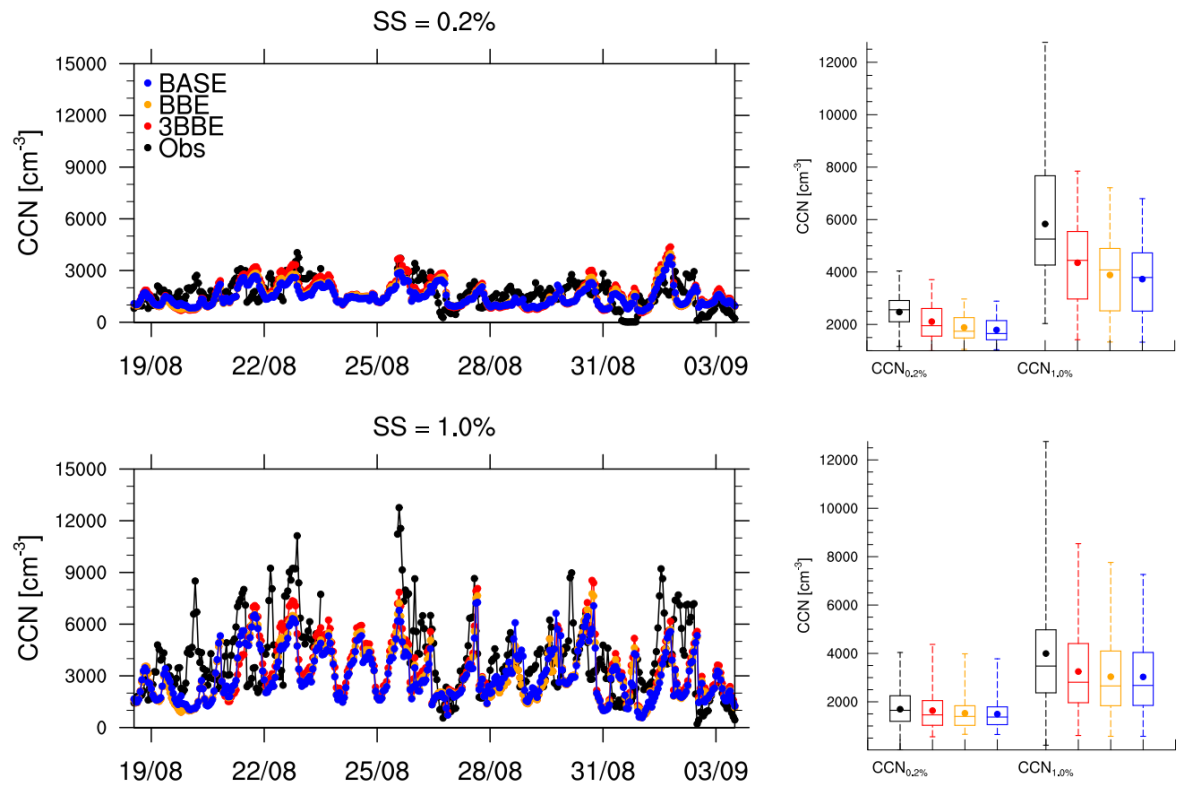

Figure 4.21: Times series (left) and box-whisker plots (right) of CCN at the IAGU site showing observed values (in black) and predicted values (in blue, orange and red, respectively, for the simulations BASE, BBE and 3BBE). The box-whisker plots show the interquartile ranges for the periods from 22 August to 26 August 2014 (top) and from 19 August to 3 September 2014 (bottom). 

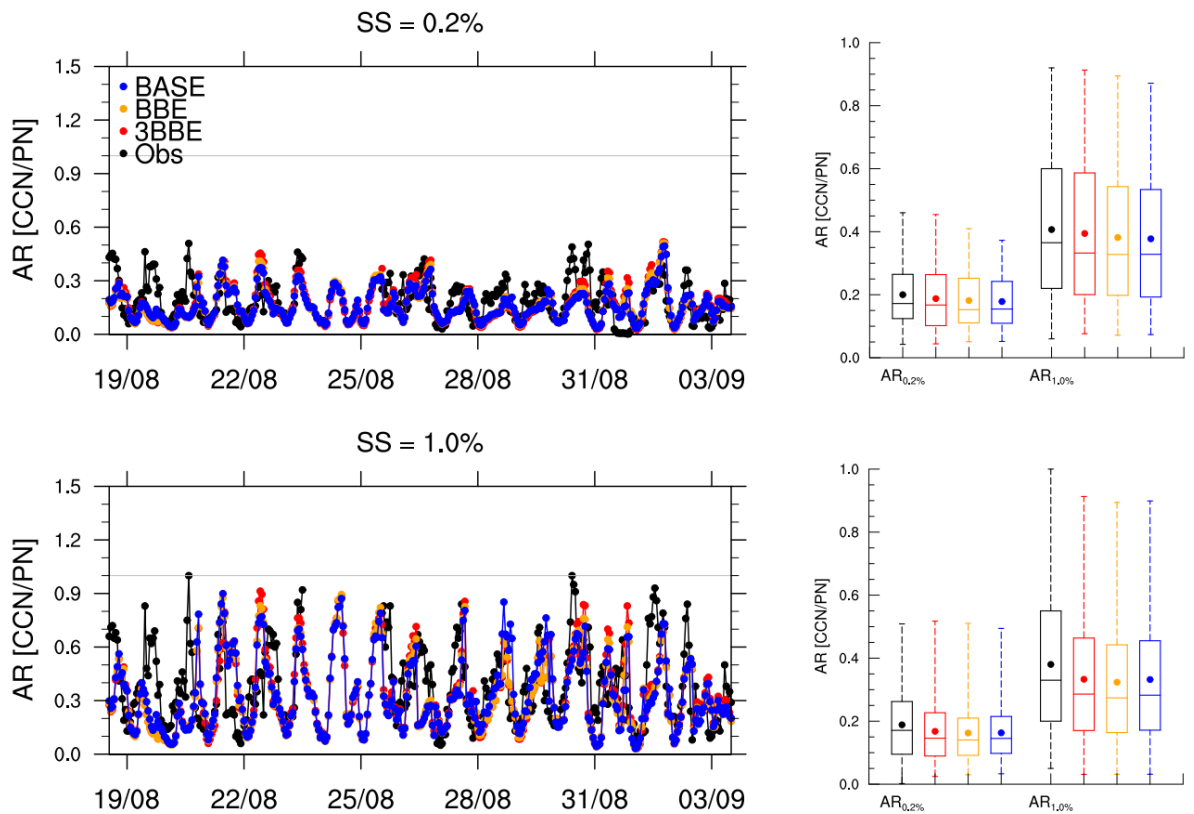

Figure 4.22: Times series (left) and box-whisker plots (right) of ARs at the IAGU site showing observed values (in black) and predicted values (in blue, orange and red, respectively, for the simulations BASE, BBE and 3BBE). The box-whisker plots show the interquartile ranges for the periods from 22 August to 26 August 2014 (top) and from 19 August to 3 September 2014 (bottom).

Although the model underestimates the CCN and PNC concentrations, the predicted AR values agreed well with the observations throughout the study period. The observed and predicted interquartile ranges were similar between them (see the right panels in Fig. 4.22). This is due to the fact that both of the terms on the right-hand side of Eq. 4.1) were underestimated by similar scale factors relative to their corresponding observed values. The observed AR peaks that were not fully captured by the model are attributable to PNC-related local-scale features. Table 4.6 summarises the observed and predicted standard deviations, correlation and mean bias of $\mathrm{PNC}(\mathrm{ac} 0), \mathrm{CCN}_{1 \%}$ and $\mathrm{AR}_{1 \%}$.

Model results for the $25 \mathrm{~km}$ baseline simulation are in good domain-wide agreement with the Moderate Resolution Imaging Spectroradiometer AOD data $(\mathrm{R}=0.55 ; \mathrm{MB}=-0.08$; $\mathrm{NMB}=-0.47)$. On the basis of a spatial average, the largest AOD underestimations occurred over the central-west region of Brazil (see panel (c) Fig. 4.23), indicating that particle loadings are underestimated over this region. Biomass burning events are quite common in the central-west region of Brazil and represent the dominant aerosol sources during the burning season (August to October), as reported by Hoelzemann et al. (2009). 
However, comparisons between the data derived from the BASE simulation and those of the two available lidar aerosol extinction profiles, show that the model failed to simulate the vertical structure of aerosols, being able to produce only some of the aerosol layering observed between 12:00 and 13:00 UTC on 26 August (left panel in Fig. 4.24), prior to the shift toward unfavourable conditions in terms of precipitation and transport from fire regions. Similarly, the higher resolution model simulation underestimated the magnitude of extinction coefficients and thus that of the AOD.

(a) $A O D_{\text {MODIS }}$

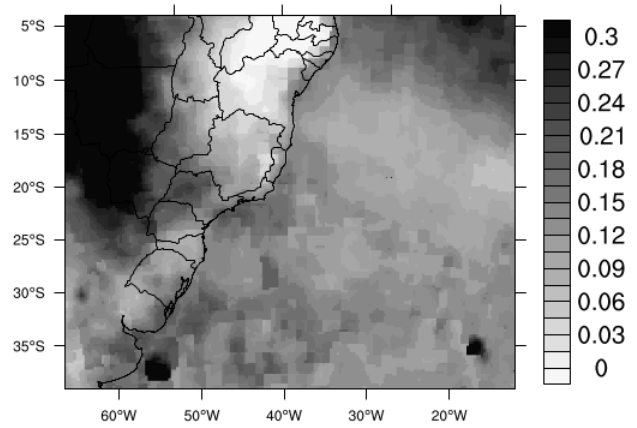

(b) $A O D_{B B E}$

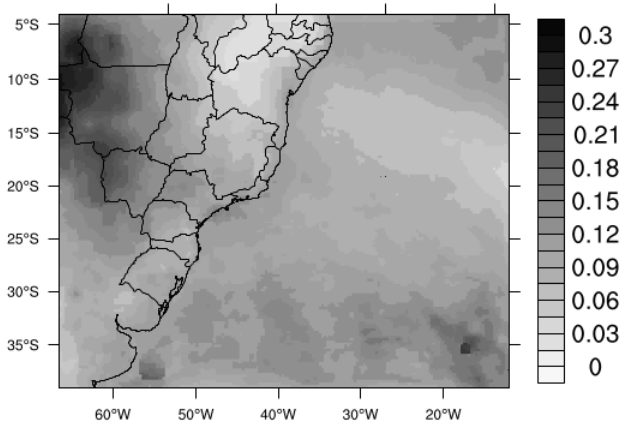

(c) $A O D_{B B E}-A O D_{\text {MODIS }}$

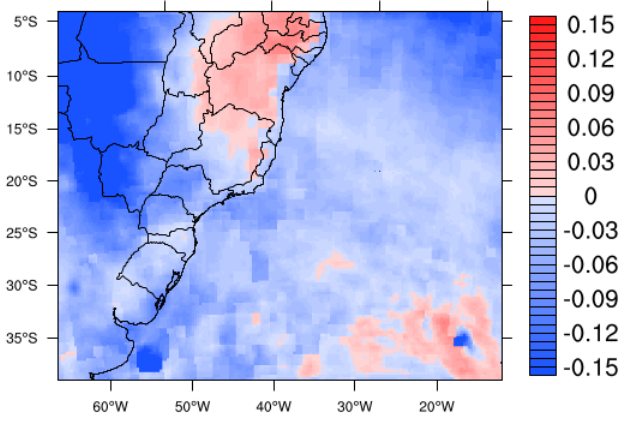

Figure 4.23: Spatial distributions of averaged AOD for (a) MODIS data, (b) BBE simulation, and (c) the difference between BBE and MODIS data. AOD data derived from the BBE simulation is compared with satellite-derived AOD (MODIS passing time approximately 15:00 UTC during wintertime) during the period from 19 August to 3 September 2014. 

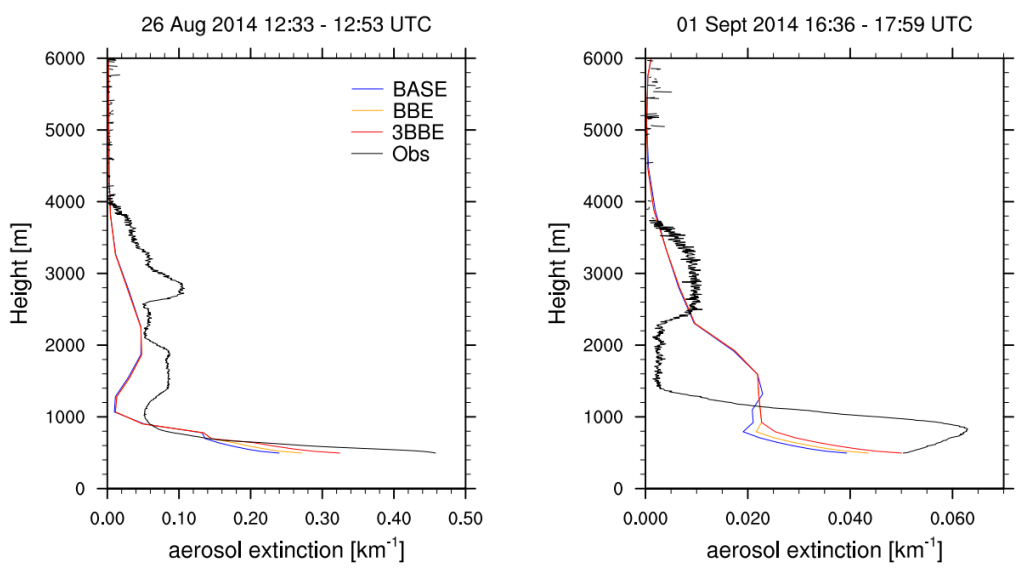

Figure 4.24: Average observed (Obs) profiles of aerosol extinction obtained by lidar at IPEN (black lines), compared with the average profiles obtained from the simulations BASE, BBE and 3BBE (blue, orange and red lines, respectively). The panels on the left and right show the comparisons of averaged profiles between 12:00 and 13:00 UTC on 26 August (no rain conditions) and between 16:00 and 18:00 UTC on 1 September (rain conditions), respectively. Winds from fire regions were favourable during both observation periods.

\subsection{Impact of different emission sources on aerosol burdens}

Period from 7 August to 6 September 2012

\subsubsection{Biomass burning emissions}

Figs. 4.12 , 4.13 and 4.14 show the impact of fire emissions on near-surface $\mathrm{PM}_{10}, \mathrm{PM}_{2.5}$ and $\mathrm{O}_{3}$ concentrations, respectively. Focusing on the fire emission contribution period, we found that fire emissions increased the concentration of fine particles and $\mathrm{O}_{3}$, reducing the $\mathrm{MB}$ and $\mathrm{NMB}$ for $\mathrm{PM}_{2.5}$, respectively, from $-1.69 \mu \mathrm{g} \mathrm{m}^{-3}$ and $-3.51 \%$ for BASE to 1.18 $\mu \mathrm{g} \mathrm{m}^{-3}$ and $3.14 \%$ for BBE, but increasing them to $6.75 \mu \mathrm{g} \mathrm{m}^{-3}$ and $17.51 \%$ for $3 \mathrm{BBE}$ (which is still within the range of NMBs expected for good performance) (see Table 4.5). However, most of the pairs (NMB, NME) for $\mathrm{PM}_{2.5}$ and $\mathrm{PM}_{10}$ were more clustered around the zero lines when compared to those from the entire study period (see Fig. 4.25). Larger contributions of fire emissions to the maximum $\mathrm{O}_{3}$ and $\mathrm{PM}_{2.5}$ concentrations may be explained by the transport of such air pollutants from fire regions (during the day for $\mathrm{O}_{3}$ and during the night for fine particles), as well as by additional in situ formation due to changes in precursor concentrations. In addition, night-time $\mathrm{O}_{3}$ concentrations deviated further from (above) the observations, indicating insufficient titration of $\mathrm{O}_{3}$ by nitrogen 
oxides (NOx). Positive $\mathrm{O}_{3} \mathrm{MB}$ and $\mathrm{NMB}$ values of $7.84 \mu \mathrm{g} \mathrm{m}^{-3}$ and $23.20 \%$, respectively, for $\mathrm{BBE}$ and of $12.72 \mu \mathrm{g} \mathrm{m}^{-3}$ and $35.84 \%$, respectively, for 3BBE, were closely related to large positive night-time biases in relation to the fire emission contribution period. In this case, insufficient titration reactions are related to underprediction of NOx emissions from biomass burning regions. The level of NOx can influence $\mathrm{O}_{3}$ mixing ratios through titration chemistry during the night and in the early morning hours (Yahya et al., 2015). In comparison with the fire emission contribution period, the period as a whole showed less noticeable performance improvements for $\mathrm{PM}_{2.5}$ and $\mathrm{O}_{3}$. It presented increases in the $\mathrm{PM}_{2.5} \mathrm{MB}$ and NMB from $1.02 \mu \mathrm{g} \mathrm{m} \mathrm{m}^{-3}$ and $4.26 \%$, respectively, for BASE to $1.87 \mu \mathrm{g} \mathrm{m}^{-3}$ and $7.37 \%$ and to $5.09 \mu \mathrm{g} \mathrm{m}^{-3}$ and $17.94 \%$, respectively, for BBE and 3BBE. Positive $\mathrm{PM}_{2.5}$ bias increases in both periods are related, not only to the inclusion of fire emissions in the simulations, but mainly to baseline bias compensation (see Fig. 4.12).

Table $4.5-\mathrm{PM}_{2.5}$ performance statistics for WRF-Chem predictions at all sites for the periods from 19 August to 3 September 2014 (ESP) and from 22 August to 26 August 2014 (FEC).

\begin{tabular}{lllllll}
\hline Index & $\mathrm{BASE}_{E S P}$ & $\mathrm{BBE}_{E S P}$ & $3_{\mathrm{BBE}} \mathrm{BAP}_{\text {OS }}$ & $\mathrm{BAEC}$ & $\mathrm{BBE}_{F E C}$ & $3 \mathrm{BBE}_{F E C}$ \\
\hline $\mathrm{SD}_{\text {Obs }}$ & 20.19 & 20.19 & 20.19 & 23.30 & 23.30 & 23.30 \\
$\mathrm{SD}_{\text {Sim }}$ & 15.61 & 16.68 & 19.61 & 18.50 & 19.67 & 21.85 \\
$\mathrm{R}$ & 0.70 & 0.71 & 0.70 & 0.81 & 0.80 & 0.79 \\
$\mathrm{RMSE}$ & 14.38 & 14.40 & 16.05 & 13.19 & 13.41 & 16.61 \\
$\mathrm{MB}$ & 1.02 & 1.97 & 5.29 & -1.69 & 1.18 & 6.75 \\
$\mathrm{MFB}$ & 18.34 & 20.59 & 26.84 & 4.56 & 10.78 & 22.50 \\
$\mathrm{MFE}$ & 51.33 & 51.66 & 53.62 & 28.97 & 30.39 & 36.57 \\
$\mathrm{NMB}$ & 4.30 & 7.87 & 18.34 & -3.51 & 3.14 & 17.51 \\
$\mathrm{NME}$ & 40.44 & 40.67 & 46.26 & 21.82 & 22.46 & 30.45 \\
\hline
\end{tabular}

ESP: entire study period; FEC: fire emission contribution (period); $\mathrm{SD}_{\mathrm{Obs}}$ : observed standard deviation; $\mathrm{SD}_{\text {Sim }}$ : simulated standard deviation; RMSE: root mean square error; MB: mean bias; MFB: mean fractional bias; MFE: mean fractional error; NMB: normalised mean bias; NME: normalised mean error.

To identify and quantify the maximum local and remote contributions with greater accuracy, time-averaged distributions of $\mathrm{EC}, \mathrm{OC}$ and $\mathrm{PM}_{2.5}$ based on the five daily $\mathrm{PM}_{2.5}$ peaks within the fire emission contribution period were calculated. Fig. 4.26 shows the temporal mean spatial distributions of absolute and relative differences of the predicted daily maximum near-surface concentrations of EC (upper panels), OC (middle panels) and 
$\mathrm{PM}_{2.5}$ (bottom panels). In line with the differences in fire emissions, the 3BBE simulation yielded higher PM impacts for the most part of the domain than the BBE simulation. In addition, the model revealed that the largest fire impacts on $\mathrm{PM}_{2.5}$, with relative differences of nearly $27 \%\left(12 \mu \mathrm{g} \mathrm{m}^{-3}\right)$ and $72 \%\left(35 \mu \mathrm{g} \mathrm{m}^{-3}\right)$, respectively, for BBE and 3BBE, were northwest and north of the MASP, within the inland portion of the state (see the deep red stain in panels $(\mathrm{j})$ and $(\mathrm{l})$ in Fig. 4.26). The larger contributions of fire emissions to $\mathrm{PM}_{2.5}$ loadings in this region are likely due to two factors. First, a large number of fire spots were identified within the region throughout the fire emission contribution period (see Fig. 3.6), leading to an increase in aerosol concentrations either directly, through the emission of aerosol particles (e.g., primary organic aerosols) or indirectly, via secondary formation due to the complex interactions between gases and aerosols released from fires and from vegetation. Second, long-range transport of pollutants from fire events occurring far inland, particularly those occurring in the northwest part of the State (relative to the area of interest), from where the winds had persistently blown toward the MASP.
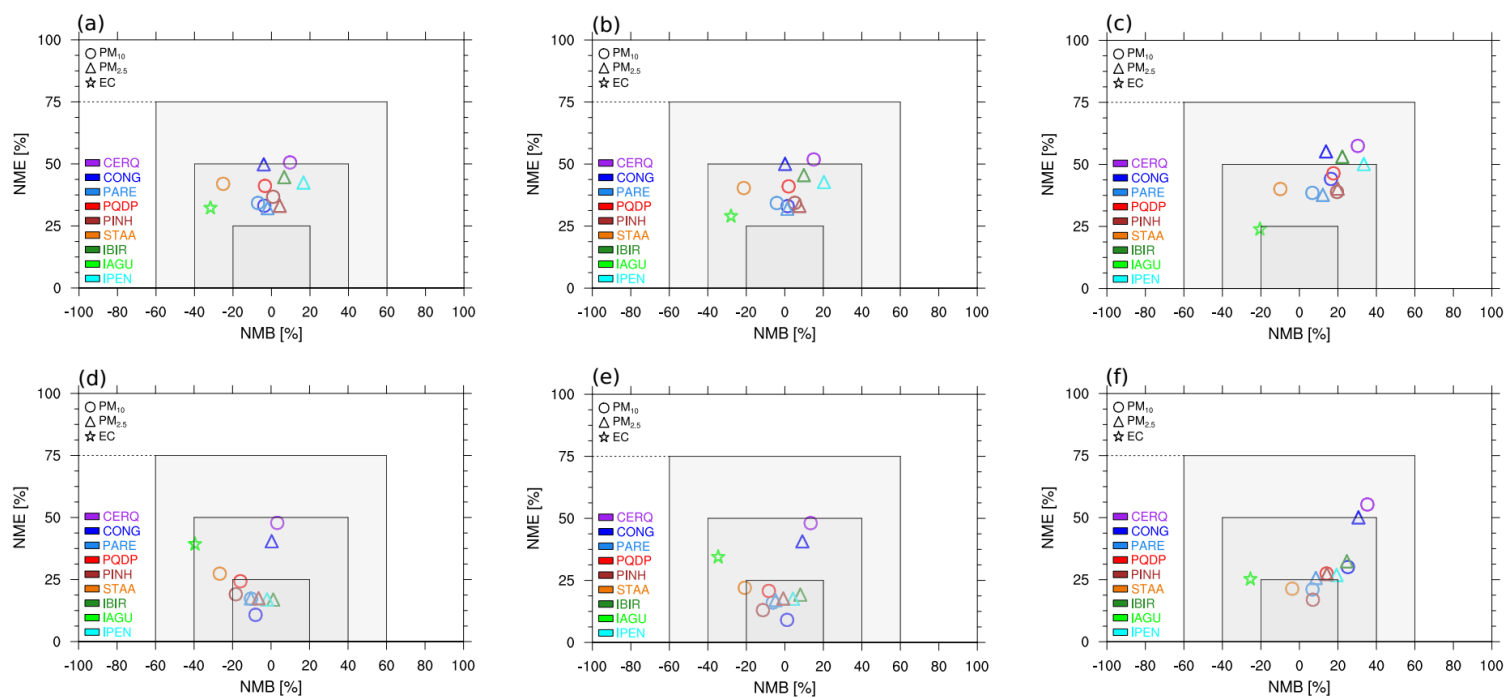

Figure 4.25: PM soccer plots (NMB vs. NME) for the simulations BASE (left), BBE (middle) and 3BBE (right) during the periods from 19 August to 3 September 2014 (upper) and from 22 August to 26 August 2014 (bottom).

As shown in Fig. 4.20, the maximum differences in the predicted PNC (BBE - BASE and $3 \mathrm{BBE}-\mathrm{BASE}$ ) for aerosol particles in the accumulation mode occurred during the fire emission contribution period, which was characterised by the transport of air pollutants from fire regions. However, the slight increases in PNC on some days during the second 
half of the period were found to be caused by gases and small particles that did not undergo dry deposition or wet scavenging during transport, as well as by new particles formed in situ from the remaining emissions. As a consequence, new CCN may arise from nucleation and subsequent growth processes.

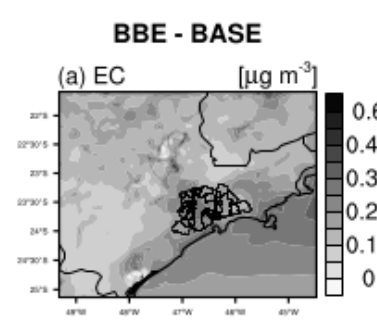

[(BBE - BASE)/BBE]*100
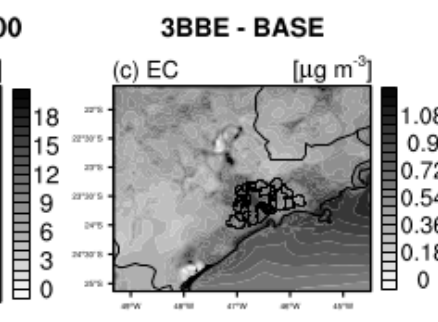

[(3BBE - BASE)/3BBE] ${ }^{*} 100$
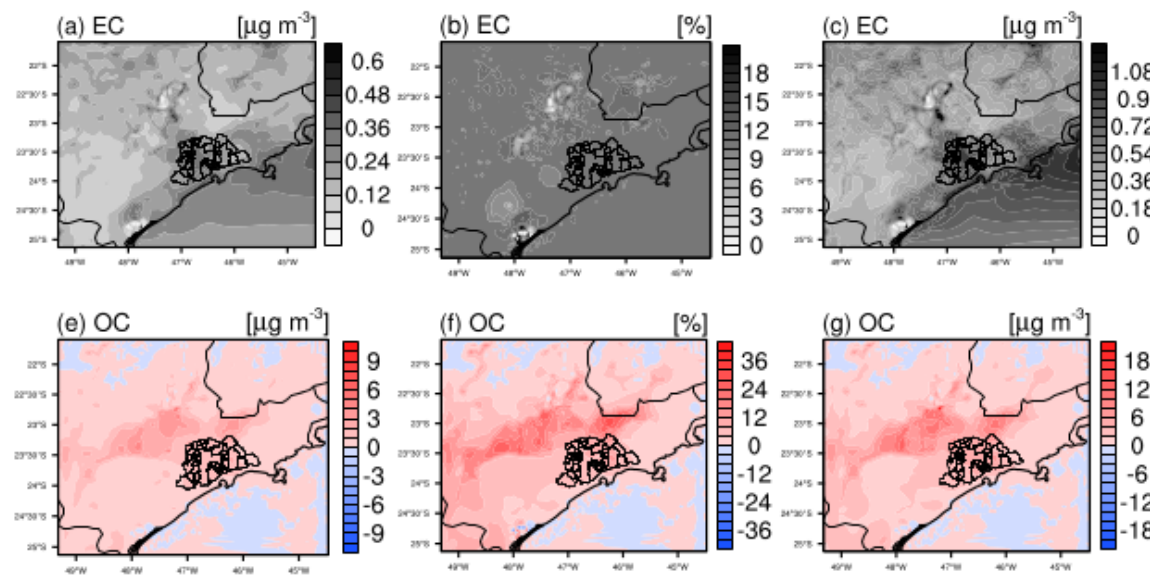

(d) EC
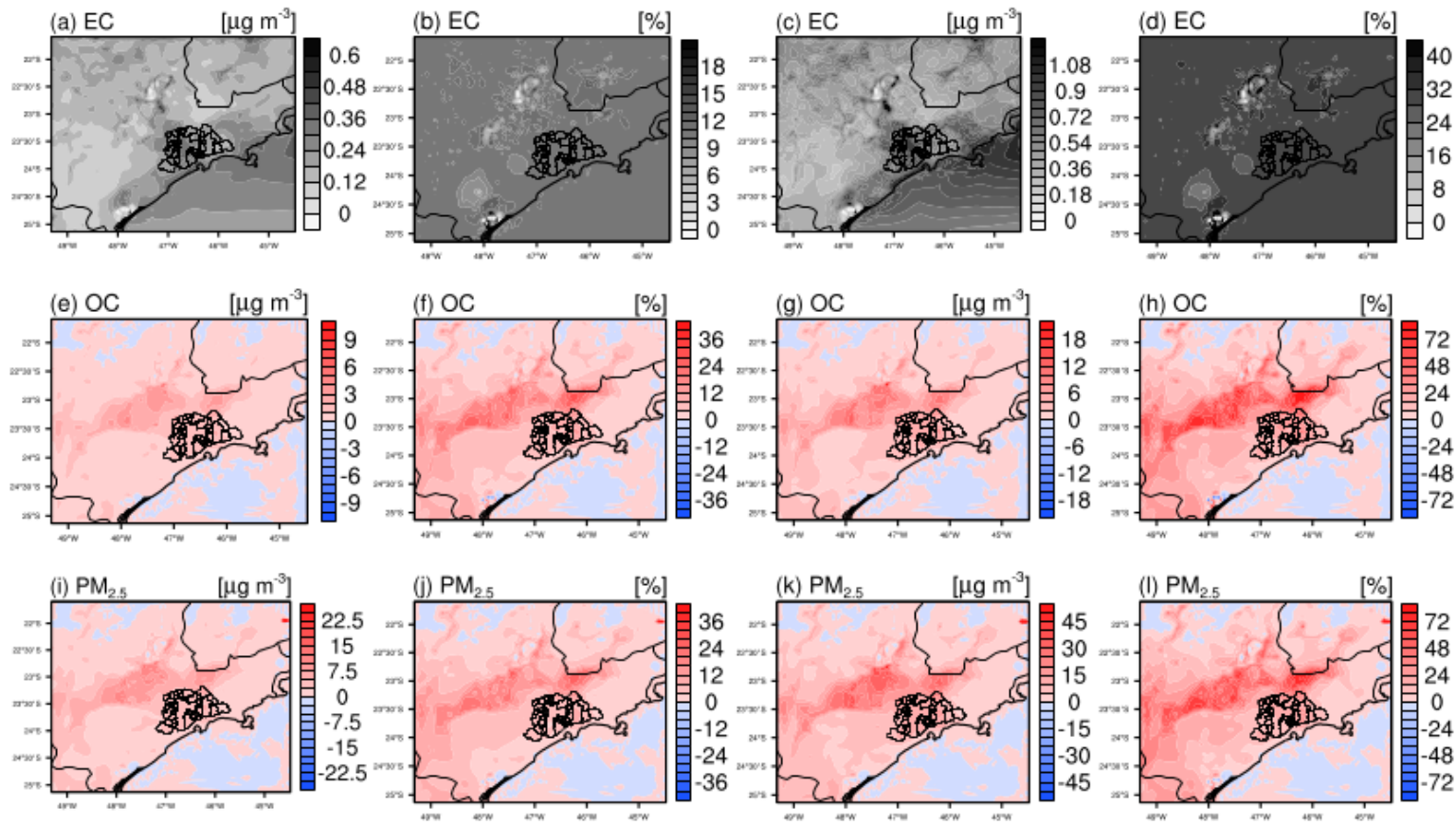

Figure 4.26: Temporal mean spatial distributions of absolute and relative differences of the predicted daily maximum near-surface concentrations of EC (upper panels), OC (middle panels) and $\mathrm{PM}_{2.5}$ (bottom panels) during the fire emission contribution period, from 22 August to 26 August 2014.

A closer look at the PNC maps for particles in the accumulation mode (ac0 in panels (a), (b), (c) and (d) in Fig. 4.27) reveals that, although larger contributions of fire emissions to $\mathrm{PM}_{2.5}$ took place some distance away from (to the northwest and north of) the MASP, their impacts on the accumulation mode PNC were found to occur primarily over the MASP, where concentrations, on the order of $900 \mathrm{~cm}^{-3}$ and $2300 \mathrm{~cm}^{-3}$ (approximately $8 \%$ and $20 \%$ of the baseline-weighted relative differences), were detected (see panels (a) and (c) in Fig. 4.27). That could be explained by in situ secondary formation processes involving pollutants originating from fire events as well as those emitted locally. The night-time chemistry of $\mathrm{NO}_{3}$, initiated by the relatively slow oxidation of $\mathrm{NO}_{2}$ by $\mathrm{O}_{3}$, is the primary process by which certain unsaturated hydrocarbons lower their vapour pressure and hence 
are converted to low-volatility compounds (Monks, 2005; Kroll and Seinfeld, 2008). Once low-volatility compounds are produced, pre-existing particles in the Aitken size range may then grow larger by condensation of those compounds onto their surfaces or by coagulation, giving rise to new particles in the accumulation mode. In polluted urban environments, $\mathrm{NO}_{3}$ can also serve as a source of organic nitrates and ammonium nitrate (Hallquist et al. 2009; Backman et al., 2012), thereby contributing to additional secondary aerosol mass. In terms of predicted OC, EC and SOA contributions to the total $\mathrm{PM}_{1}$ mass at the IAGU site, the mass percentages increased roughly in proportion to the increase of FINN particulate and ozone precursor emissions from 49.1\%, $9.3 \%$ and 12\%, respectively, for BBE to $49.6 \%$, $9.5 \%$ and $12.6 \%$, respectively, for $3 \mathrm{BBE}$.
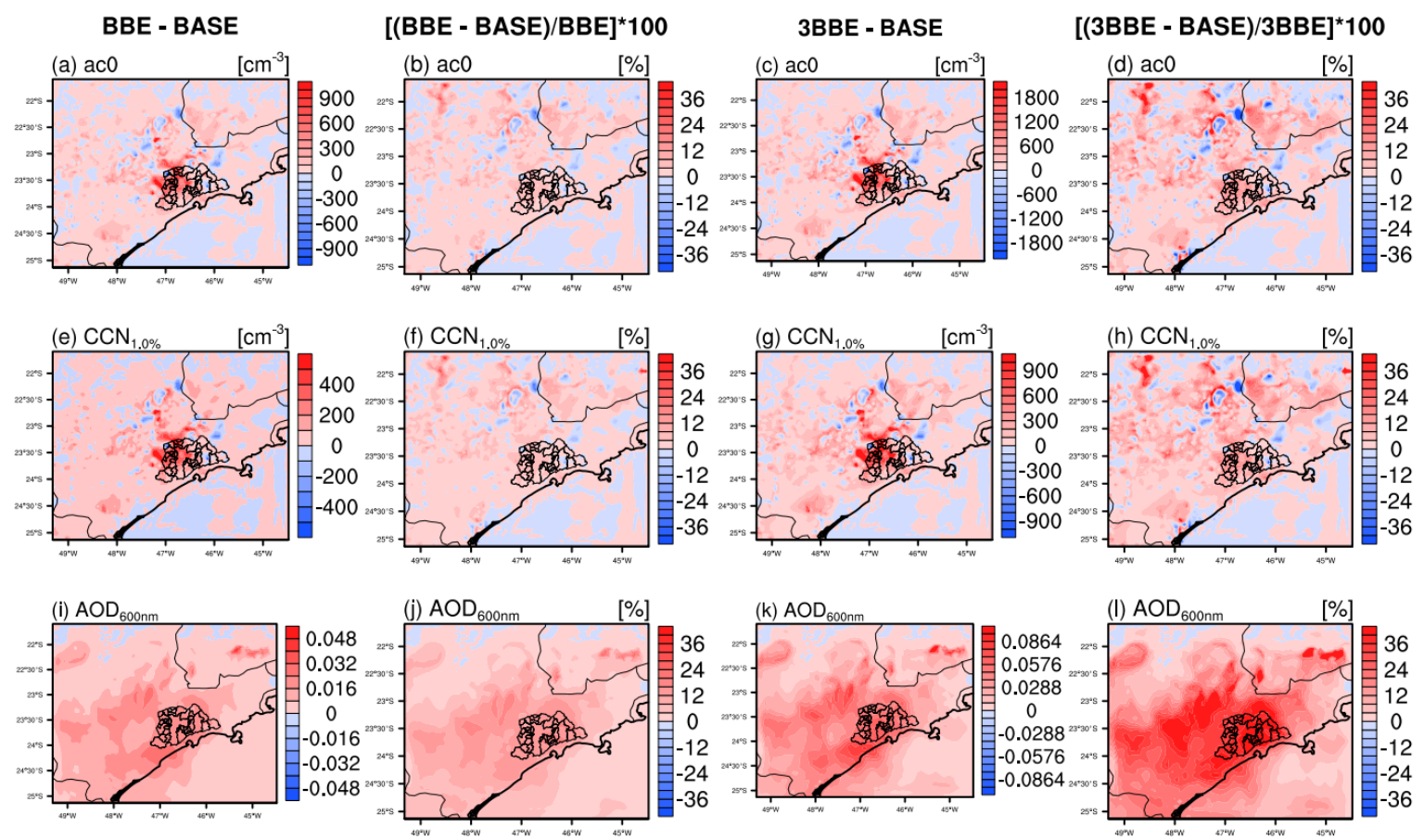

Figure 4.27: Temporal mean spatial distributions of absolute and relative differences of the predicted daily maximum concentrations of ac0 (upper panels), $\mathrm{CCN}_{1.0 \%}$ (middle panels), both at surface, and column-integrated $\mathrm{AOD}_{600 n m}$ (bottom panels) during the fire emission contribution period, from 22 August to 26 August 2014.

Predicted aerosol extinction profiles derived from the BBE and 3BBE simulations differ slightly near the surface but are overlapped at higher altitudes (see Fig.4.24). The observed and predicted profiles both show that aerosols were mostly confined to below $4 \mathrm{~km}$ in altitude. Most of the aerosols measured on 26 August were trapped and well mixed within 
Table 4.6 - WRF-Chem performance statistics for PNC (ac0), $\mathrm{CCN}_{1 \%}$ and $\mathrm{AR}_{1 \%}$ at the IAGU site for the periods from 19 August to 3 September 2014 (ESP) and from 22 August to 26 August 2014 (FEC).

\begin{tabular}{llllllll}
\hline Var & Index & BASE $_{E S P}$ & BBE $_{E S P}$ & $3 \mathrm{BBE}_{E S P}$ & $\mathrm{BASE}_{F E C}$ & $\mathrm{BBE}_{F E C}$ & $3 \mathrm{BBE}_{F E C}$ \\
\hline PNC $\left[\mathrm{cm}^{-3}\right]$ & $\mathrm{SD}_{\text {Obs }}$ & 4012.10 & 4012.10 & 4012.10 & 3657.51 & 3657.51 & 3657.51 \\
& $\mathrm{SD}_{\text {Sim }}$ & 2341.40 & 2410.26 & 2892.99 & 3024.20 & 3229.41 & 3664.66 \\
& $\mathrm{R}$ & 0.49 & 0.50 & 0.52 & 0.44 & 0.46 & 0.49 \\
& $\mathrm{RMSE}$ & 3733.46 & 3634.11 & 3493.02 & 4297.82 & 4211.12 & 4019.19 \\
& $\mathrm{MB}$ & -1133.67 & -985.87 & -806.83 & -1926.52 & -1644.02 & -1105.37 \\
$\mathrm{CCN}\left[\mathrm{cm}^{-3}\right]$ & $\mathrm{SD}$ Obs & 1519.12 & 1519.12 & 1519.12 & 1575.87 & 1575.87 & 1575.87 \\
& $\mathrm{SD}$ Sim & 1006.62 & 1072.29 & 1219.87 & 913.19 & 986.23 & 1131.71 \\
& $\mathrm{R}$ & 0.37 & 0.36 & 0.39 & 0.38 & 0.38 & 0.40 \\
& $\mathrm{RMSE}$ & 1605.32 & 1615.98 & 1637.21 & 2071.75 & 2003.35 & 1857.88 \\
& $\mathrm{MB}$ & -626.50 & -607.47 & -435.99 & -1230.86 & -1073.58 & -650.54 \\
& $\mathrm{SD}$ & 0.16 & 0.16 & 0.16 & 0.16 & 0.16 & 0.16 \\
& $\mathrm{SD}$ & 0.14 & 0.14 & 0.15 & 0.16 & 0.16 & 0.17 \\
& $\mathrm{R}$ & 0.39 & 0.42 & 0.41 & 0.40 & 0.42 & 0.42 \\
& $\mathrm{RMSE}$ & 0.18 & 0.17 & 0.17 & 0.17 & 0.17 & 0.18 \\
& $\mathrm{MB}$ & -0.05 & -0.04 & -0.03 & -0.02 & -0.02 & -0.001
\end{tabular}

ESP: entire study period; FEC: fire emission contribution (period); $\mathrm{SD}_{\text {Obs }}$ : observed standard deviation; $\mathrm{SD}_{\text {Sim }}$ : simulated standard deviation; R: correlation coefficient; RMSE: root mean square error; MB: mean bias.

the PBL, which reached a maximum altitude of $750 \mathrm{~m}$; however, the lidar system detected two additional aerosol layers above the PBL: one at 1200-2000 $\mathrm{m}$ and one at 2600-4000 m. Similarly, most of the aerosol loadings measured on 1 September were concentrated within the PBL (maximum altitude of $1100 \mathrm{~m}$ ) with a second aerosol layer above it, at 2400-3800 m. When aerosol layers are detected above the PBL during the burning season (from August to October), they may be associated with the long-range transport of particles originated mainly from biomass burning events in the central-west region of Brazil Lopes et al., 2014; Miranda et al., 2017). Larger impacts of fire emissions on AOD during the fire emission contribution period were identified not only in the same region as they did for $\mathrm{PM}_{2.5}$ but also over the southwestern part (coastal side) of the MASP, which was quite likely due to an increase in the water uptake by aerosols as well as to a redistribution of aerosols at higher altitudes (see panels (i) and (k) in Fig. 4.27). 
Although an appropriate evaluation of $\mathrm{CCN}$ activation in terms of chemical composition was not possible to perform, due to a lack of concurrent size-resolved PM composition measurements, depending on the magnitude of the fire events and wind direction, the differences in the predicted CCN (as shown in Fig. 4.21 and Fig. 4.27) suggest that OC (and hence SOA) is one of the major contributors, if not the major contributor, to CCN activation in the MASP. Previous field studies conducted around the world have shown that biomass burning events can influence the total PNC and CCN concentrations (Mallet et al., 2017), major impacts being attributable to the increased organic mass (Bougiatioti et al. 2016). Aging processes by coagulation of particles can alter the particle hygroscopicity, converting small hydrophobic particles into larger and hydrophilic ones, thus increasing the CCN activation of aerosols. Likewise, large hydrophilic particles may lower their hygroscopicity by incorporating small hydrophobic particles, leading to less activated particles. The overall impact of these interactions in WRF-Chem is primarily accounted for by the chemical composition, through the volume-weighted average hygroscopicity of each aerosol component, as coating effects are not treated in the model. In the present study, the maximum differences in the predicted CCN and PNC correlated well with each other (see panels (a) and (e) and panels (c) and (g) in Fig. 4.27). In terms of spatial distribution, the larger contributions of fire emissions during the fire emission contribution period were in the same regions as those identified for PNC (see panels (a) to (d) and panels (e) to (h) in Fig. 4.27) and were related to the formation of highly hygroscopic aerosols, mainly $\mathrm{NO}_{3}$. Over the MASP, fire emissions contributed approximately $8 \%\left(600 \mathrm{~cm}^{-3}\right)$ and $20 \%\left(1400 \mathrm{~cm}^{-3}\right)$ of the baseline $\mathrm{CCN}$-weighted relative differences, respectively, for BBE and 3BBE (see panels (f) and (h) in Fig. 4.27). Slight increases in CCN during the second half of the period likely arose from aging processes among the surviving particles, as precipitation events occurred throughout the MASP during that time.

\subsubsection{Anthropogenic emissions}

The predicted average $\mathrm{PM}_{2.5}$ (NAE): $\mathrm{PM}_{2.5}$ (BASE) ratio is shown in Fig. 4.28a. A contribution between 20 and $30 \%$ in the predicted baseline $\mathrm{PM}_{2.5}$ concentration in downtown MASP is found to correspond to the fine particles formation and transportation processes. Higher concentration ratios over the MASP surroundings (30-50\%) could be associated with more efficient biogenic emissions. Overall, it is observed that the formation efficiency 
increases towards the northwest from the ocean. In addition to having a more efficient production of fine particles from biogenic emissions, deep red areas in Fig. $4.28 \mathrm{a}$ could also be associated with the transportation of fine particles and gases from other regions. Additionally, the comparison between the predicted and observed OC and EC concentrations at IAGU, shown in Fig. 4.11, includes the NAE simulation in which only emission of primary gases is taken into account in the assessment of fine particles formation. The concentration peaks observed at the beginning and at the end of the study period may be associated with the transport of aerosol particles from both biomass and fossil fuel burning areas. Considering the NAE simulation, we can observe very low concentrations for EC (mean concentration of $0.01 \mu \mathrm{g} \mathrm{m}^{-3}$ ), as expected. This is because these particles are not produced by photochemical processes in the atmosphere, but associated mainly with the diesel exhaust.
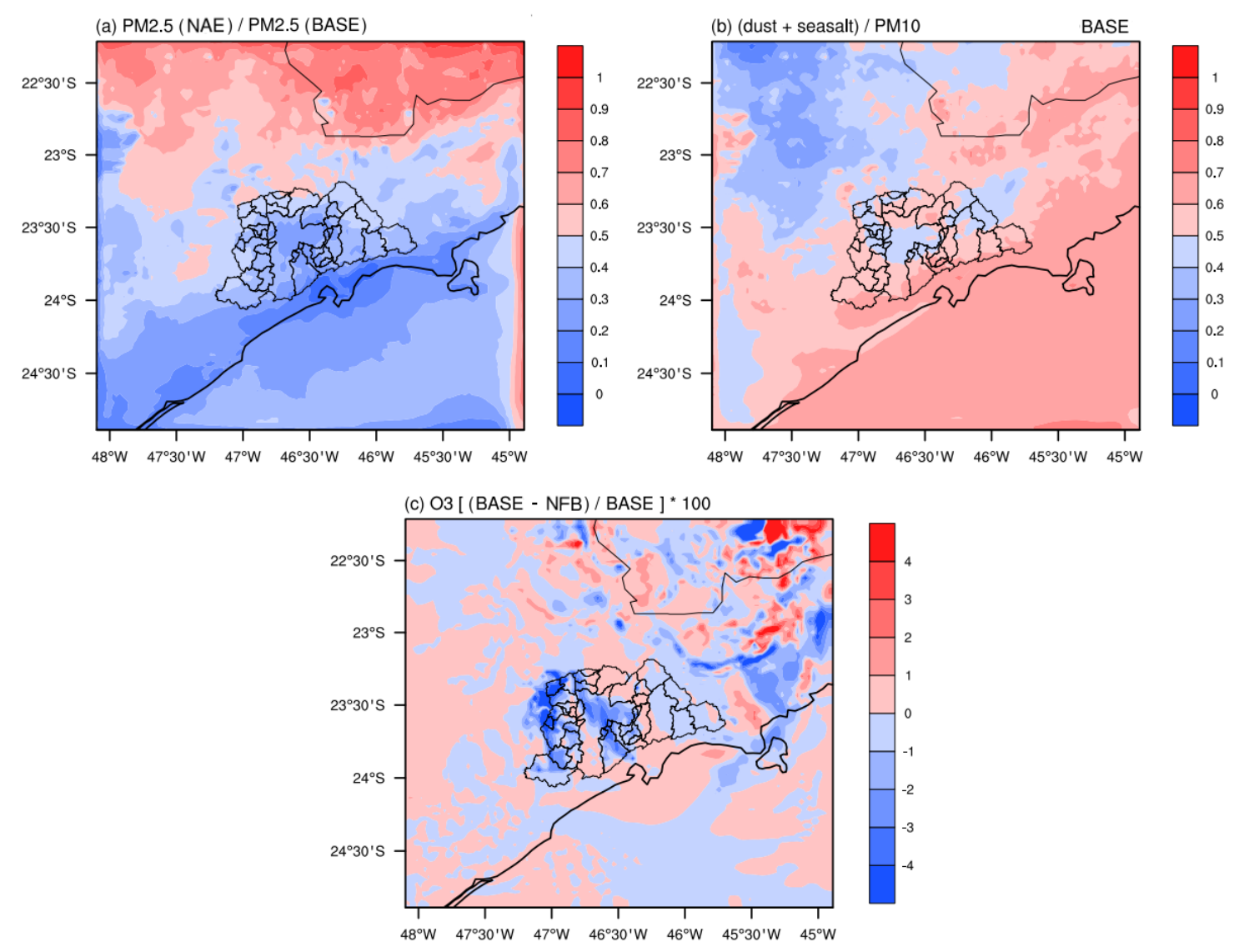

Figure 4.28: The impact of (a) emissions of primary gases on the fine particles formation, (b) emissions of dust-sea salt aerosols on the $\mathrm{PM}_{10}$ concentration, and (c) aerosol direct effect on the ground level $\mathrm{O}_{3}$ concentrations at 16:00 h (local time). 


\subsubsection{Dust and sea salt emissions}

The evaluation of the contribution of dust and sea salt aerosols on $\mathrm{PM}_{10}$ concentration is performed from the sum of their concentrations divided by the $\mathrm{PM}_{10}$ concentration. The simulated average ratio between dust-sea salt aerosols and the total $\mathrm{PM}_{10}$ mass concentration is shown in Fig. $4.28 \mathrm{~b}$. High concentration ratios have been observed over the ocean where sea salt emissions are by far the most important aerosols source. Unlike high concentration ratios over the ocean, lower concentration ratios are observed over the continent far away from the coast. In this region, the main sources of atmospheric aerosols would be the emission of primary biological aerosol, SOA formed from the emission of biogenic volatile organic compounds (BVOCs), and forest fires. However, particles could also be transported from remote areas. In addition, we can also observe that dust and sea salt aerosols have a contribution between 40 and $50 \%$ of the total $\mathrm{PM}_{10}$ concentration in the downtown MASP. Furthermore, it is possible to estimate the contribution of all the other $\mathrm{PM}_{10}$ (i.e., the coarse anthropogenic aerosol) to the total $\mathrm{PM}_{10}$ mass concentration. It may be directly calculated from the model or estimated from the Figs. 4.10 and $4.28 \mathrm{~b}$ once the sum of concentrations of $\mathrm{PM}_{2.5}$, dust and sea salt, and coarse anthropogenic aerosol represents $100 \%$ of the total $\mathrm{PM}_{10}$ mass concentration. For example, we found that the coarse anthropogenic aerosol represents around $10 \%$ of $\mathrm{PM}_{10}$ in the downtown MASP.

\subsection{Aerosol impact on $\mathrm{O}_{3}$ photochemistry}

Ozone photochemistry production mainly depends on the two photolysis rates, as shown in Eqs. (4.2) and (4.3), i.e., shortwave radiation able to reach the surface to break molecules of $\mathrm{O}_{3}$ and $\mathrm{NO}_{2}$.

$$
\begin{gathered}
\mathrm{O}_{3}+h \nu \stackrel{\lambda<320 \mathrm{~nm}}{\longrightarrow} O_{3}+O\left({ }^{1} D\right) \\
N_{2}+h \nu \stackrel{\lambda<420 \mathrm{~nm}}{\longrightarrow} N O+O\left({ }^{3} P\right)
\end{gathered}
$$

Therefore, the impact of aerosols on $\mathrm{O}_{3}$ photochemistry has been evaluated from the impact of aerosols on downward shortwave radiation. Attenuation (scattering and absorption) of downward shortwave radiation by aerosols may substantially modify the photolysis 
rates, and thereby affecting the ozone photochemistry production.

The average percentage change in surface $\mathrm{O}_{3}$ concentrations at 16:00 h (local time) with and without the aerosol-radiation feedback module turned on are shown Fig. 4.28. Overall, $\mathrm{O}_{3}$ is destroyed or formed in small quantities between -1 and $+1 \%$ in relation to its total concentration. In addition, it was observed that surface $\mathrm{O}_{3}$ concentration decreased by around $2 \%$ in the downtown MASP. Li et al. (2011b) found that the impact of aerosols on $\mathrm{O}_{3}$ formation in Mexico City was most pronounced in the morning with the $\mathrm{O}_{3}$ reduction of $5-20 \%$, but the reduction is less than $5 \%$ in the afternoon. Low reductions in the $\mathrm{O}_{3}$ concentration in the downtown MASP compared to results from other studies may be explained by the lower predicted $\mathrm{PM}_{10}$ concentrations, which can lead to a minor attenuation of the incoming solar radiation. Simulated mean downward shortwave fluxes at ground surface (not shown) were up to $5 \%$ higher for the NFB than for the BASE during the afternoon. The inclusion of aerosol direct effect led to small reductions in the surface temperature (changes by around $2 \%$ ), presumably due to an increase in the number of atmospheric processes involving downward longwave fluxes over this area. Forkel et al. (2012) found an underestimation of predicted downward longwave radiation over the southern Baltic Sea when the direct effect of aerosol particles was neglected. Despite the highly non-linear behavior of tropospheric $\mathrm{O}_{3}$, the reduction in the predicted $\mathrm{O}_{3}$ concentrations indicates a high efficiency of aerosols to attenuate the downward shortwave radiation, what is plausible once it was found that low $\mathrm{PM}_{10}$ concentrations have a capability to reduce ground level $\mathrm{O}_{3}$ concentrations around $2 \%$ in the downtown MASP. 
Chapter 5

\section{Summary and Conclusions}

For the first time, aerosol data derived from a fully coupled meteorology-chemistryaerosol model, in synergy with an extensive set of measurements of aerosol properties, were used to investigate the evolution and properties of atmospheric aerosol particles over the Metropolitan Area of São Paulo (MASP), the largest metropolitan area in South America. To that end, two sets of nested simulations using the Weather Research and Forecasting with Chemistry (WRF-Chem) community model were carried out covering the periods from 7 August to 6 September 2012 and from 19 August to 3 September 2014. Model results were evaluated against available ground-, satellite- and lidar-based measurements from the Narrowing the Uncertainties on Aerosol and Climate Change in São Paulo State (NUANCE-SPS) campaigns. The NUANCE-SPS campaigns, coordinated by the Institute of Astronomy, Geophysics and Atmospheric Sciences of the University of São Paulo (IAGUSP) and carried out over the MASP between 2011 and 2015, aimed to improve the current knowledge of chemistry and transport processes of the pollutants emitted in the MASP and in other areas of the São Paulo State.

Overall, the comparisons show that the model qualitatively captured most of the observed variations and trends in meteorological conditions, as well as the observed concentrations of chemical species throughout the study periods. However, although predicted particulate matter species and $\mathrm{O}_{3}$ were found to agree well with the observations in terms of temporal variations and trends $(\mathrm{R}>0.6$ in most cases), the maximum concentrations were often underestimated, probably due to uncertainties in the emissions inventories as well as to inaccuracies in meteorological parameters prediction.

The results derived from the first case study, from 7 August to 6 September 2012, indicate that the emissions of primary gases coming mainly from on-road vehicles have a 
potential to form new particles between 20 and $30 \%$ in relation to the total $\mathrm{PM}_{2.5}$ mass, whereas dust and sea salt aerosols contributed between 40 and $50 \%$ of the total $\mathrm{PM}_{10}$ mass found in the downtown MASP. Over the same period, it was found a reduction in the surface $\mathrm{O}_{3}$ concentration by around $2 \%$ in the afternoon (16:00; local time) when the aerosol-radiation feedback is taken into account in the simulations.

Although the meteorological conditions during the second study period, from 19 August to 3 September 2014, were not generally favourable for long-range transport into the MASP, a five-day transport event from 22 August to 26 August, referred to throughout the text as the fire emission contribution period (FEC), was studied in detail in order to investigate further the influence of biomass burning on aerosol properties over this area. This transport event would have brought elevated gas and aerosol concentrations from fire regions when the favourable meteorological conditions and fire events coincided. However, according to model results, biomass burning, on average, accounted for 8-24 \% (5-15 $\mu \mathrm{g}$ $\left.\mathrm{m}^{-3}\right)$ of $\mathrm{PM}_{2.5}$ and for $15-32 \%\left(12-26 \mu \mathrm{g} \mathrm{m}^{-3}\right)$ of $\mathrm{O}_{3}$, suggesting that air pollutant levels depend largely on local emissions. The model also revealed that the largest fire impacts on $\mathrm{PM}_{2.5}$, with relative differences of 27-72\% (10-35 $\left.\mu \mathrm{g} \mathrm{m}^{-3}\right)$, took place northwest and north of the MASP, within the inland portion of the state. In contrast, we found that the largest impacts on particle number concentration (PNC) did not take place within the same area as they did for $\mathrm{PM}_{2.5}$; rather, maximum concentration differences were detected over the MASP. As a consequence, new cloud condensation nuclei (CCN) arose in the same area. Biomass burning accounted for approximately 8-20\% of the PNC- and CCN-weighted relative differences over the MASP: $900-2300 \mathrm{~cm}^{-3}$ and $600-1400 \mathrm{~cm}^{-3}$, respectively. Despite the fact that small signs of fire emissions were seen over the MASP (mostly weak fire events occurring during the fire emission contribution period), we can conclude that the impacts of air pollutants resulting from fire events are dependent on the magnitude of those events, not only for $\mathrm{PM}_{2.5}$ and $\mathrm{O}_{3}$ but also for the formation of CCN.

\subsection{Final statement and suggestions for future works}

This study provides a first step to understand the impact of on-road vehicle emissions and biomass burning on the particles formation over the MASP. There, the WRF-Chem model proved to be a powerful tool in simulating air quality and can be used for evaluating 
public policies in terms of changing and reducing air pollution sources. Nevertheless, more experimental campaigns are recommended for future work in order to characterise aerosols in ambient air and to improve their emission estimates so that a better understanding of physical and chemical properties can be established. Recent WRF-Chem model versions that simulate the atmospheric aerosol formation and cloud droplet activation processes more realistically, together with aerosol data derived from high-resolution satellite products, can also be used to further improve the knowledge of aerosol formation mechanisms in MASP. 


\section{Bibliography}

Abdul-Razzak H., Ghan S. J., A parameterization of aerosol activation: 2. Multiple aerosol types, J. Geophys. Res., 2000, vol. 105, p. 6837

Ackermann I. J., Hass H., Memmesheimer M., Ebel A., Binkowski F. S., Shankar U., Modal aerosol dynamics model for Europe: development and first applications, Atmos. Environ., 1998, vol. 32, p. 2981

Ahmadov R., McKeen S. A., Robinson A. L., Bahreini R., Middlebrook A. M., Gouw J. A. D., Meagher J., Hsie E. Y., Edgerton E., Shaw S., Trainer M., A volatility basis set model for summertime secondary organic aerosols over the eastern United States in 2006, J. Geophys. Res., 2012, vol. 117, D06301, p. doi:10.1029/2011JD016831

Albuquerque T. T. A., Formação e transporte das partículas finas inorgânicas em uma atmosfera urbana: o exemplo de São Paulo, Department of Atmospheric Sciences, University of São Paulo, 2010, Tese de Doutorado, 187 p.

Albuquerque T. T. A., Andrade M. F., Ynoue R. Y., Characterization of atmospheric aerosols in the city of São Paulo, Brazil: comparisons between polluted and unpolluted periods, Water Air Soil Poll., 2012, vol. 195, p. 201

Almeida G. P., Brito J., Morales C. A., Andrade M. F., Artaxo P., Measured and modelled cloud condensation nuclei (CCN) concentration in São Paulo, Brazil: the importance of aerosol size-resolved chemical composition on CCN concentration prediction, Atmos. Chem. Phys., 2014, vol. 14, p. 7559

Andrade M. F., Fornaro A., Miranda R. M., Kerr A., Oyama B., Andre P. A., Saldiva 
P., Vehicle emissions and $\mathrm{PM}_{2.5}$ mass concentrations in six Brazilian cities, Air Qual. Atmos. Health, 2012, vol. 5, p. 79

Andrade M. F., Kumar P., Freitas E. D., Ynoue R. Y., Martins J., Martins L. D., Nogueira T., Perez-Martinez P., Miranda R. M., Albuquerque T., Gonçalves F. L. T., Oyama B., Zhang Y., Air quality in the megacity of São Paulo: Evolution over the last 30 years and future perspectives, Atmospheric Environment, 2017, vol. 159, p. 66

Andrade M. F., Ynoue R. Y., Freitas E. D., Todesco E., Vara-Vela A., Ibarra S., Martins L. D., Martins J. A., Carvalho V. S. B., Air quality forecasting system for Southeastern Brazil, Front. Environ. Sci., 2015, vol. 3, p. 1

Angström A., On the atmospheric transmission of Sun radiation and on dust in the air, Geogr. Ann., 1929, vol. 11, p. 156

Arakawa A., Computational design for long-term numerical integration of the equations of fluid motion: Two-dimensional incompressible flow. Part 1, J. Comput. Phys., 1966, vol. 1 , p. 119

Archer-Nicholls S., Evaluated developments in the WRF-Chem model; comparison with observations and evaluation of impacts, Engineering and Physical Sciences, University of Manchester, 2014, Tese de Doutorado, 292 p.

Archer-Nicholls S., Lowe D., Darbyshire E., Morgan W. T., Bela M. M., Pereira G., Trembath J., Kaiser J. W., Longo K. M., Freitas S. R., Coe H., McFiggans G., Characterising Brazilian biomass burning emissions using WRF-Chem with MOSAIC sectional aerosol, Geosci. Model Dev., 2015, vol. 8, p. 549

Backman J., Rizzo L. V., hakala J., Nieminen T., Manninen H. E., Morais F., Aalto P. P., Siivola E., Carbone S., Hillamo R., Artaxo P., Virkkula A., Petaja T., Kulmala M., On the diurnal cycle of urban aerosols, black carbon and the occurrence of new particle formation events in springtime São Paulo, Brazil, Atmos. Chem. Phys., 2012, vol. 12, p. 11733

Barnard J. C., Fast J. D., Paredes-Miranda G., Arnott W. P., Laskin A., Technical Note: Evaluation of the WRF-Chem "Aerosol Chemical to Aerosol Optical Properties" Module using data from the MILAGRO campaign, Atmos. Chem. Phys., 2010, vol. 10, p. 7325 
Barth M., Pfister G., Wiedinmyer C., Emmons L., Kumar R., Biogenic, Fire, Lightning Emissions and Chemical Boundary Conditions. Atmospheric Chemistry Observations \& Modeling, Boulder, Colo, 2015

Binkowski F. S., Shankar U., The regional particulate model, 1. Mode description and preliminary results, Journal of Geophysical Research, 1995, vol. 100, p. 26191

Birch M. E., Cary R. A., Elemental carbon-based method for occupational monitoring of particulate diesel exhaust: methodology and exposure issues, Aerosol Sci. Tech., 1996, vol. 25 , p. 221

Bohren C. Z., Huffman D. R., Absorption and Scattering of Light by Small Particles. Wiley Press, New York, USA, 1983

Bond T. C., Bergstrom R. W., Light absorption by carbonaceous particles: An investigative review, Aerosol Sci. Tech., 2006, vol. 40, p. 27-67

Boucher O., Randall D., Artaxo P., Bretherton C., Feingold G., Forster P., Kerminen V. M., Kondo Y., Liao H., Lohmann U., Rasch P., Satheesh S. K., Sherwood S., Stevens B., Zhang X. Y., Clouds and Aerosols. In: Climate Change 2013: The Physical Science Basis. Contribution of Working Group I to the Fifth Assessment Report of the Intergovernmental Panel on Climate Change [T. F. Stocker, D. Qin, G.-K. Plattner, M. Tignor, S. K. Allen et al. (eds.)], Cambridge University Press, Cambridge, United Kingdom and New York, NY, USA, 2013

Bougiatioti A., Bezantakos S., Stavroulas I., Kalivitis N., Kokkalis P., Biskos G., Mihalopoulos N., Papayannis A., Nenes A., Biomass-burning impact on CCN number, hygroscopicity and cloud formation during summertime in the eastern Mediterranean, Atmos. Chem. Phys., 2016, vol. 16, p. 7389

Boylan J. W., Russell A. G., PM and light extinction model performance metrics, goals, and criteria for three-dimensional air quality models, Atmospheric Environment, 2006, vol. 40 , p. 4946

Brito J., Rizzo L. V., Herckes P., Vasconcellos P. C., Caumo S. E. S., Fornaro A., Ynoue R. Y., Artaxo P., Andrade M. F., Physical-chemical characterisation of the particulate 
matter inside two road tunnels in the São Paulo Metropolitan Area, Atmos. Chem. Phys., 2013, vol. 13, p. 12199

CETESB Relatório Anual de Qualidade do Ar no Estado de Sao Paulo 2017. Série Relatórios/Secretaria do Estado do Meio Ambiente, São Paulo, 2018

Chang J. S., Binkowki F. S., Seaman N. L., McHenry J. N., Samson P. J., Stockwell W. R., Walcek C. J., madronich S., Middleton P. B., Pleim J. E., Lansford H. H., The regional acid deposition model and engineering model, State-of-Science/Technology, Report 4, National Acid Precipitation Assessment Program. Washington, DC, 1989

Chapman E. G., Jr. W. I. G., Easter R. C., Barnard J. C., Ghan S. J., Pekour M. S., Fast J. D., Coupling aerosol-cloud-radiative processes in the WRF-Chem model: Investigating the radiative impact of elevated point sources, Atmos. Chem. Phys., 2009, vol. 9, p. 945

Che H. C., Zhang X. Y., Zhang L., Wang Y. Q., Zhang Y. M., Shen X. J., Ma Q. L., Sun J. Y., Zhong J. T., Prediction of size-resolved number concentration of cloud condensation nuclei and long-term measurements of their activation characteristics, Scientific Reports, 2017, vol. 7, 5819, p. doi:10.1038/s41598

Chen F., Dudhia J., Coupling an advanced land surface-hydrology model with the Penn State-NCAR MM5 modeling system, Part I: Model implementation and sensitivity, Mon. Wea. Rev., 2001, vol. 129, p. 569

Chou M. D., Suarez M. J., An efficient thermal infrared radiation parameterization for use in general circulation models, NASA Tech. Memo., 1994, vol. 104606, 3

Courant R., Fredrichs K. O., Lewy H., Uber die Differenzengleichungen der Mathematischen Physik, Math. Ann., 1928, vol. 100, p. 32-74

Davies H. C., A lateral boundary formulation for multi-level prediction models, Quarterly Journal of the Royal Meteorological Society, 1976, vol. 102, p. 405

Donahue N. M., Robinson A. L., Stanier C. O., Pandis S. N., Coupled partitioning, dilution, and chemical aging of semivolatile organics, Environmental Science and Technology, 2006, vol. 40, p. 2635-2643 
Easter R. C., Ghan S. J., Zhang Y., Saylor R. D., Chapman E. G., Laulainen N. S., Abdul-Razzak H., Leung L. R., Bian X., Zaveri R. A., MIRAGE: model description and evaluation of aerosols and trace gases, J. Geophys. Res.-Atmos., 2004, vol. 109, D20210, p. doi:10.1029/2004JD004571

Elleman R. A., Covert D. S., Aerosol size distribution modeling with the Community Multiscale Air Quality modeling system in the Pacific Northwest: 1. Model comparison to observations, J. Geophys. Res., 2009, vol. 114,D11206, p. doi:10.1029/2008JD010791

EPA, Guidance on the Use of Models and Other Analyses for Demonstrating Attainment of Air Quality Goals for Ozone, PM2.5, and Regional Haze. U.S. Environmental Protection Agency, Research Triangle Park, NC, 2007

Fast J. D., Gustafson W. I., Easter R. C., Zaveri R. A., Barnard J. C., Chapman E. G., Grell G. A., Peckham S. E., Evolution of ozone, particulates, and aerosol direct radiative forcing in the vicinity of Houston using a fully coupled meteorologychemistry-aerosol module, Journal of Geophysical Research, 2006, vol. 111, D21305, p. doi:10.1029/2005JD006721

Finlayson-Pitts B. J., Pitts J. N., Chemistry of the Upper and Lower Atmosphere: Theory, Experiments, and Applications. Academis Press, Cambridge, MA, USA, 2000

Forkel R., Werhahn J., Hansen A. B., McKeen S., Peckham S., Grell G., Suppan P., Effect of aerosol-radiation feedback on regional air quality - A case study with WRF/Chem, Atmospheric Environment, 2012, vol. 53, p. 202

Freitas S. R., Longo K. M., Chatfiled R., Latham D., Dias M. A. F. S., Andreae M. O., Prins E., Santos J. C., Gielow R., Jr J. A. C., Including the sub-grid scale plume rise of vegetation fires in low resolution atmospheric transport models, Atmos. Chem. Phys., 2007, vol. 7, p. 3385

Gelencser A., Hoffer A., Kiss G., Tombacz E., Kurdi R., Bencze L., In-situ Formation of Light-Absorbing Organic Matter in Cloud Water, Journal of Atmospheric Chemistry, 2003, vol. 45 , p. 25

Ginoux P., Chin M., Tegen I., Prospero J. M., Holben B., Dubovik O., Lin S.-. J., Sources 
and distributions of dust aerosols simulated with the GOCART model, Journal of Geophysical Research, 2001, vol. 106, p. 255

Gong S. L., A parameterization of sea-salt aerosol source function for sub- and super-micron particles, Global Biogeochemical Cycles, 2003, vol. 17, p. doi:10.1029/2003GB002079

GrEC Relatório climatológico mensal, monitoramento climático para o Brasil: Set/2012. Grupo de Estudos Climáticos, São Paulo, Brazil, 2012a

GrEC Relatório climatológico mensal, previsão climática para o Brasil: Set-Out-Nov/2012. Grupo de Estudos Climáticos, São Paulo, Brazil, 2012b

Grell G. A., Devenyi D., A generalized approach to parameterizing convection combining ensemble and data assimilation techniques, Geophys. Res. Lett., 2002, vol. 29(14)

Grell G. A., Freitas S. R., Stuefer M., Fast J., Inclusion of biomass burning in WRF-Chem: impact of wildfires on weather forecasts, Atmos. Chem. Phys., 2011, vol. 11, p. 5289

Grell G. A., Peckham S. E., Schmitz R., McKeen S. A., Wilczak J., Eder B., Fully coupled "online" chemistry within the WRF model, Atmos. Environ., 2005, vol. 39, p. 6957

Guenther A., Karl T., Harley P., Wiedinmyer C., Palmer P. I., Geron C., Estimates of global terrestrial isoprene emissions using MEGAN (Model of Emissions of Gases and Aerosols from Nature), Atmos. Chem. Phys., 2006, vol. 6, p. 3181

Guenther A., Zimmerman P., Wildermuth M., Natural volatile organic compound emission rateestimates for US woodland landscapes, Atmos. Environ., 1994, vol. 28, p. 1197

Guenther A. B., Zimmerman P. R., Harley P. C., Monson R. K., Fall R., Isoprene and monoterpene emission rate variability: model evaluations and sensitivity analyses, Journal of Geophysical Research, 1993, vol. 98D, p. 12609

Gustafson W. I., Chapman E. G., Ghan S. J., Easter R. C., Impact on modelled cloud characteristics due to simplified treatment of uniform cloud condensation nuclei during NEAQS 2004, Geophys. Res. Lett., 2007, vol. 34, L19809, p. doi:10.1029/2007GL030021

Hallquist M., Wenger J. C., Baltensperger U., Rudich Y., Simpson D., Claeys M., Dommen J., Donahue N. M., George C., Goldstein A. H., Hamilton J. F., Hemmann H., Hoffmann 
T., Iinuma Y., jang M., Jenkin M. E., Jimenez J. L., Kiendler-Scharr A., Maenhaut W., McFiggans G., The formation, properties and impact of secondary organic aerosol: current and emerging issues, Atmos. Chem. Phys., 2009, vol. 9, p. 5155

Hartmann D. L., Klein-Tank A. M. G., Rusticucci M., Alexander L. V., Bronnimann S., Charabi Y., Dentener F. J., Dlugokencky F. J., Easterling D. R., Kaplan A., Soden B. J., Thorne P. W., Wild M., Zhai P. M., Observations: Atmosphere and Surface. In: Climate Change 2013: The Physical Science Basis. Contribution of Working Group I to the Fifth Assessment Report of the Intergovernmental Panel on Climate Change [T. F. Stocker, D. Qin, G. K. Plattner, M. Tignor, S. K. Allen, J. Boschung, A. Nauels, Y. Xia, V. Bex and P. M. Midgley (eds.)]. Cambridge University Press, Cambridge, United Kingdom and New York, NY, USA, 2013

Henry W., Experiments on the quantity of gases absorbed by water, at different temperatures, and under different pressures, Phil. Trans. R. Soc. Lond., 1803, vol. 93, p. $29-274$

Hoelzemann J. J., Longo K. M., Fonseca R. M., do Rosario N. M. E., Elbern H., Freitas S. R., Pires C., Regional representativity of AERONET observation sites during the biomass burning season in South America determined by correlation studies with MODIS Aerosol Optical Depth, Journal of Geophysical Research, 2009, vol. 114, D13301, p. doi:10.1029/2008JD010369

Hong S. Y., Noh Y., Dudhia J., A new vertical diffusion package with an explicit treatment of entrainment processes, Mon. Wea. Rev., 2006, vol. 134, p. 2318

Hoshyaripour G., Brasseur G., Andrade M. F., Gavidia-Calderon M., Bouarar I., Ynoue R. Y., Prediction of ground-level ozone concentration in São Paulo, Brazil: Deterministic versus statistic models, Atmospheric Environment, 2016, vol. 145, p. 365

Husar R. B., Whitby K. T., Liu B. Y. H., Physical Mechanisms Governing the Dynamics of Los Angeles Smog Aerosol, J. Colloid Interface Sci., 1972, vol. 39, p. 211

Iacono M. J., Delamere J. S., Mlawer E. J., Shephard M. W., Clough S. A., Collins W. D., Radiative forcing by long-lived greenhouse gases: Calculations with the AER 
radiative transfer models, Journal of Geophysical Research, 2008, vol. 113, D13103, p. doi:10.1029/2008JD009944

IBGE, Estimativas da população residente no Brasil e unidades da federação com data de referência em 1 de julho de 2018. Instituto Brasileiro de Geografia e Estatística, São Paulo, 2018

Ichoku C., Kahn R., Chin M., Satellite contributions to the quantitative characterization of biomass burning for climate modeling, Atmospheric Research, 2012, vol. 111, p. 1

Jacobson M. Z., Fundamentals of Atmospheric Modeling. Cambridge University Press, New York, USA, 2005

Jaecker-Voirol A., Mirabel P., Reiss H., Hydrates in supersaturated binary sulphuric acidwater vapor: A reexamination, J. Chem. Phys., 1987, vol. 87, p. 4849

Janssens-Maenhout G., Crippa M., Guizzardi D., Dentener F., Munteau M., Pouliot G., Keating T., Zhang Q., Kurokawa J., Wankmuller R., der Gon H. D. V., Kuenen J. J. P., Klimont Z., Frost G., Darras S., Koffi B., Li M., HTAP_v2.2: a mosaic of regional and global emission grid maps for 2008 and 2010 to study hemispheric transport of air pollution, Atmos. Chem. Phys., 2015, vol. 15, p. 11411

Jiménez P. A., Dudhia J., González-Rouco J. F., Navarro J., Montávez J. P., GarcíaBustamante E., A Revised Scheme for the WRF Surface Layer Formulation, Mon. Wea. Rev., 2012, vol. 140, p. 898

Jones S., Creighton G., AFWA dust emission scheme for WRF/Chem-GOCART. In: 2011 WRF Workshop, June 20-24, Boulder, CO, 2011

Kanakidou M., Seinfeld J. H., Pandis S. N., Barnes I., Dentener F. J., Facchini M. C., Dingenen R. V., Ervens B., Nenes A., Nielsen C. J., Swietlicki E., Putaud J. P., Balkanski Y., Fuzzi S., Horth J., Moorgat G. K., Winterhalter R., Myhre C. E. L., Tsigaridis K., Vignati E., Stephanou E. G., Organic aerosol and global climate modeling: A review, Atmos. Chem. Phys., 2005, vol. 5, p. 1053

Klemp J. B., Skamarock W. C., Dudhia J., Conservative Split-Explicit Time Integration Methods for the Compressible Nonhydrostatic Equations, Monthly Weather Review, 2007, vol. 135, p. 2897 
Kroll J. H., Seinfeld J. H., Chemistry of secondary organic aerosol: Formation and evolution of low-volatility organics in the atmosphere, Atmos. Environ., 2008, vol. 42, p. 3593

Kulmala M., Laaksonen A., Pirjola L., Parameterizations for sulfuric acid/water nucleation rates, Journal of Geophysical Research, 1998, vol. 103, p. 8301

Kulmala M., Petaja T., Nieminen T., Sipila M., Manninen H. E., Lehtipalo K., Maso M. D., Aalto P. P., Junninen H., Paasonen P., Riipinen I., Lehtinen K. E. J., Laaksonen A., Kerminen V. M., Measurement of the nucleation of atmospheric aerosol particles, Nature Protocols, 2012, vol. 7(9), p. 1651

Kumar P., Ketzel M., Vardoulakis S., Pirjola L., Britter R., Dynamics and dispersion modelling of nanoparticles from road traffic in the urban atmospheric environment - a review, J. Aerosol Sci., 2011, vol. 42, p. 580

Kumar P., Morawska L., Birmili W., Paasonen P., Hu M., Kulmala M., Harrison R. M., Norford L., Britter R., Ultrafine particles in cities, Environ. Int., 2014, vol. 66, p. 1

Köhler H., The nucleus in and the growth of hygroscopic droplets, Trans. Faraday Soc., 1936, vol. 32 , p. 1152

Lance S., Medina J., Smith J. N., Nenes A., Mapping the Operation of the DMT Continuous Flow CCN Counter, Aerosol Sci. Technol., 2006, vol. 40, p. 242

Laprise R., The Euler Equations of motion with hydrostatic pressure as an independent variable, Mon. Wea. Rev., 1992, vol. 120, p. 197

Li G., Zavala M., Lei W., Tsimpidi A. P., Karydis V. A., Pandis S. N., Canagaratna M. . R., Molina L. T., Simulations of organic aerosol concentrations in Mexico city using the WRF-CHEM model during the MCMA-2006/MILAGRO campaign, Atmos. Chem. Phys., 2011a, vol. 11, p. 3789

Li G., Zavala M., Lei W., Tsimpidi A. P., Karydis V. A., Pandis S. N., Canagaratna M. R., Molina L. T., Simulations of organic aerosol concentrations in Mexico City using the WRF-CHEM model during the MCMA-2006/MILAGRO campaign, Atmos. Chem. Phys., 2011b, vol. 11, p. 3789 
Lin Y. L., Farley R. D., Orville H. D., Bulk parameterization of the snow field in a cloud model, J. Climate Appl. Meteor., 1983, vol. 22, p. 1065-1092

Lopes F. J. S., Moreira G. A., Rodrigues P. F., Guerrero-Rascado J. L., Andrade M. F., landulfo E., Lidar measurements of tropospheric aerosol and water vapor profiles during the winter season campaigns over the metropolitan area of São Paulo, Brazil, Proceedings of SPIE, Lidar Technologies, Techniques, and Measurements for Atmospheric Remote Sensing X, 2014, vol. 92460H, p. doi:10.1117/12.2067374

McMurry P., Shepherd M., Vickery J., Particulate Matter Science for Policy Makers: A NARSTO Assessment. Cambridge University Press, Cambridge, UK, 2004

Mallet M. D., Cravigan L. T., Milic A., Alroe J., Ristovski Z. D., Ward J., Keywood M., Williams L. R., Selleck P., Miljevic B., Composition, size and cloud condensation nuclei activity of biomass burning aerosol from northern Australian savannah fires, Atmos. Chem. Phys., 2017, vol. 17, p. 3605

Marple V. A., Rubow K. L., Ananth G. P., Fissan H. J., Micro-Orifice Uniform Deposit Impactor, J. Aerosol Sci., 1986, vol. 17, p. 489

Martins L. D., Vasconcellos P. C., Carvalho L. F., Andrade M. F., Estimated impact of biogenic hydrocarbon emissions on photochemical oxidant formation in São Paulo during two periods of the winters of 1999-2000, Revista Brasileira de Meteorologia, 2006, vol. 21, p. 190

Matsui H., Koike M., Kondo Y., Takami A., Fast J. D., Kanaya Y., Takigawa M., Volatility basis-set approach simulation of organic aerosol formation in East Asia: implications for anthropogenic-biogenic interaction and controllable amounts, Atmos. Chem. Phys., 2014, vol. 14, p. 9513

Merikanto J., Spracklen D. V., Mann G. W., Pickering S. J., Carslaw K. S., Impact of nucleation on global CCN, Atmos. Chem. Phys., 2009, vol. 9, p. 8601

Mie G., Beiträge zur Optik trüber Medien, speziell kolloidaler Metallösungen, Annalen der physic, 1908, vol. 25, p. 377 
Miranda R. M., Andrade M. F., Physicochemical characteristics of atmospheric aerosols during winter in the São Paulo Metropolitan Area in Brazil, Atmos. Environ., 2005, vol. 39, p. 6188

Miranda R. M., Lopes F., Rosario N. E., Yamasoe M. A., landulfo E., Andrade M. F., The relationship between aerosol particles chemical composition and optical properties to identify the biomass burning contribution to fine particles concentration: a case study for São Paulo city, Brazil, Environ. Monit. Assess., 2017, vol. 189, p. 9

Mishra S. K., Tripathi S. N., Modeling optical properties of mineral dust over the Indian Desert, J. Geophys. Res., 2008, vol. 113,D23201, p. doi:10.1029/2008JD010048

Mlawer E. J., Taubman S. J., Brown P. D., Iacono M. J., Clough S. A., Radiative transfer for inhomogeneous atmosphere: RRTM, a validated correlated-k model for the longwave, J. Geophys. Res., 1997, vol. 102 (D14), p. 16663-16682

Monahan E. C., Spiel D. E., Davidson K. L., A model of marine aerosol generation via whitecaps and wave disruption. In: Monahan, E. C., MacNiocaill, G. D. (Eds.), Oceanic Whitecaps. Reidel Publishing Company, Norwell, MA, 1986

Monks P. S., Gas-phase radical chemistry in the troposphere, Chem. Soc. Rev., 2005, vol. 34 , p. 376

Morrison H., Thompson G., Tatarskii V., Impact of cloud microphysics on the development of trailing stratiform precipitation in a simulated squall line: Comparison of one- and two-moment schemes, Mon. Wea. Rev., 2009, vol. 137, p. 991

Myhre G., Samset B. H., Schulz M., Balkanski Y., Bauer S., Berntsen T. K., Bian H., Bellouin N., Chin M., Diehl T., Easter R. C., Feichter J., Ghan S. J., Hauglustaine D., Iversen T., Kinne S., Kirkevag A., Lamarque J. F., Lin G., Liu X., Lund M. T., Luo G., Ma X., van Noije T., Penner J. E., Radiative forcing of the direct aerosol effect from AeroCom Phase II simulations, Atmos. Chem. Phys., 2013, vol. 13, p. 1853

Müller V. H., Zur allgemeinen Theorie der raschen Koagulation, Kolloidchemische Beihefte, 1928, vol. 27, p. 223 
NAS, The Future of Atmospheric Chemistry Research: Remembering Yesterday, Understanding Today, Anticipating Tomorrow. The National Academies Press, Washington, DC, USA, 2016

Nogueira T., Dominutti P. A., Carvalho L. R. F. D., Fornaro A., Andrade M. F., Formaldehyde and acetaldehyde measurements in urban atmosphere impacted by the use of ethanol biofuel: Metropolitan Area of São Paulo, 2012-2013, Fuel, 2014, vol. 134, p. 505

Odum J. R., Hoffmann T., Bowman F., Collins D., Flagan R. C., Seinfeld J. H., Gas/particle partitioning and secondary organic aerosol yields, Environmental Science and Technology, 1996, vol. 30, p. 2580

Oliveira M. G. L., Impacto dos aerossóis atmosféricos na formação de nuvens e precipitação sobre a região metropolitana de São Paulo, Department of Atmospheric Sciences, University of São Paulo, 2012, Tese de Doutorado, 123 p.

Ooyama K. V., A thermodynamic foundation for modeling the moist atmosphere, J. Atmos. Sci., 1990, vol. 47 , p. 2580

Oyama B. S., Andrade M. F., Herckes P., Dusek U., Rockmann T., Holzinger R., Chemical characterization of organic particulate matter from on-road traffic in São Paulo, Brazil, Atmos. Chem. Phys., 2016, vol. 16, p. 14397

Pankow J. F., An absorption model of the gas aerosol partitioning involved in the formation of secondary organic aerosol, Atmos. Environ., 1994a, vol. 28, p. 185

Pankow J. F., An absorption model of the gas aerosol partitioning involved in the formation of secondary organic aerosol, Atmos. Environ., 1994b, vol. 28, p. 189

Park S. K., Marmur A., Kim S. B., Tian D., Hu Y., McMurry P. H., Russell A. G., Evaluation of fine particle number concentrations in CMAQ, Aerosol Sci. Technol., 2006, vol. 40 , p. $985-996$

PBMC Executive summary: scientific basis of climate change - Contribution from Grupo de Trabalho 1 (GT1, acronym for the Working Group 1) to the Primeiro Relatório de Avaliação Nacional sobre Mudanças Climáticas (RAN1) of the Painel Brasileiro de 
Mudanças Climáticas (PBMC). [Ambrizzi, T., Araujo, M. (eds)] Universidade Federal do Rio de Janeiro (COPPE), Rio de Janeiro, RJ, Brasil, 2013

Pereira G., Siqueira R., Rosario N. E., Longo K. L., Freitas S. R., Cardozo F. S., Kaiser J. W., Wooster M. J., Assessment of fire emission inventories during the South American Biomass Burning Analysis (SAMBBA) experiment, Atmos. Chem. Phys., 2016, vol. 16, p. 6961

Pereira G. M., Teinila K., Custódio D., Santos A. G., Xian H., Alves R. H. C. A., Andrade J. B., Rocha G. O., Kumar P., Balasubramanian R., Andrade M. F., Vasconcellos P. C., Particulate pollutants in the Brazilian city of São Paulo: 1-year investigation for the chemical composition and source apportionment, Atmos. Chem. Phys., 2017, vol. 17, p. 11943

Pitzer K. S., Simonson J. M., Thermodynamics of Multicomponent, Miscible, Ionic Systems: Theory and Evaluation, The journal of physical chemistry, 1986, vol. 90, p. 3005

Prasad A. K., Singh R. P., Changes in aerosol parameters during major dust storm events (2001-2005) over the Indo-Gangetic Plains using AERONET and MODIS data, J. Geophys. Res., 2007, vol. 112,D09208, p. doi:10.1029/2006JD007778

Riccobono F., Schobesberger S., Scott C. E., Dommen J., Ortega I. K., Rondo L., Almeida J. A., Amorim A., Bianchi F., Breitenlechner M., David A., Downard A., Dunne E. M., Duplissy J., Ehrhart S., Flagan R. C., Franchin A., Hansel A., Junninen H., Kajos M., Keskinen H., Kupc A., Oxidation products of biogenic emissions contribute to nucleation of atmospheric particles, Science, 2014, vol. 344, p. 717

Roberts G. C., Nenes A., A continuous-flow streamwise thermal-gradient CCN chamber for atmospheric measurements, Aerosol Sci. Technol., 2005, vol. 39, p. 206

Rozante J. R., Moreira D. S., Gonçalves L. G. G., Vila D. A., Combining TRMM and Surface Observations of Precipitation: Technique and Validation over South America, Wea. Forecasting, 2010, vol. 25, p. 885

Sarwar G., Fahey K., Napelenok S., Roselle S., Mathur R., Examining the impact of CMAQ model updates on aerosol sulfate predictions. the 10th Annual CMAS Models-3 User's Conference, Chapel Hill, NC, 2011 
Sarwar G., Luecken D., Yarwood G., Chapter 2.9 developing and implementing an updated chlorine chemistry into the community multiscale air quality model, Dev. Environ. Sci., 2007, vol. 6, p. 168

Schell B., Ackermann I. J., Hass H., Binkowski F. S., Ebel A., Modelling the formation of secondary organic aerosol within a comprehensive air quality model system, J. Geophys. Res., 2001, vol. 106, p. 28275

Seinfeld J. H., Bretherton C., Carslaw K. S., Coe H., DeMott P. J., Dunlea E. J., Feingold G., Ghan S., Guenther A. B., Kahn R., Kraucunas I., Kreidenweis S. M., Molina M. J., Neves A., Penner J. E., Prather K. A., Ramanathan V., Ramaswamy V., Rasch P. J., Ravishankara A. R., Rosenfeld D., Improving our fundamental understanding of the role of aerosol-cloud interactions in the climate system, PNAS, 2016, vol. 113(21), p. 5781

Shrivastava M., Berg L. K., Fast J. F., Easter R. C., Laskin A., Chapman E. G., Jr W. I. G., Liu Y., Berkowitz C. M., Modelling aerosols and their interactions with shallow cumuli during the 2007 CHAPS field study, J. Geophys. Res.-Atmos., 2013, vol. 118, p. 1343

Skamarock W. C., Klemp J. B., Dudhia J., Gill D. O., Barker D. M., Wang W., Powers J. G., A description of the advanced research WRF version 3. NCAR Tech. Note, NCAR/TN-475+STR, Boulder, CO, 2008

Souto-Oliveira C. E., Andrade M. F., Kumar P., Lopes F. J. D., Babinski M., Landulfo E., Effect of vehicular traffic, remote sources and new particle formation on the activation properties of cloud condensation nuclei in the megacity of São Paulo, Brazil, Atmos. Chem. Phys., 2016, vol. 16, p. 14635

Spracklen D. V., Carslaw K. S., Kulmala M., Kerminen V. M., Mann G. W., Sihto S. L., The contribution of boundary layer nucleation events to total particle concentrations on regional and global scales, Atmos. Chem. Phys., 2006, vol. 6, p. 5631

Stier P., C5 Physics of Atmospheres and Oceans, Lecture 3: Warm Cloud Microphysics. Department of Physics, University of Oxford, Oxford, UK, 2011

Swinehart D. F., The Beer-Lambert, Journal of Chemical Education, 1962, vol. 39, p. 333 
Tamar M., Flores J. M., Rudich Y., Optical Properties of Secondary Organic Aerosols and Their Changes by Chemical Processes, Chem. Rev., 2015, vol. 115, p. 4400

Taylor K. E., Summarizing multiple aspects of model performance in a single diagram, J. Geophys. Res., 2001, vol. 106, p. 7183

Tuccella P., Curci G., Grell G. A., Visconti G., Crumeyrolle S., Schwarzenboeck A., Mensah A. A., A new chemistry option in WRF-Chem v 3.4 for the simulation of direct and indirect aerosol effects using VBS: evaluation against IMPACT-EUCAARI data, Geosci. Model Dev., 2015, vol. 8, p. 2749

Tuccella P., Curci G., Visconti G., Bessagnet B., Menut L., Park R. J., Modeling of gas and aerosol with WRF/Chem over Europe: Evaluation and sensitivity study, J. Geophys. Res., 2012, vol. 117, D03303, p. doi:10.1029/2011JD016302

Vara-Vela A., Andrade M. F., Kumar P., Ynoue R. Y., Muñoz A. G., Impact of vehicular emissions on the formation of fine particles in the Sao Paulo Metropolitan Area: a numerical study with the WRF-Chem model, Atmos. Chem. Phys., 2016, vol. 16, p. 777

Vara-Vela A., Muñoz A. G., Lomas A., González C. M., Gavidia-Calderon M., Andrade M. F., The Another Assimilation System for WRF-Chem (AAS4WRF): a new massconserving emissions preprocessor for WRF-Chem regional modelling. Abstract A53F2343, 2017 AGU Fall Meeting, New Orleans, LA, 2017

Vehkamaki H., Kulmala M., Napari I., Lehtinen K. E. J., Timmreck C., Noppel M., Laaksonen A., An improved parameterization for sulfuric acid-water nucleation rates for tropospheric and stratospheric conditions, J. Geophys. Res., 2002, vol. 107(D22), p. doi:10.1029/2002JD002184

Wang K., Zhang Y., Yahya K., Wu S. Y., Grell G., Implementation and initial application of new chemistry-aerosol options in WRF/Chem for simulating secondary organic aerosols and aerosol indirect effects for regional air quality, Atmospheric Environment, 2015, vol. 115 , p. 716

Wedding J. B., Weigand M., John W., Wall S., Sampling effectiveness of the inlet to the dichotomous sampler, Environ. Sci. Technol., 1980, vol. 14, p. 1367 
Whitby E. R., McMurry P. H., Shankar U., Binkowski F. S., Modal aerosol dynamics modeling, Rep. 600/3-91/020, Atmospheric Research and Exposure Assessment Laboratory. US Environmental Protection Agency, Research Triangle Park, NC, 1991

Whitby K. T., Husar R. B., Liu B. Y. H., The Aerosol Size Distribution of Los Angeles Smog, J. Colloid Interface Sci., 1972, vol. 39, p. 177

Whitby K. T., Liu B. Y. H., Husar R. B., Barsic N. J., The Minnesota Aerosol Analyzing System Used in the Los Angeles Smog Project, J. Colloid Interface Sci., 1972, vol. 39, p. 136

Wiedinmyer C., Akagi S. K., Yokelson R. J., Emmons L. K., Al-Saadi J. A., Orlando J. J., Soja A. J., The Fire INventory from NCAR (FINN): a high resolution global model to estimate the emissions from open burning, Geosci. Model Dev., 2011, vol. 4, p. 625

Wilemski G., Composition of the critical nucleus in multicomponent vapor nucleations, J. Chem. Phys., 1984, vol. 80, p. 1370

Winklmayr W., Reischl G. P., Lindner A. O., Berner A., A new electromobility spectrometer for the measurement of aerosol size distributions in the size range from 1 to 1000 nm, J. Aerosol Sci., 1991, vol. 22, p. 289

Yahya K., He J., Zhang Y., Multiyear applications of WRF/Chem over continental U. S.: Model evaluation, variation trend, and impacts of boundary conditions, J. Geophys. Res., 2015, vol. 20(24), p. 12748

Yarwood G., Rao S., Yocke M., Whitten G. Z., Final report - Updates to the Carbon Bond Chemical Mechanism: CB05, Rep. RT-04-00675. Yocke and Co., Novato, Calif.,, 2005

Ynoue R. Y., Modelagem numérica da formação, crescimento e transporte das partículas inorgânicas secundárias constituintes do aerossol urbano na Região Metropolitana de São Paulo, Department of Atmospheric Sciences, University of São Paulo, 2004, Tese de Doutorado

Ynoue R. Y., Andrade M. F., Size-resolved mass balance of aerosol particles over the São Paulo Metropolitan Area of Brazil, Aerosol Sci. Tech., 2004, vol. 1, p. 52 
Zhang Y., Liu P., Liu X. H., Jacobson M. Z., McMurry P. H., Yu F., Yu S., Schere K. L., A comparative study of nucleation parameterizations: 2. Three-dimensional model application and evaluation, J. Geophys. Res., 2010, vol. 115(D20213), p. doi:10.1029/2010JD014151

Zhang Y., Liu P., Pun B., Seigneur C., A comprehensive performance evolution of MM5CMAQ for the summer 1999 Southern Oxidants Study episode - Part I: Evaluation protocols, databases, and meteorological predictions, Atmospheric Environment, 2006, vol. 40 , p. 4825

Zheng Y., Alapaty K. A., Herwehe J. A., Genio A. D. D., Niyogi D., Improving high resolution weather forecasts using the Weather Research and Forecasting (WRF) Model with an updated Kain-Fritsch scheme, Mon. Wea. Rev., 2016, vol. 144, p. 833 
Appendix 



\section{Appendix A}

\section{Quantitative statistical measures}

Table A.1 - List of performance measures used in the model evaluation.

Index $\quad$ Mathematical expression ${ }^{1} \quad$ Range

Standard Deviation (SD)

$$
S D_{\text {Obs }}=\frac{1}{n} \sum_{n=1}^{n}\left(O_{n}-\bar{O}\right)^{2} \quad 0 \text { to }+\infty
$$

$$
S D_{S i m}=\frac{1}{n} \sum_{n=1}^{n}\left(M_{n}-\bar{M}\right)^{2}
$$

Mean Bias (MB)

$$
M B=\frac{1}{n} \sum_{n=1}^{n}\left(M_{n}-O_{n}\right) \quad-\infty \text { to }+\infty
$$

Mean Fractional Bias (MFB) $\quad M F B=\frac{2}{n} \sum_{n=1}^{n}\left(\frac{M_{n}-O_{n}}{M_{n}+O_{n}}\right) 100-200 \%$ to $+200 \%$

Mean Fractional Error (MFE) $\quad M F E=\frac{2}{n} \sum_{n=1}^{n} \frac{\left|M_{n}-O_{n}\right|}{M_{n}+O_{n}} 100 \quad 0$ to $+200 \%$

Normalised Mean Bias (NMB) $\quad N M B=\sum_{n=1}^{n} \frac{M_{n}-O_{n}}{O_{n}} 100 \quad-100 \%$ to $+\infty$

Normalised Mean Error (NME) $N M B=\sum_{n=1}^{n} \frac{\left|M_{n}-O_{n}\right|}{O_{n}} 100 \quad 0 \%$ to $+\infty$

Root Mean Square Error

$$
R M S E=\sqrt{\frac{1}{n} \sum_{n=1}^{n}\left(M_{n}-O_{n}\right)^{2}} \quad 0 \text { to }+\infty
$$

(RMSE)

${ }^{1} \bar{O}$ and $\bar{M}$ are the average values of the individual observed and predicted values, $O_{n}$ and $M_{n}$, respectively. " $n$ " is the number of observations. 
Table A.2 - Continuation of Table A.1

\begin{tabular}{lll}
\hline Index & Mathematical expression ${ }^{1}$ & Range \\
\hline Root Mean Square Error & $R M S E_{U B}=\sqrt{\frac{1}{n} \sum_{n=1}^{n}\left[\left(M_{n}-\bar{M}\right)-\left(O_{n}-\bar{O}\right)\right]^{2}}$ & 0 to $+\infty$ \\
UB $\left(\right.$ RMSE $\left._{U B}\right)$ & \\
Correlation Coefficient (R) & $R=\frac{\sum_{n=1}^{n}\left(M_{n}-\bar{M}\right)\left(O_{n}-\bar{O}\right)}{\sqrt{\sum_{n=1}^{n}\left(M_{n}-\bar{M}\right)^{2}} \sqrt{\sum_{n=1}^{n}\left(O_{n}-\bar{O}\right)^{2}}}$ & -1 to +1
\end{tabular}

${ }^{1} \bar{O}$ and $\bar{M}$ are the average values of the individual observed and predicted values, $O_{n}$ and $M_{n}$, respectively. " $n$ " is the number of observations. 